أنماط الشخصية السائدة لدى الطالبات ذوات صعهبات التعلم بالمرحلة الثانوية وعلاقتها بإدراكهن لسلوك المعلم

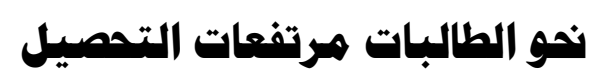

\author{
د/ أحلام محمل خاطر حمثناوي

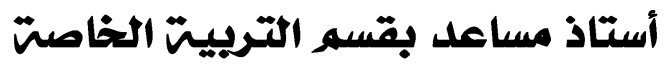 \\ كليت الترييت للبنات -جامعت القصييه
}




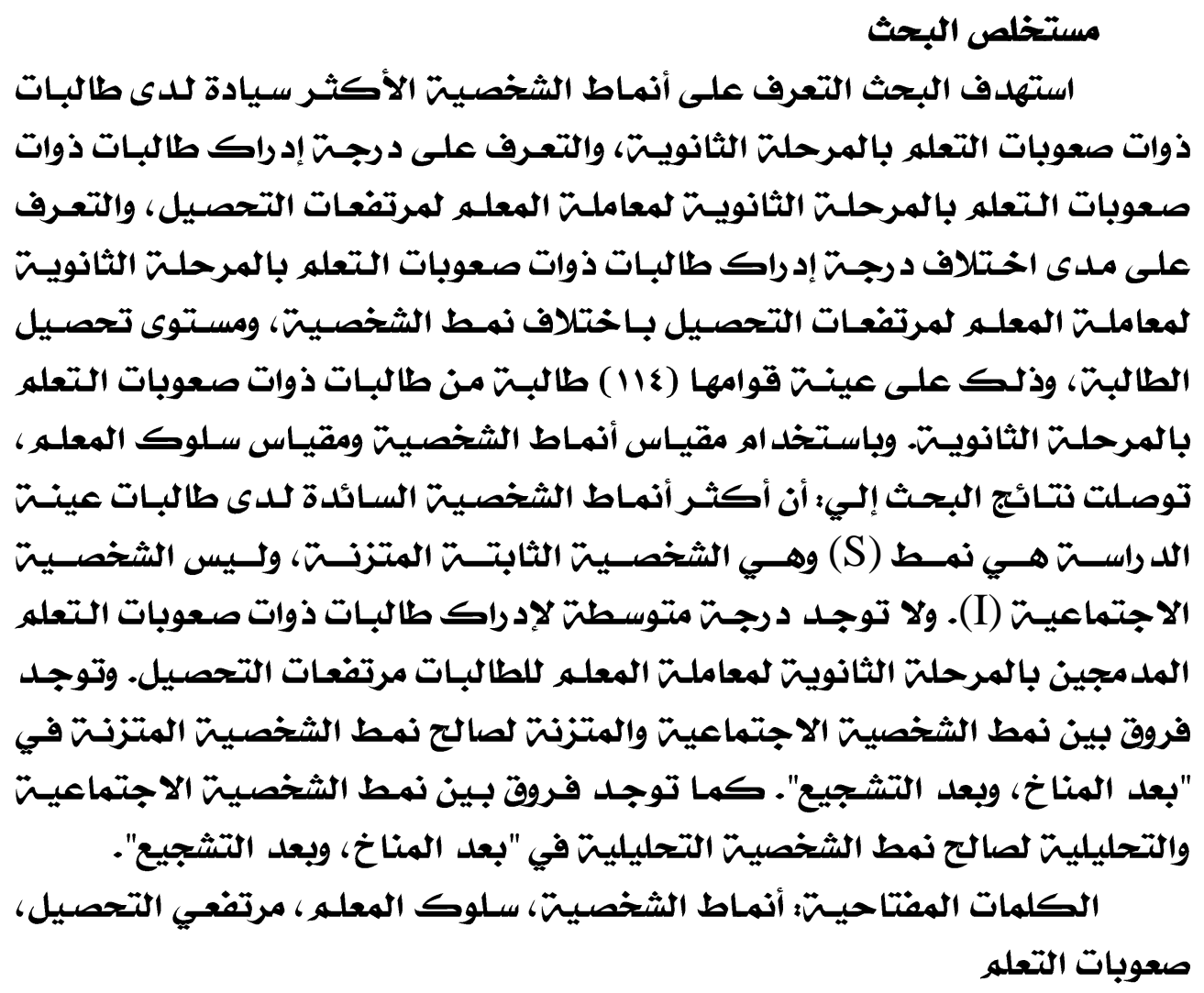




\begin{abstract}
:
The aim of the researcher was to identify the more dominant personality patterns of the female students of the Faculty of Education for Girls in ABHA and to identify the degree of awareness of the students of the Faculty of Girls in ABHA for the treatment of the faculty member for higher achievement levels. (114 students) from the Faculty of Education at King Khalid University. Using the Personality Scale and Teacher Behavior Scale, the results of the research were: 1 -The most common personality patterns among the students of the study sample is the pattern (S), which is the fixed personality, not the social character (I). 2. There is no middle degree for the students of the Faculty of Education for girls in ABHA to treat the faculty member of the students high achievement.3.There are differences between the social and balanced personality pattern in favor of the balanced personality pattern of "after climate, after encouragement".4.There are differences between the social and analytical personality pattern in favor of the analytical personality pattern in "after climate, after encouragement".

achievers

Key words: Type of personality, Teacher treatment, High
\end{abstract}




\section{مقدمت البحث}

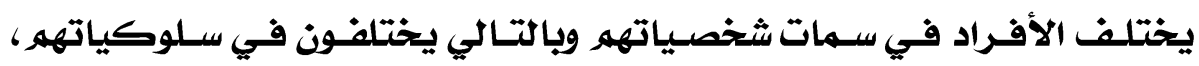

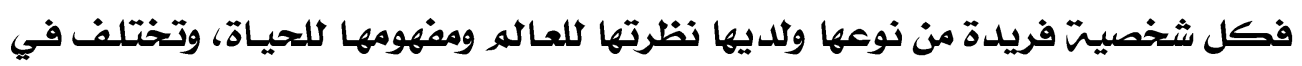

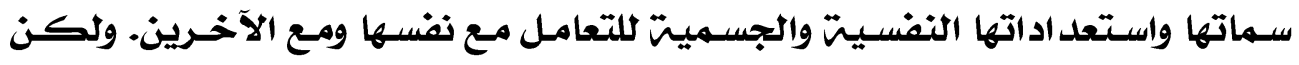

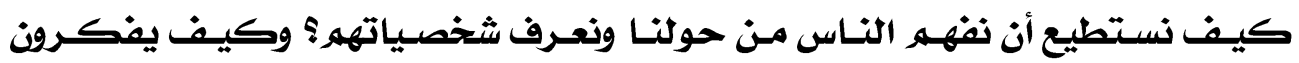

$$
\text { وينظرون للعالهي. }
$$

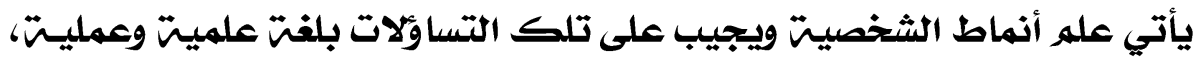

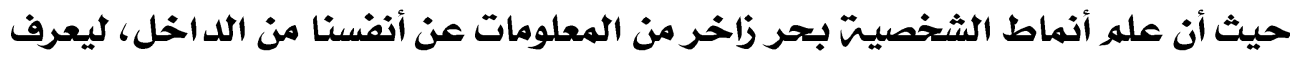

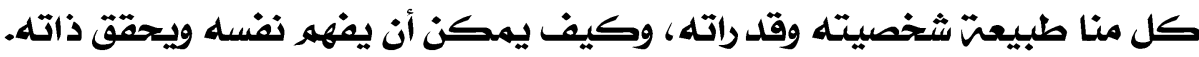

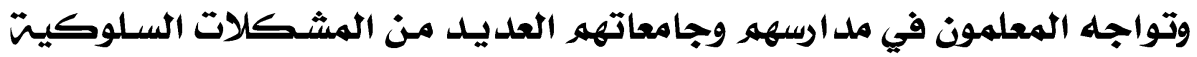

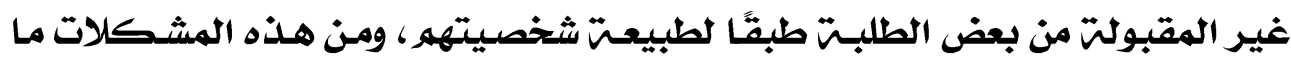

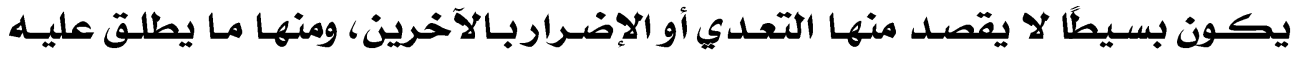

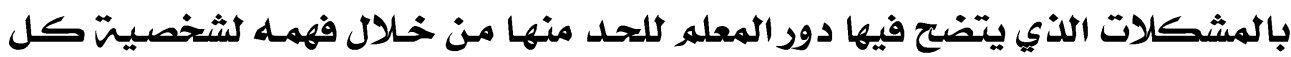
طالب.

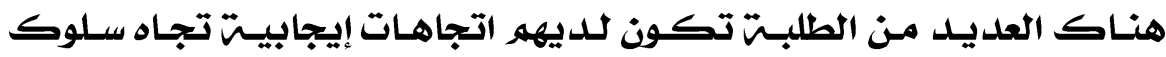

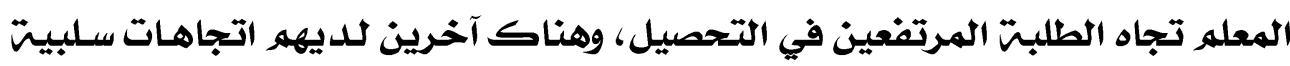
ويرجع ذلك إلى طبيعت شخصيتهه.

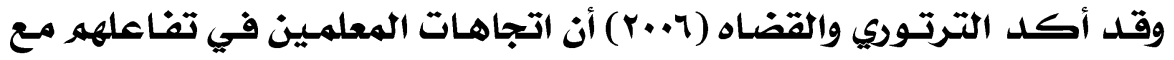

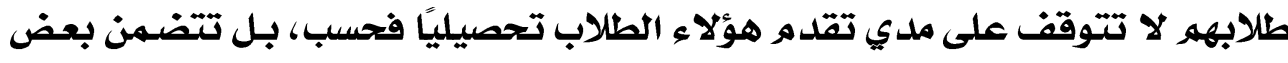

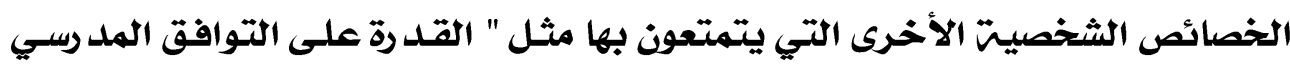

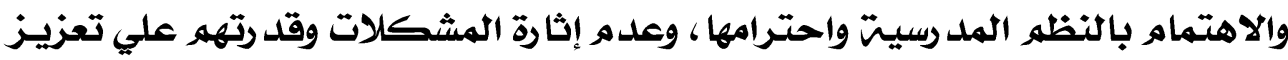
سلوك معلميهه.

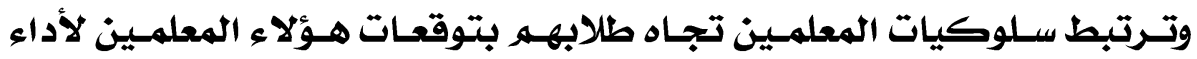

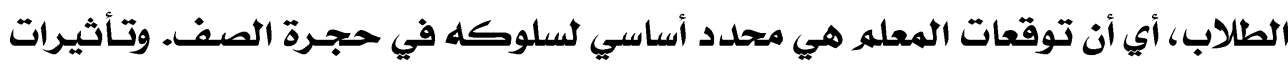

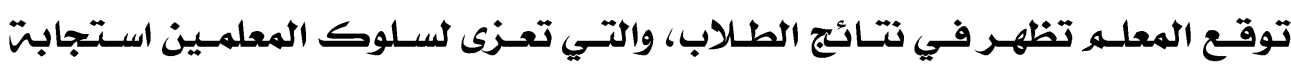

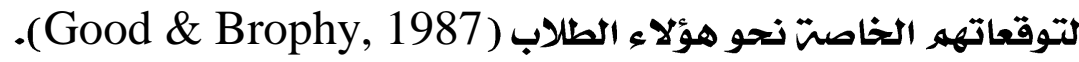

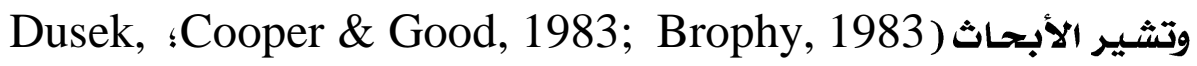

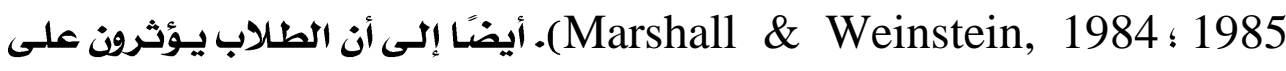

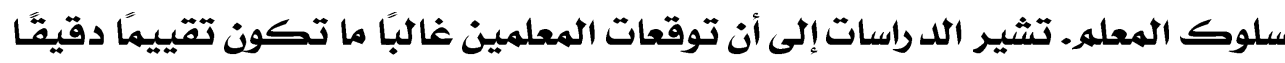

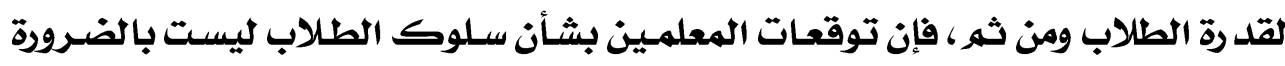

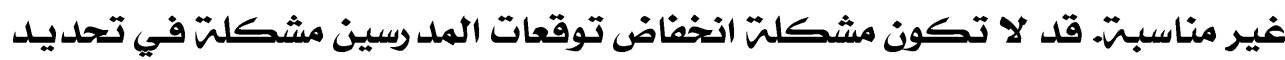

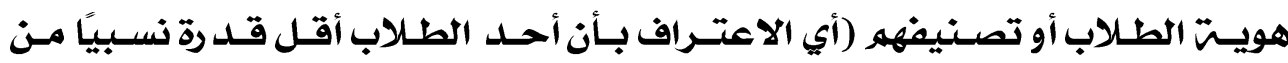




$$
\text { الآخرين)، بل هـي معرفت غيـر ملائهت لكيفيـت الاستجابت للطلاب الذين يجدل ون }
$$

Hoge \& Butcher, 1984 ؛ Egan \& Archer, 1985 (وفي ضوء دراسات العلئ

Pedulla, Airasian, \& Madaus, ؛ Monk, 1983 ؛Mitman, 1985 ؛

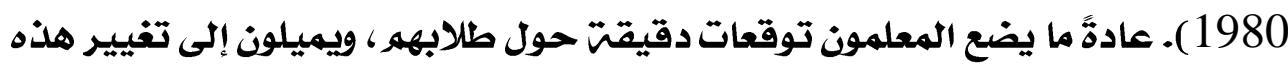

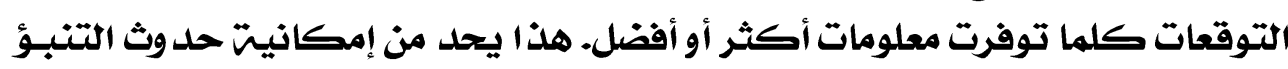

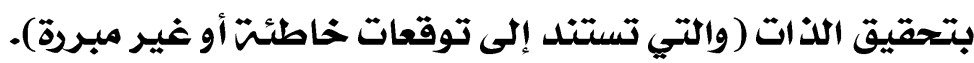

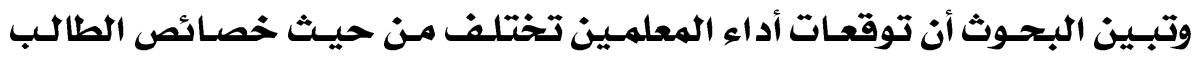

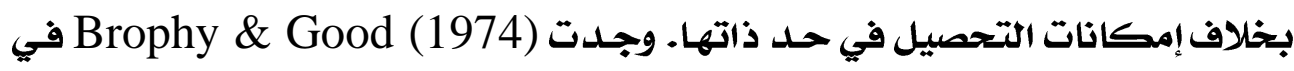

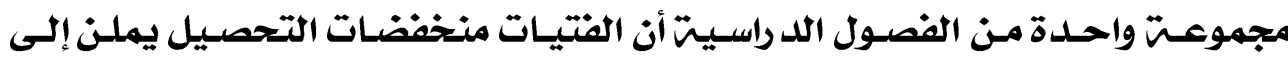

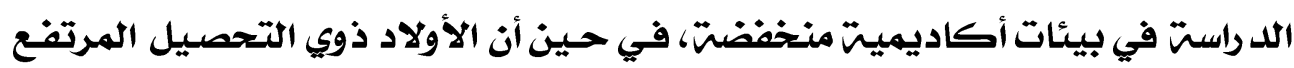

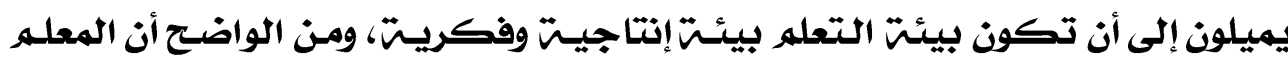

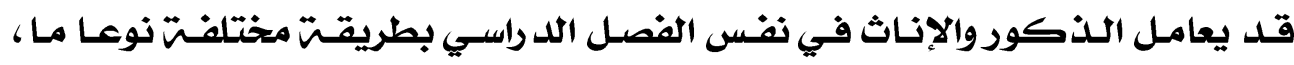

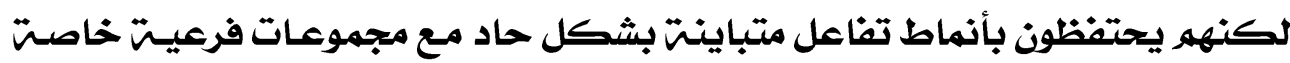

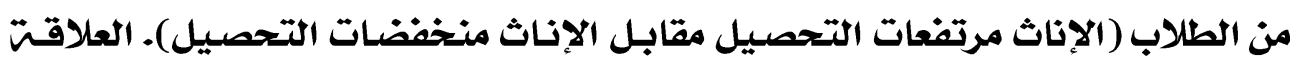

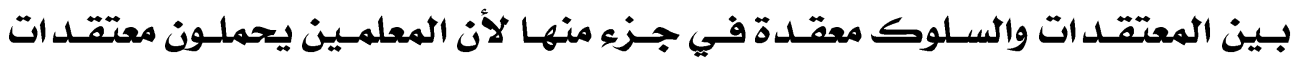

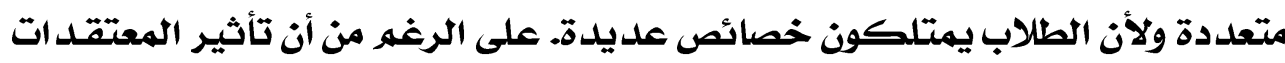

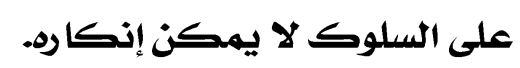

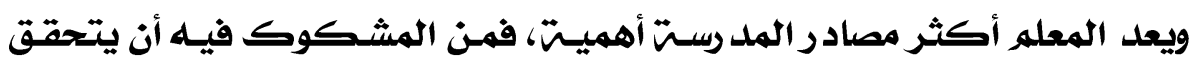

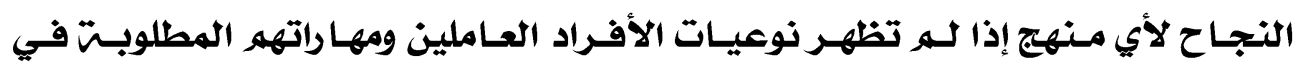

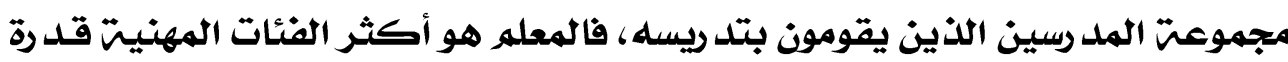

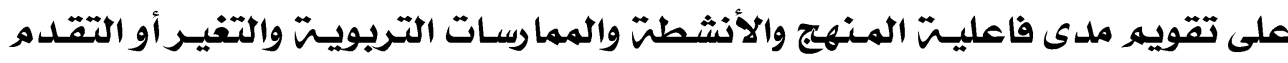

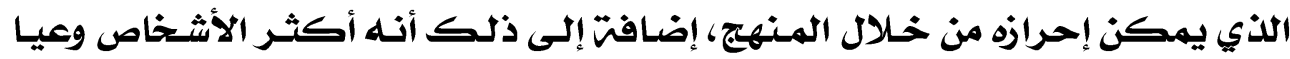

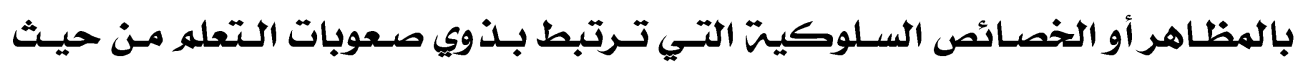

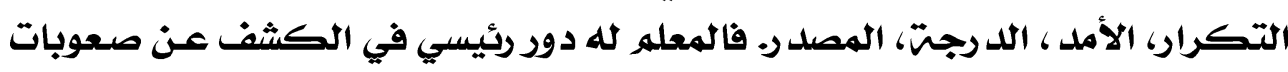

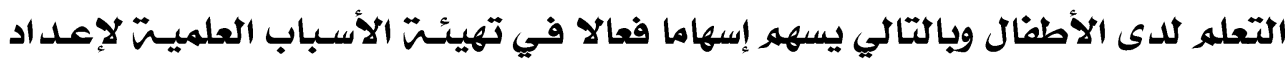

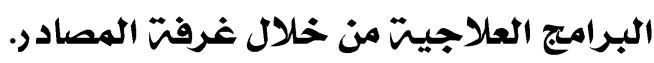

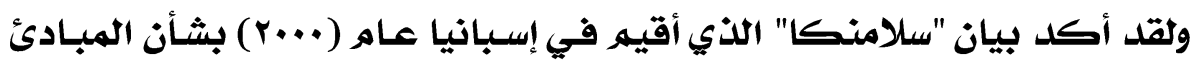

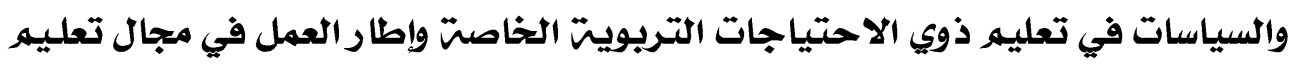

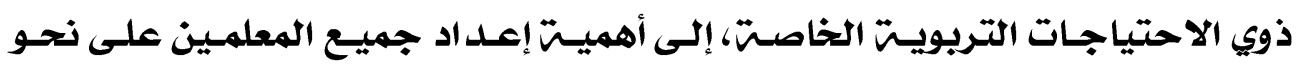

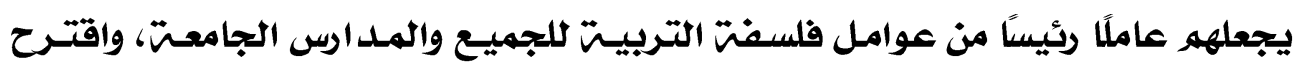

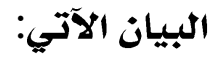




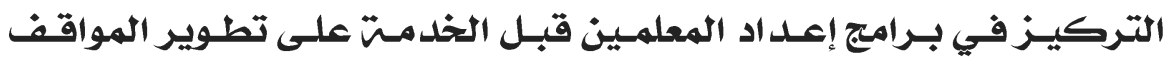

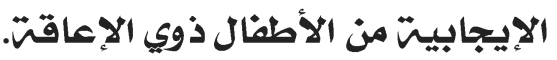

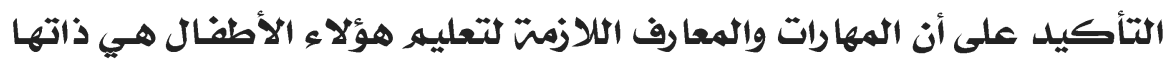

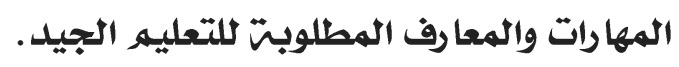

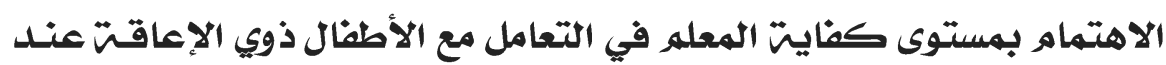

$$
\text { منح شهادات مزاولت مهنت التعليه. }
$$

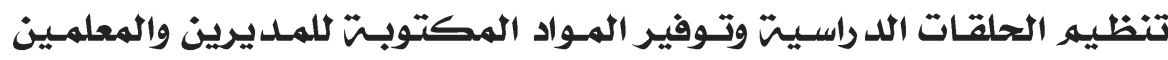

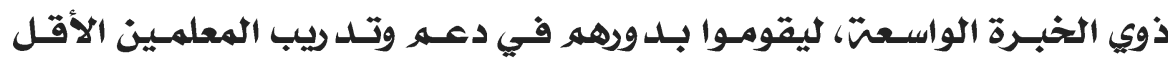

$$
\text { خبرة. }
$$

دمج برامج إعد اد معلمي التربيتت الخاصـت في بـرامج إعـداد معلمي الصفوف

العاديت.

قيـاهر الجامعـات ومعاهــد التعلـيه العـالي بـإجراء البـحــوث وتنفيـذ البــرامج

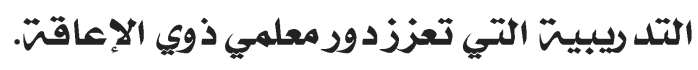

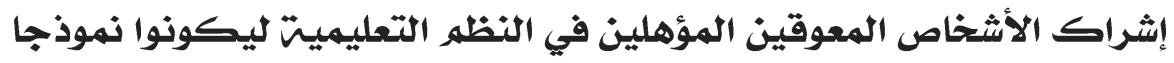

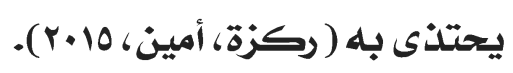

$$
\text { مشكلت البحث: }
$$

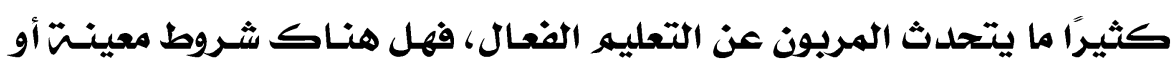

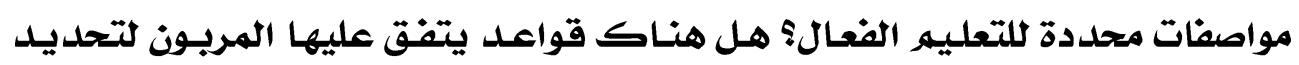
شروط التعليه الفعال ومواصفاته.

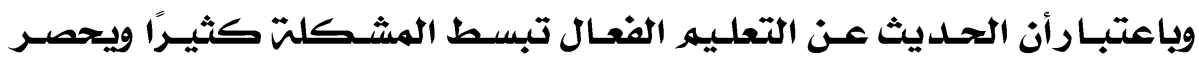

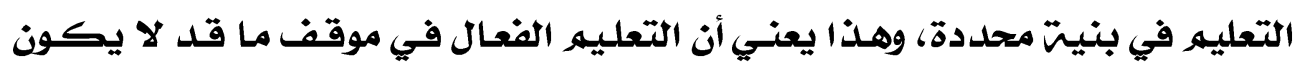

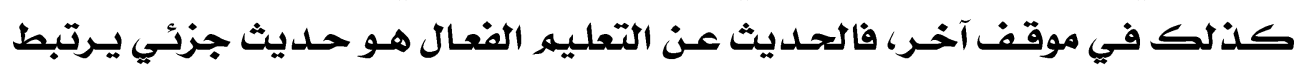

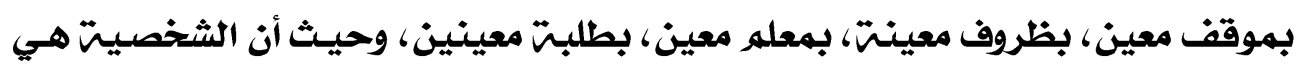

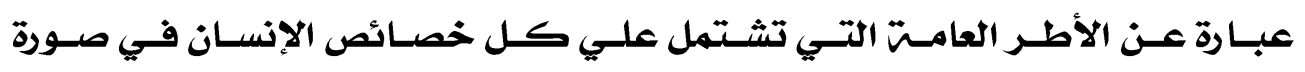

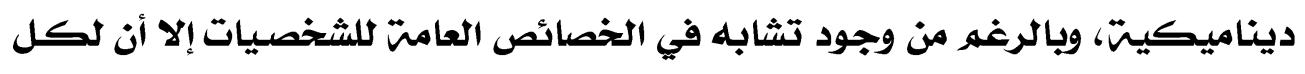

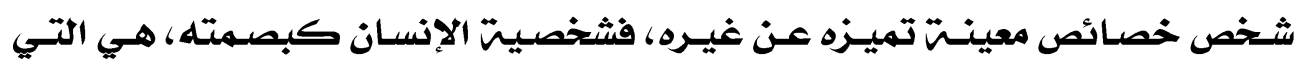

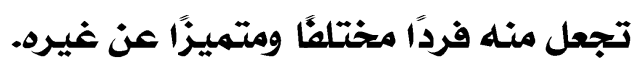

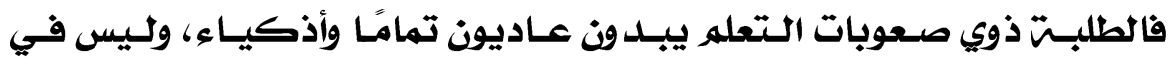

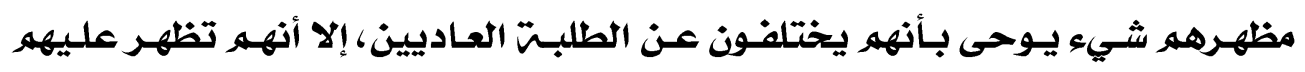

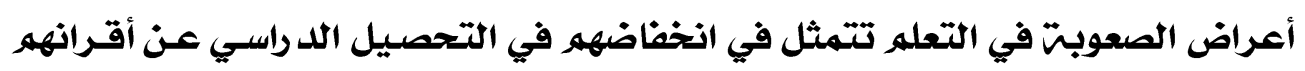

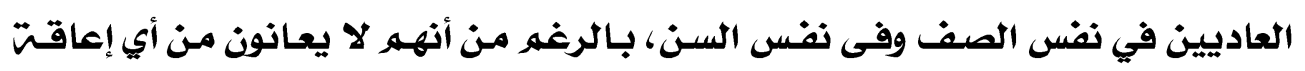

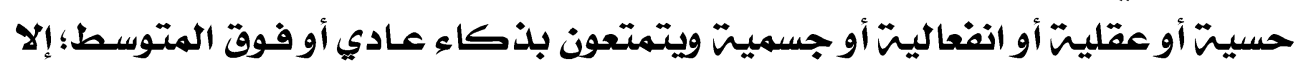




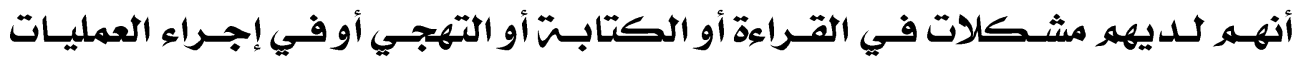

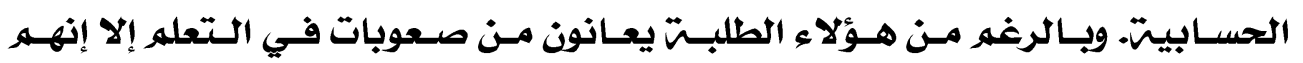
يمتلكون قد رات تخفي جوانب الضعف في أد ائهم.

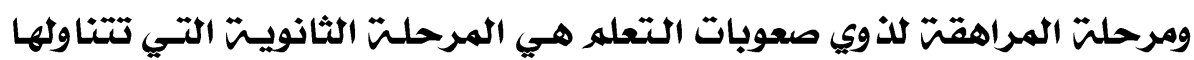

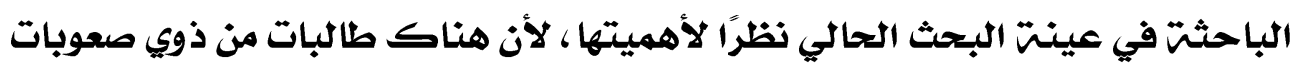

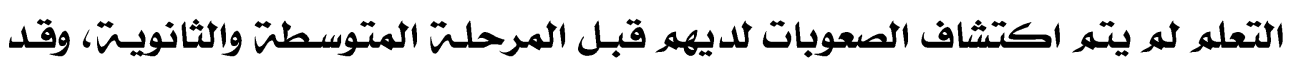

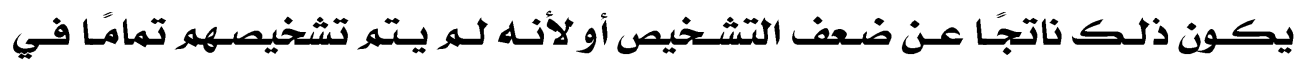

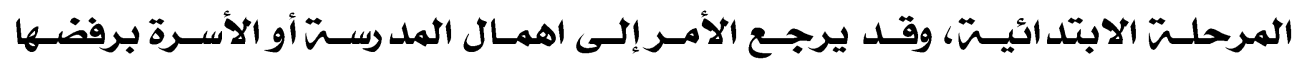

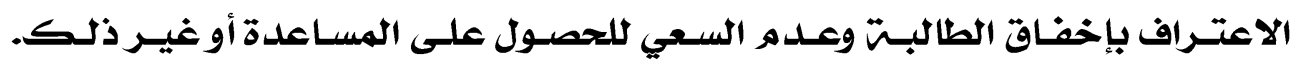

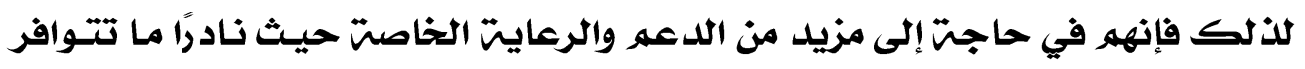

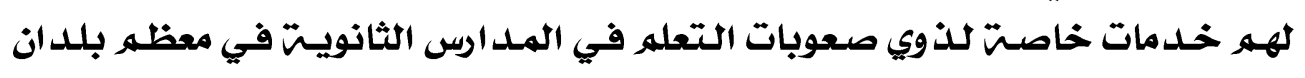

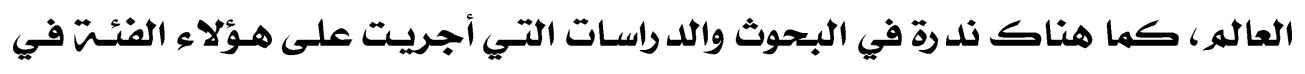
تلك المرحلته.

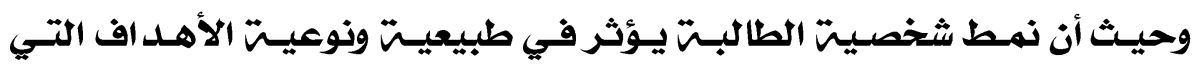

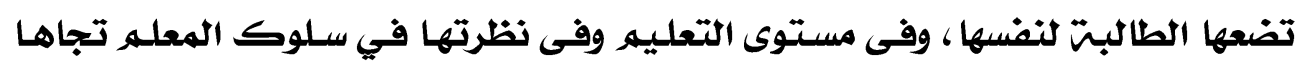

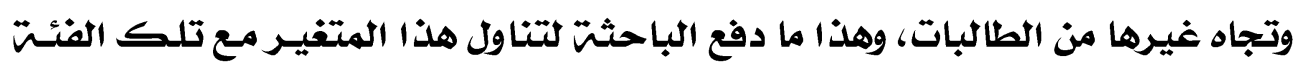

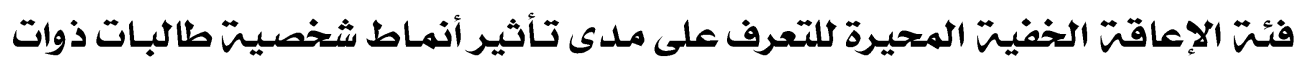

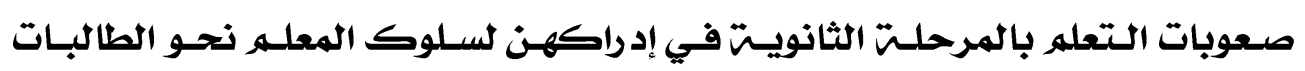

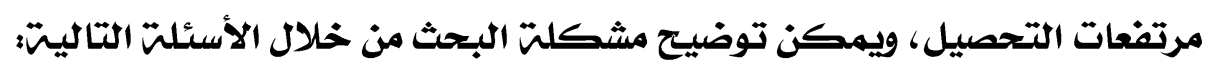

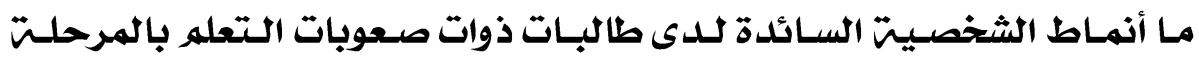
الثانويتما مانها

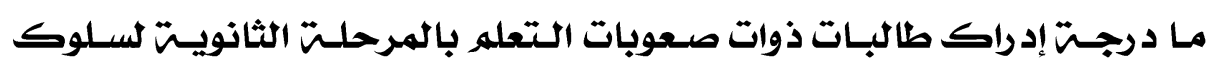

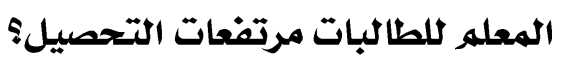

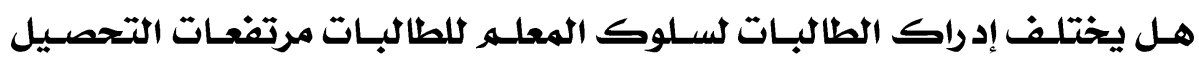

باختلاف نمط الشخصيتئ

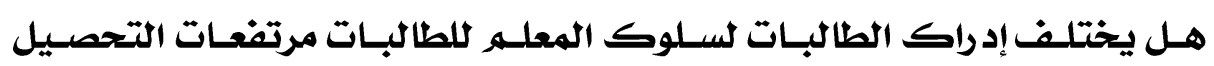

باختالاف نوع الصعوبته

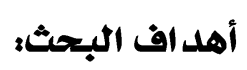

التعرف على أنماط الشخصيت الأكثر سيادة لدى طالبات ذوات صعوبات التعله

$$
\text { بالمرحلت الثانويتت. }
$$

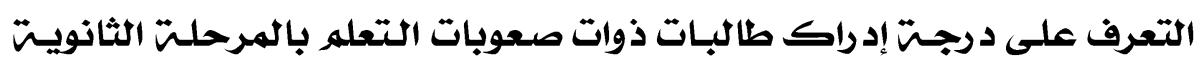

$$
\text { لسلوك المعله للطالبات مرتفعات التحصيل. }
$$


التعـرف علـى مــدى اخــتلاوف درجــت إدراك طالبـات ذوات صـعوبات الـتعله

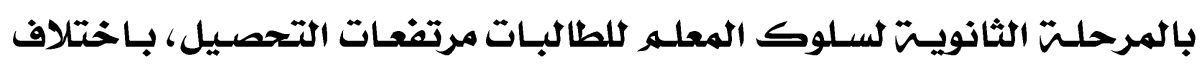
نمط الشخصيتة، ونوع الصعوبت.

$$
\text { أهميت البحث }
$$

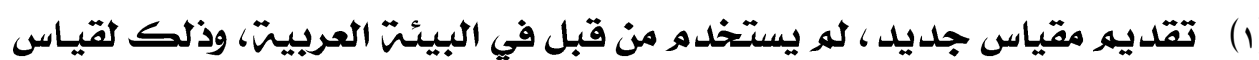

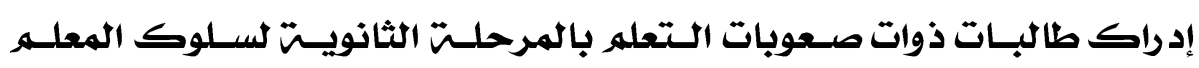
للطالبات مرتفعات التحصيل.

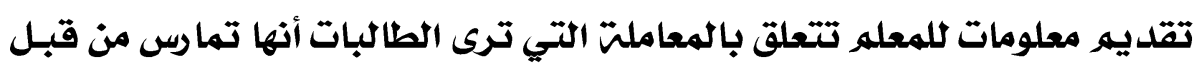

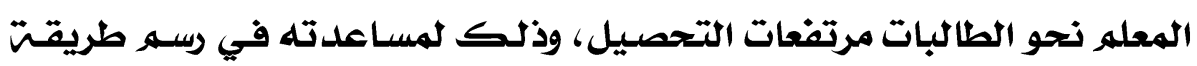
التد ريس الملاكئمت.

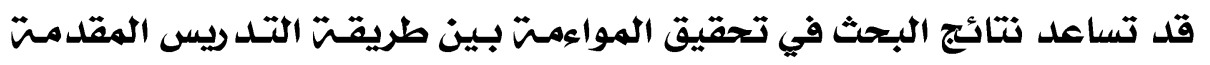
لهن، وإد راكهن لسلوك المعله للطالبات مرتفعات التحصيل.

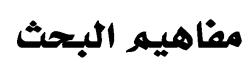

الشخصيتّ: هي مجموعت من الصفات الجسديت والنفسيت "موروثت ومكتسبتث"

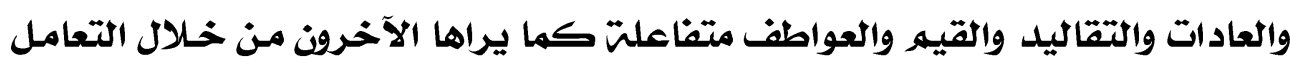

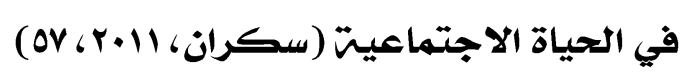

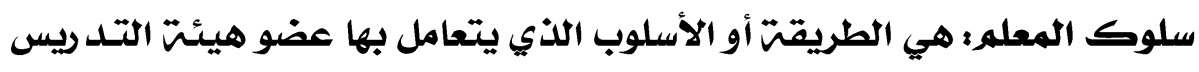
مع الطالبات.

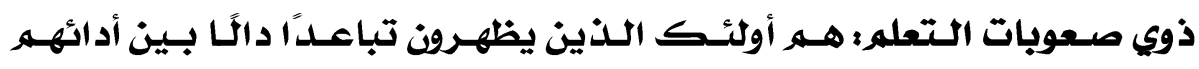

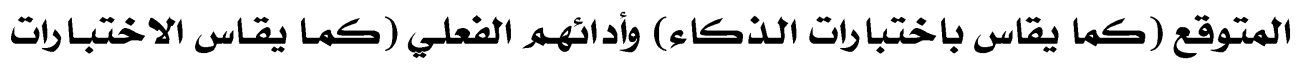

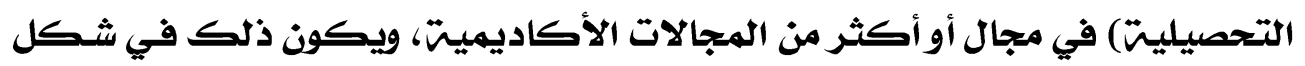

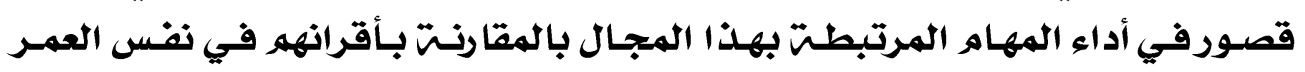

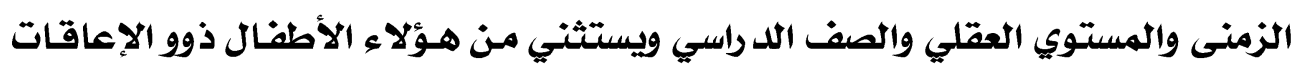

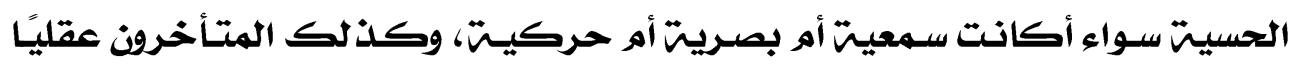

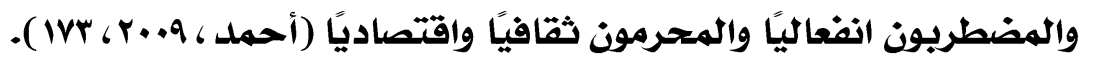

$$
\text { محلد يتحدات البحث البحث الجحالي بالهحددات التاليتت: }
$$

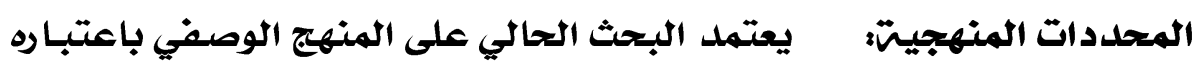

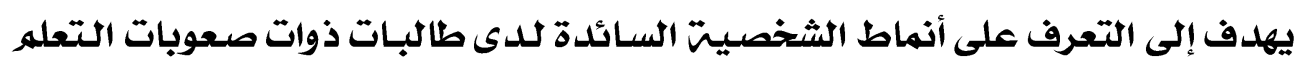

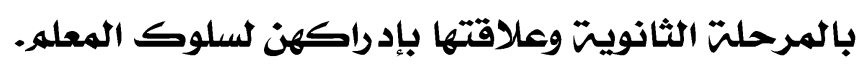




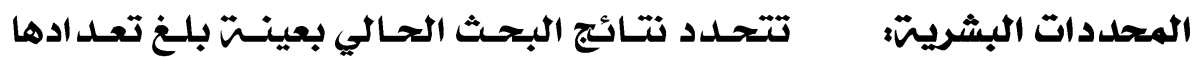

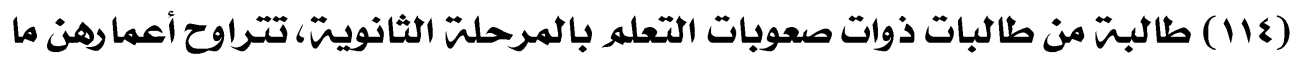

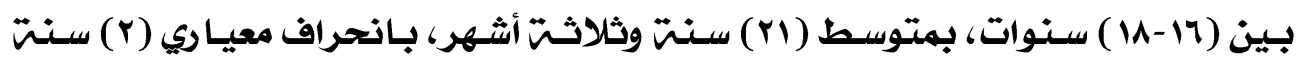

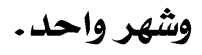

المحدد ات المكانيتّ: تمر تطبيق البحث الحالي على طالبات ذوات صعوبات

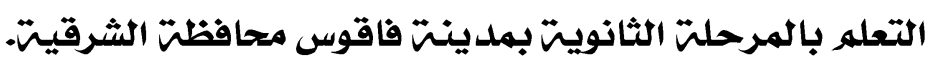

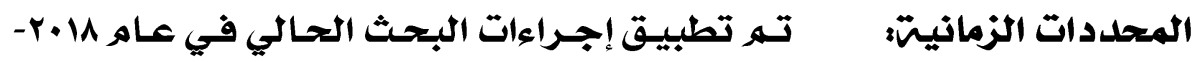
. 0 . 19

$$
\begin{aligned}
& \text { الإطار النظري والد راسات السابقتّ: } \\
& \text { أونًاء الشخصيتة } \\
& \text { تعريف الشخصيتاء }
\end{aligned}
$$

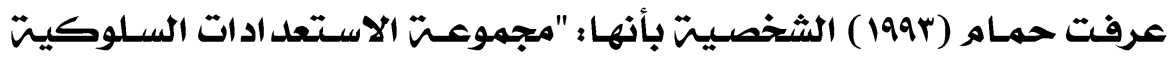

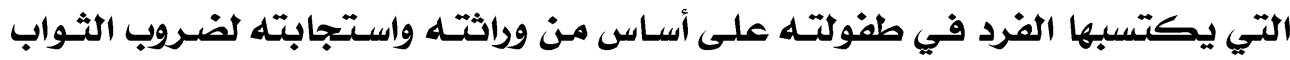
والعقاب، والتي تظل ثابتت نسبيًا في مراحل حياته التاليت والتي تجعله فريلًا وتميزه

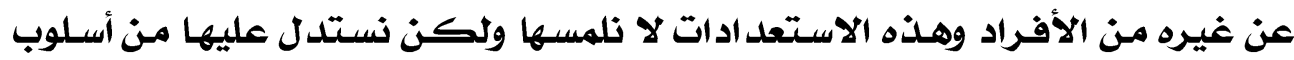

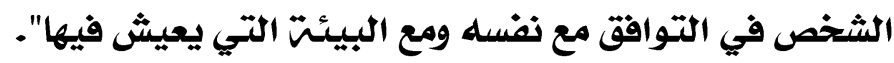

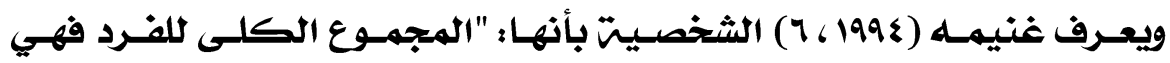

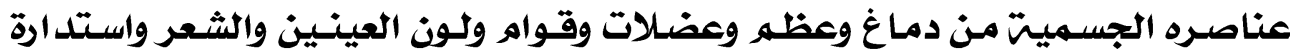

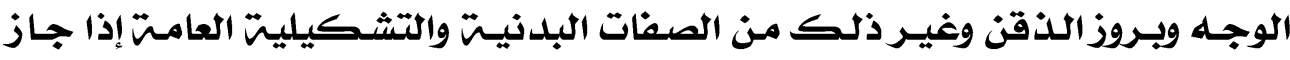

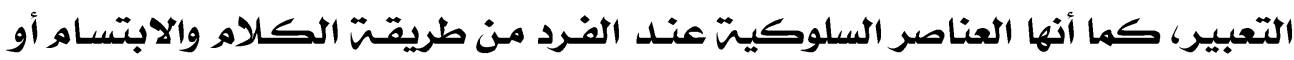

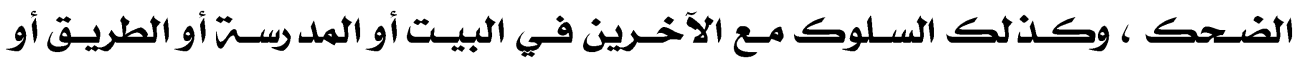
الأماكن العامتة، وهى أيضًا عناصره الذهنيـت والوجد انيـت وأفكا وه ومشاعره وآمالـه

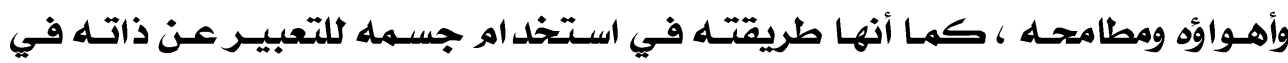
ادراكاته واحساساته وحركاته".

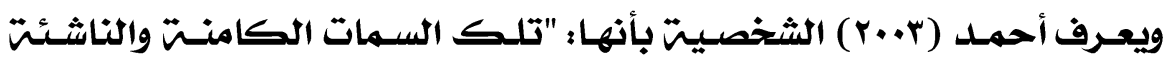

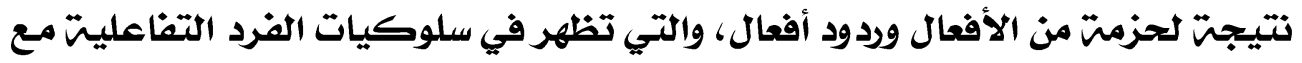

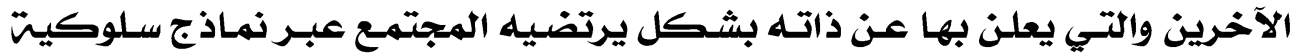

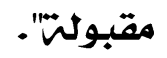

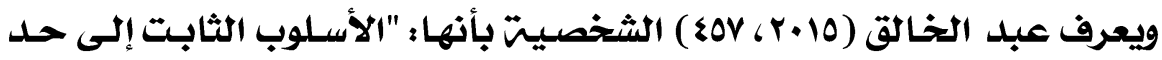

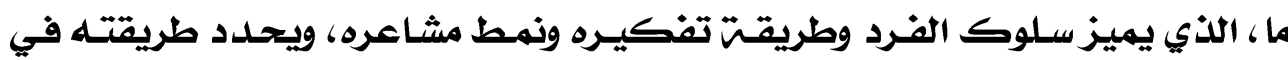

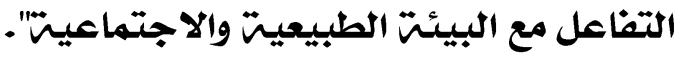




\section{محددات الشخصيت:}

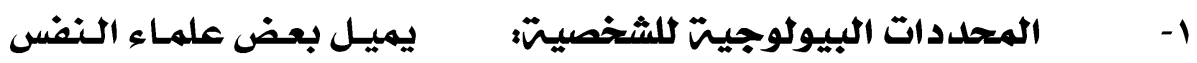

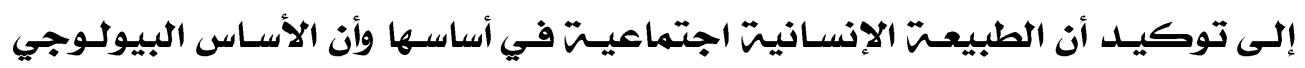
للسلوك هو المشترك بين الإنسان والحيوانات الأخرى.

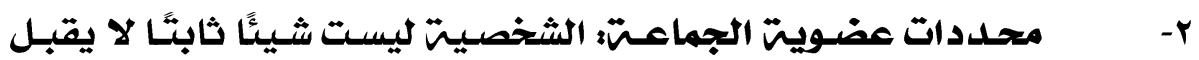

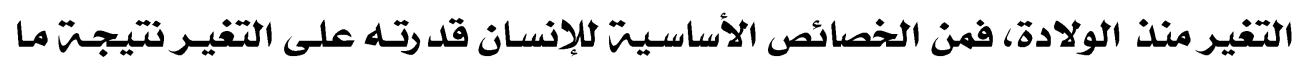

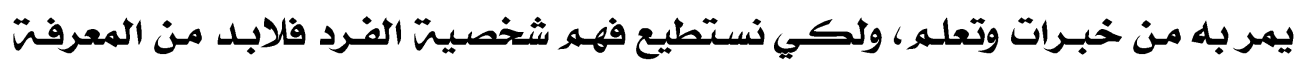

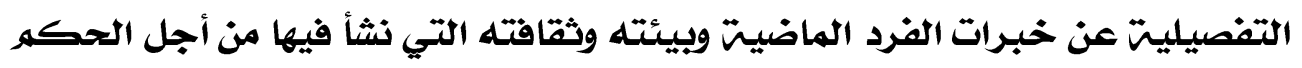

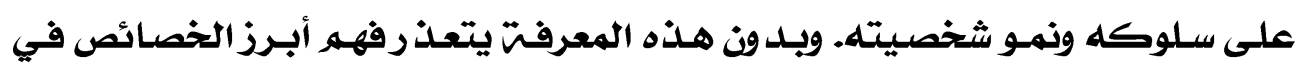

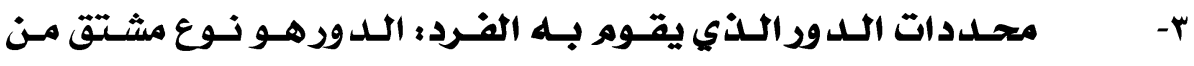

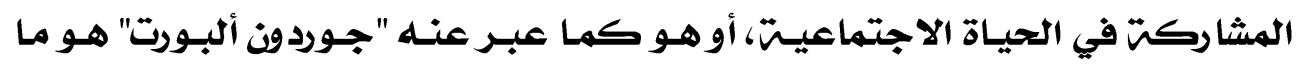

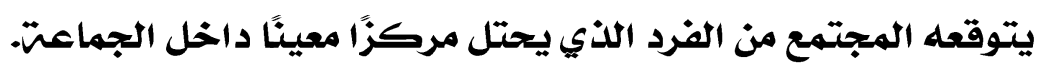

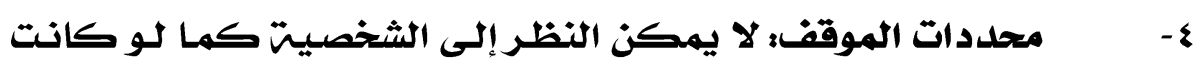

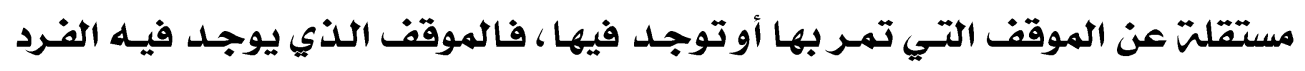

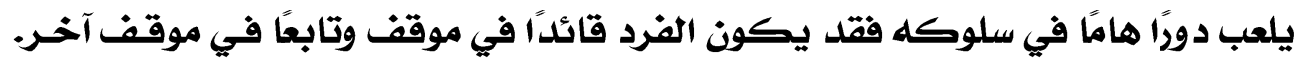

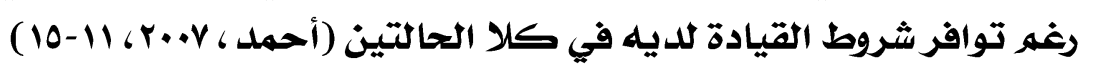

\section{خصائص الشخصين}

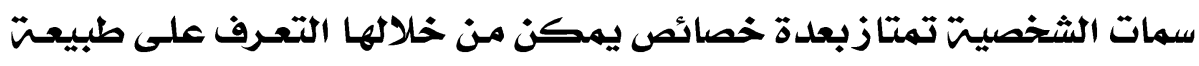

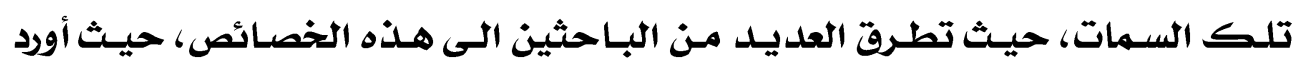

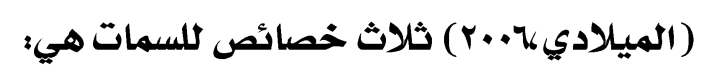

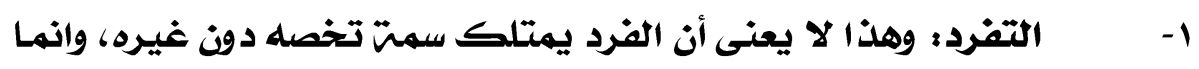

يعنى أن له الكه, الخاص به من نوع معين من السلوك.

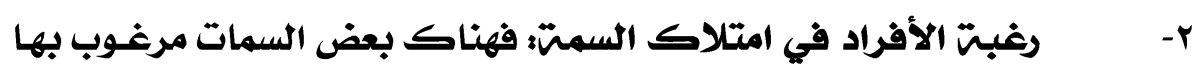

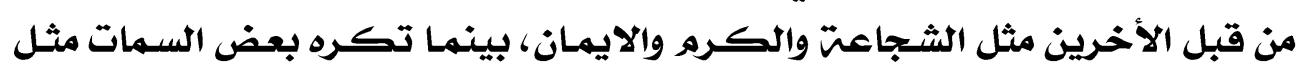

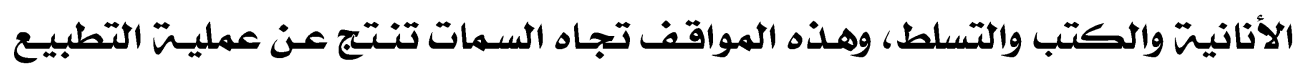

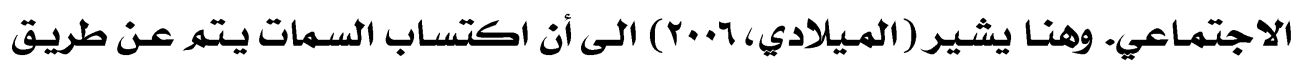

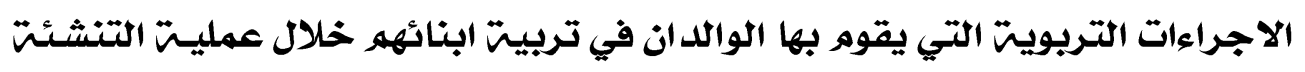

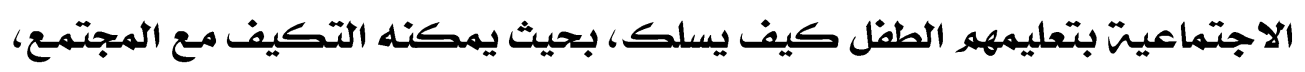

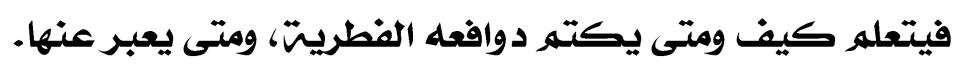

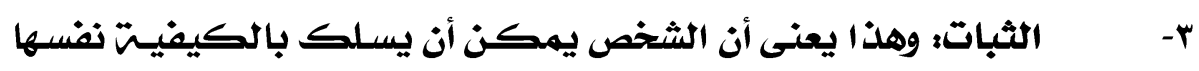

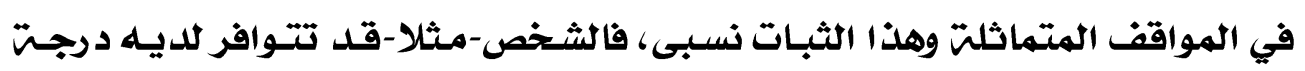




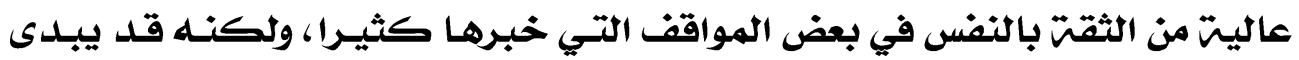

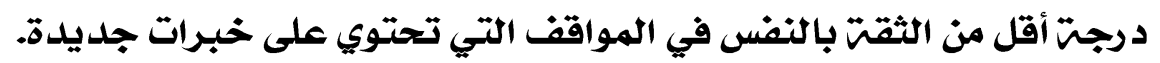

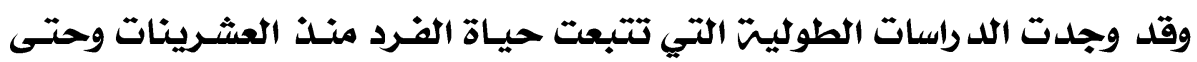

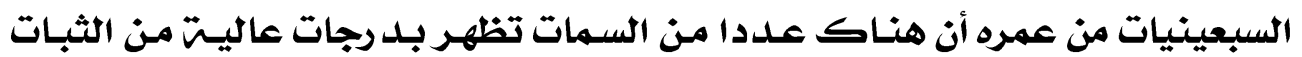

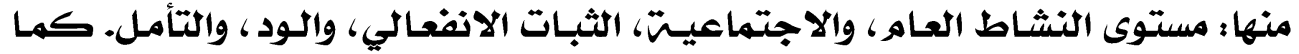

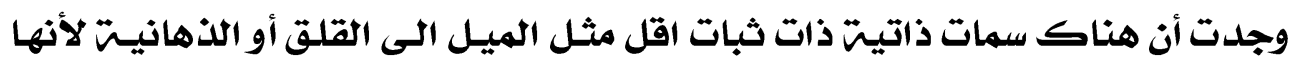

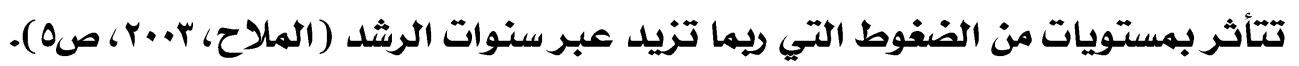
التفسيرات النظريت للشخصيت

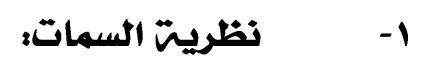

يرى البورت Allport أن الشخصيت هي ذلك الكي التنظيه الديناميكي المتفاعل

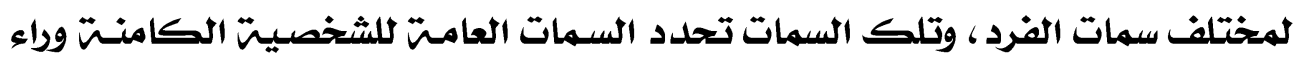

$$
\text { السلوك. }
$$

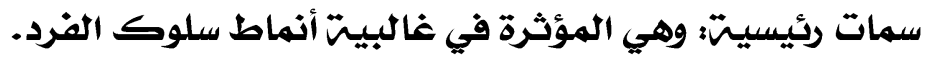

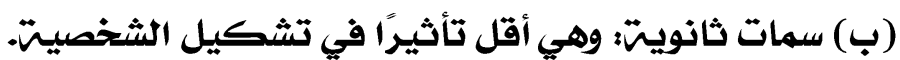

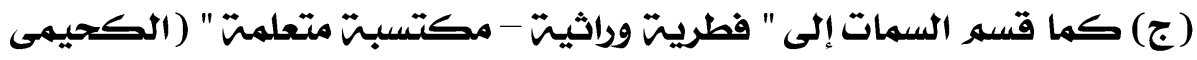

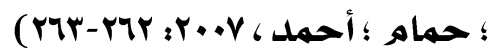

$$
\text { r-النظريت السلوكيتا }
$$

تنسب هذه النظريت إلى ثورنديك وبافلوف وواطسون وسـكنر، ويـرى أصحاب

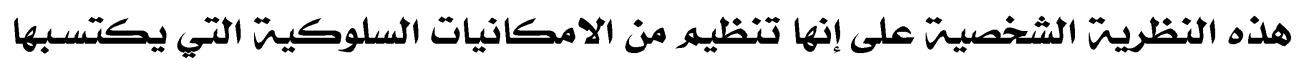

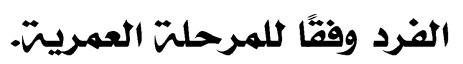

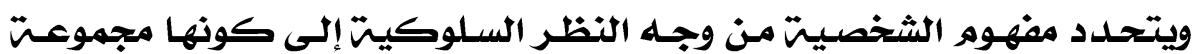

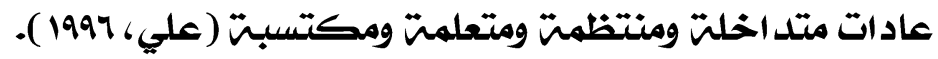

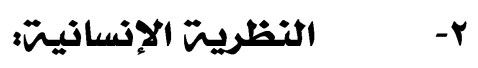

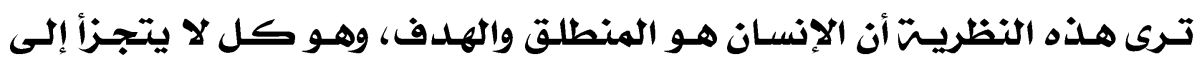

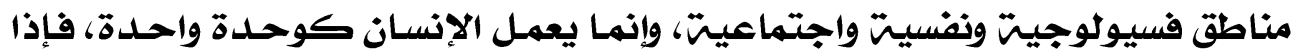
حقق السويت حقق اتزانه والا اختلت وظائفه.

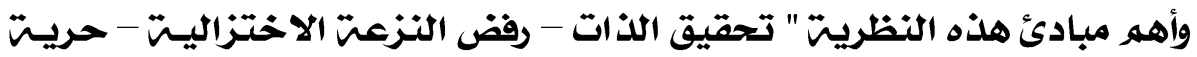

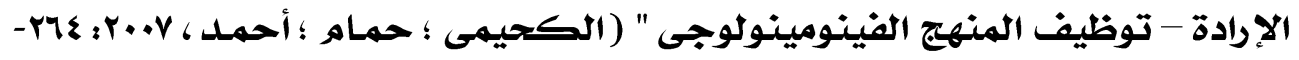




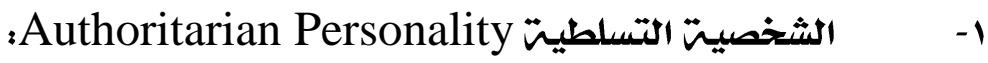

$$
\begin{aligned}
& \text { وهي تعنى الشخص الذي يتصف بالتسلطيتر. } \\
& \text { وهي تعنى الشخص المصاب بالذهان. } \\
& \text { وهي تعنى الشخص الهصاب بالعصاب. }
\end{aligned}
$$

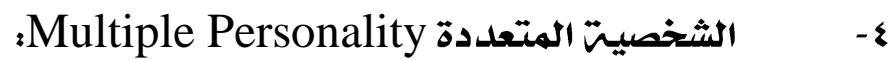

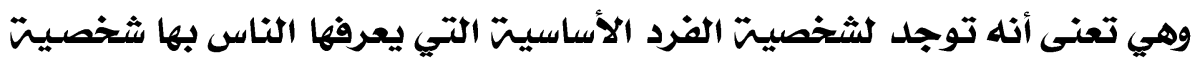

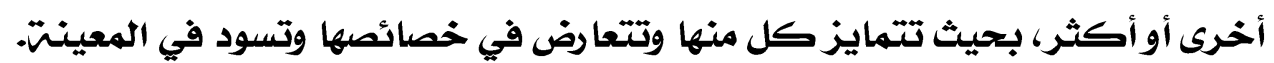

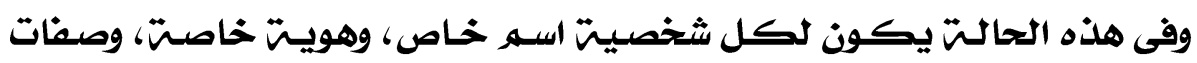

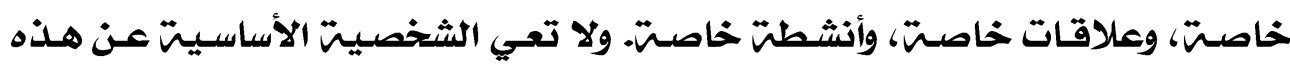

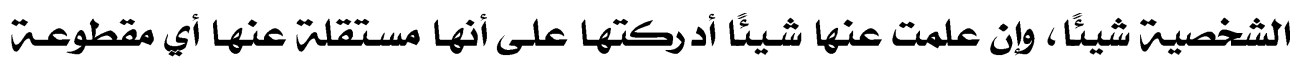

الصلت بها.

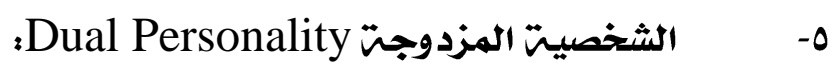

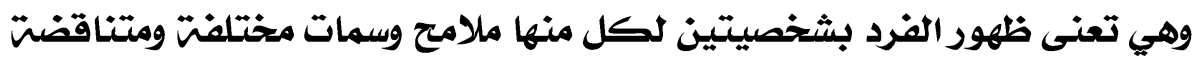

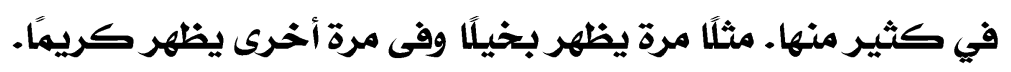

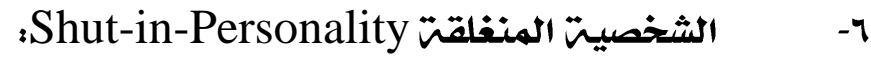

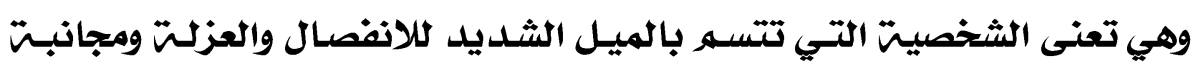

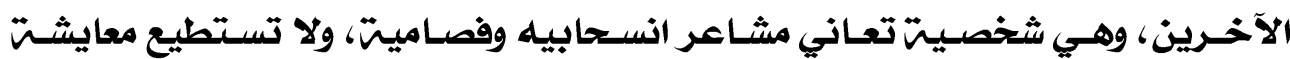

$$
\text { الواقع ولا تحتمل مواقف التفيخ تهاعل الاجتي مثاعر انسي. }
$$

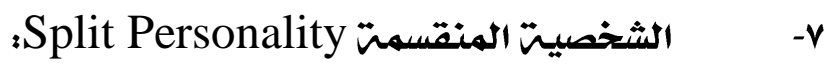

$$
\text { وهي تعنى الشخصيت المتعددة. }
$$

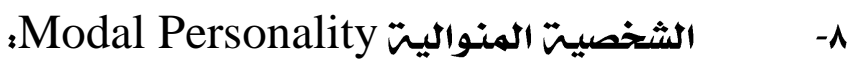

وهي تعنى الشخصيت الأكثر تكرارًا وشيوعًا في أفراد مجتمع ما.

9-

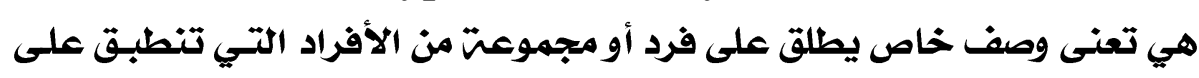
شخصياتهه خصائص وسمات شخصيت معينتة. . Marginal Personality الشخصيت الهامشيتية وهي تعنى الشخص ضعيف التأثير على من حوله، وكذلك الهيت قليل الأهميت في

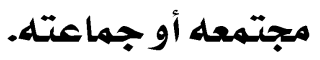
أنماط الشخصيت من وجهت نظر ماروستون:

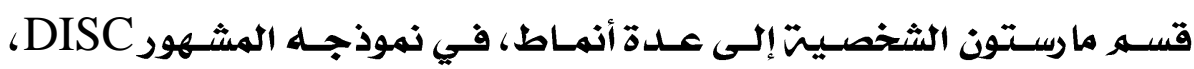

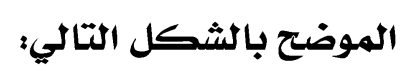




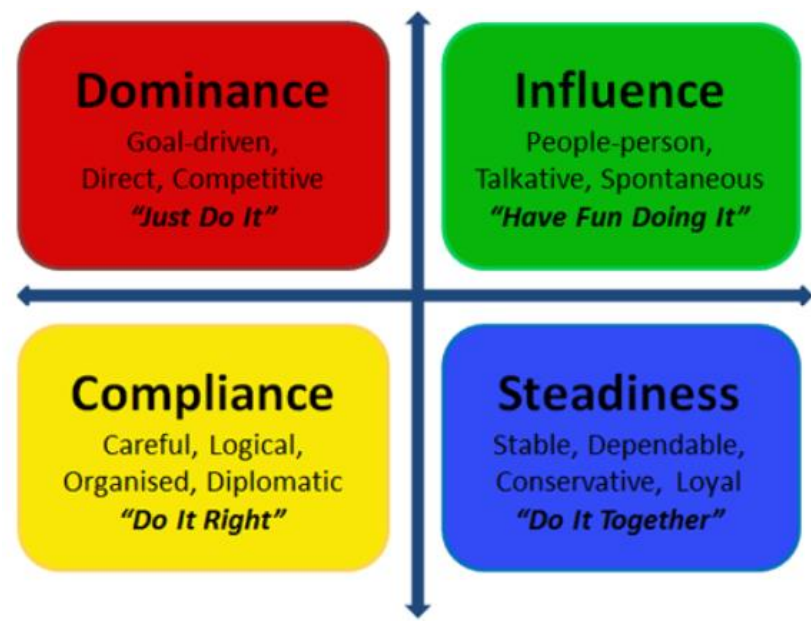

النهط D: وهو يعنى الهيمنت والمقصود بها الشخصيت " القياديت "

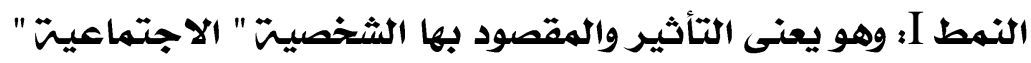

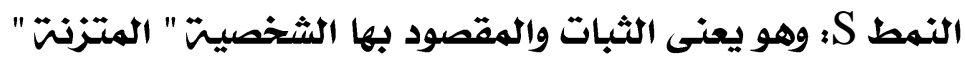

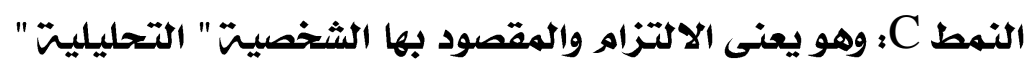
http://expertisegrp.blogspot.com/p/blog-page_16.html

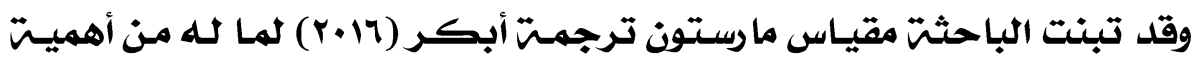
بارزة في تحديل أنماط شخصيت الأفراد.

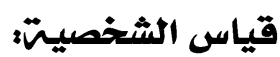

أجمع الباحثون في مجال الشخصيتت إلى أن الوسائل العلميـت لقيـاس الشخصيت

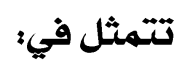
الملاحظت: تعتبـر الملاحظت من الطرق التـي تستخده في تقيـيه

الشخصيت وذلك مـ خـلال الملاحظت المباشـرة لسـلوك الفـرد في مواقف الحيـاة

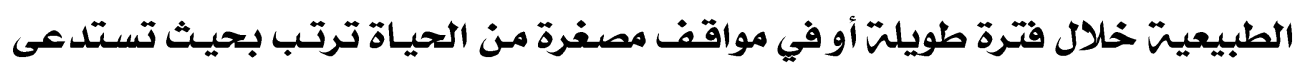
ظهورسمات الشخصيت المطلوب قياسها.

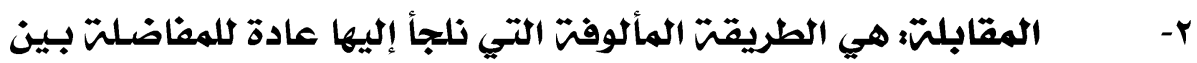

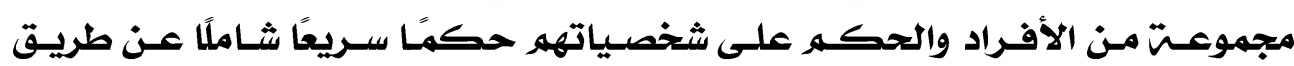

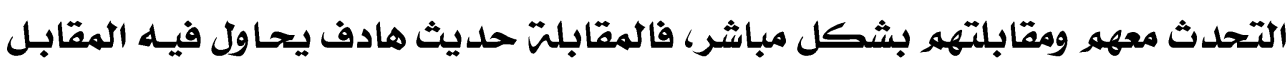

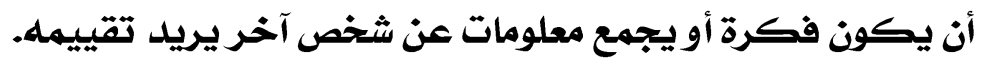

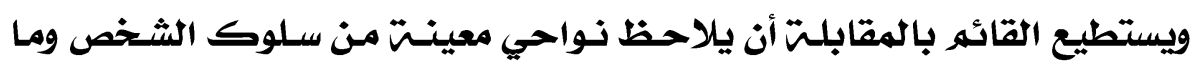

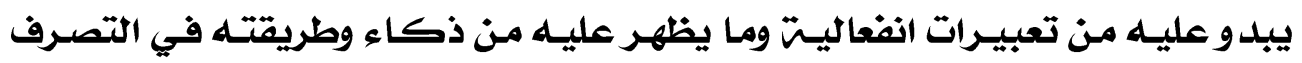

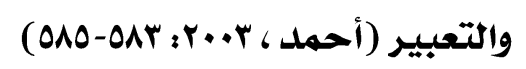

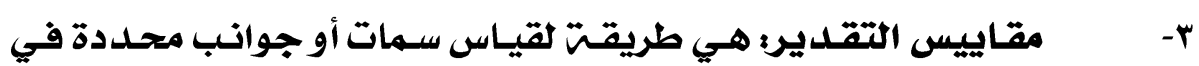

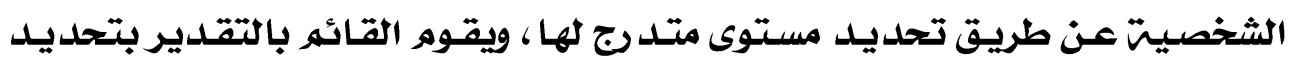


الد رجت التي تنطبق على المبحوث من بين عدد من الد رجات يضمها هـذا المقياس

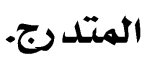

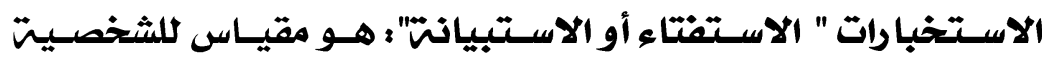

$-\varepsilon$

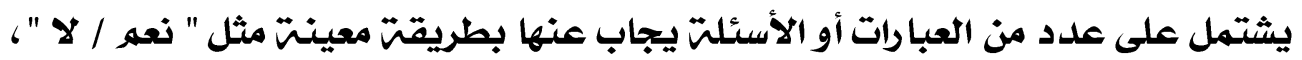
وتقد رد رجاتها بطريقت خاصنت.

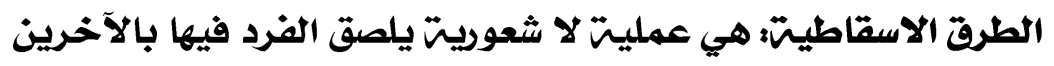

$-0$

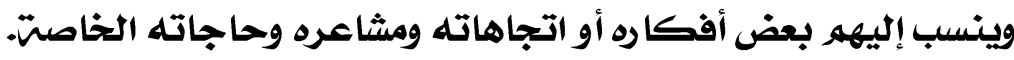

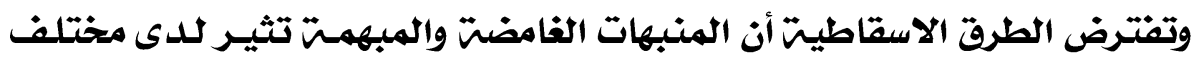

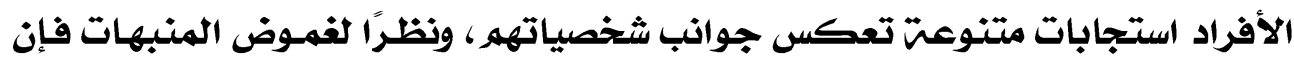

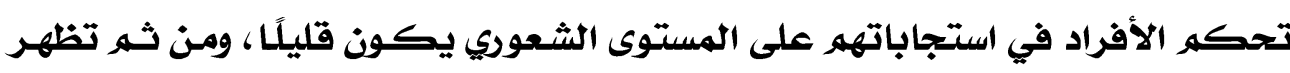

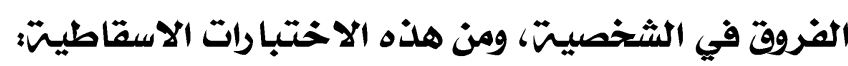

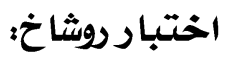

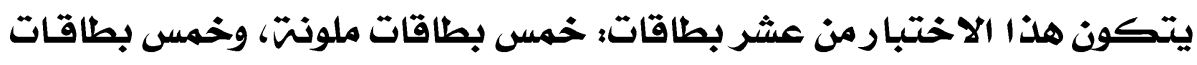

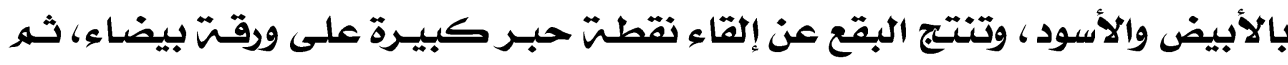

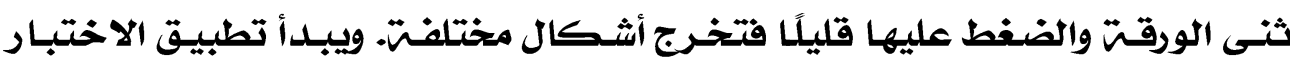

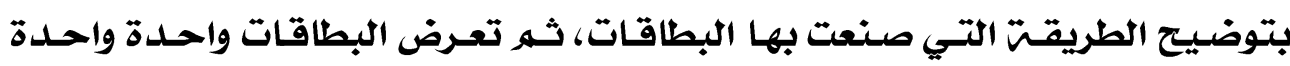

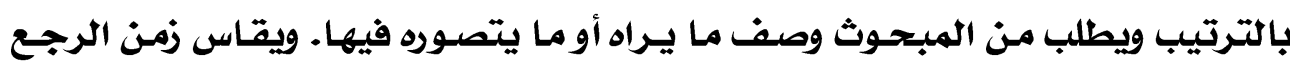

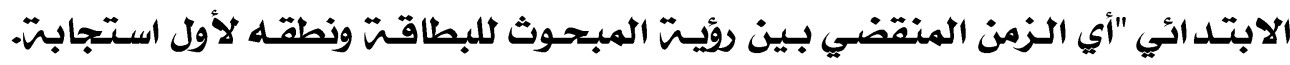

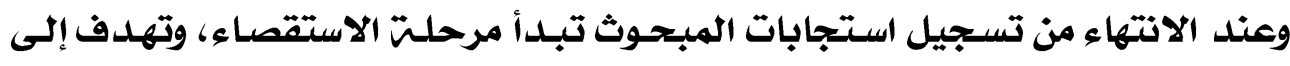

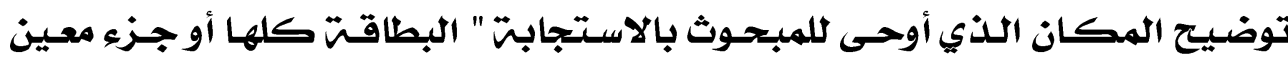

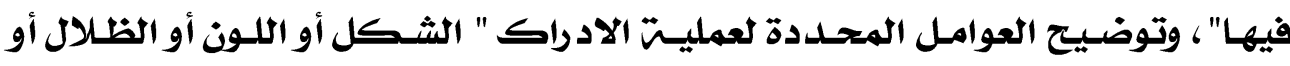

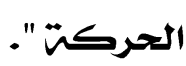

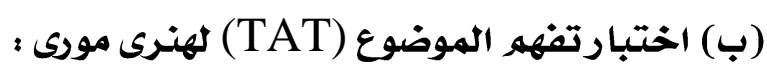

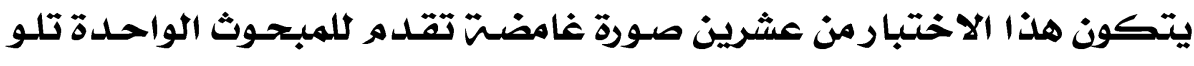

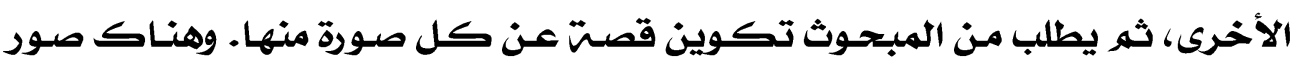

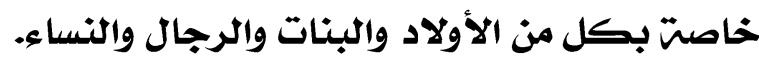

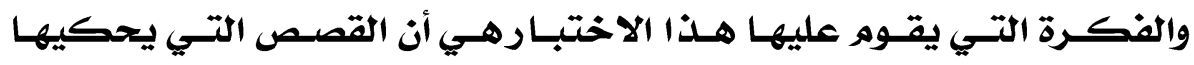

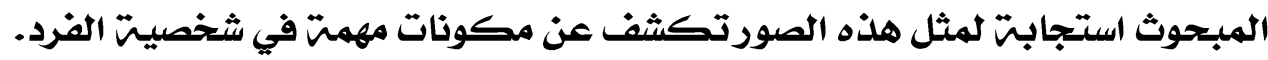

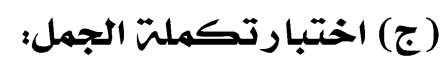

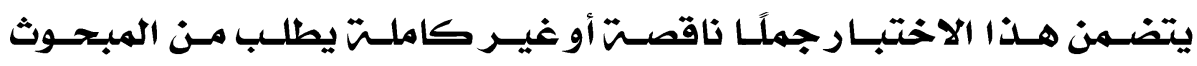

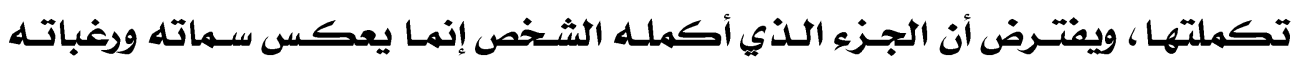

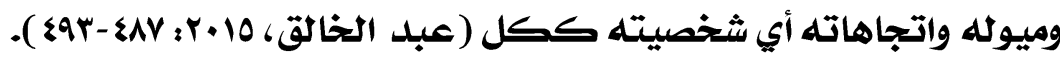


7- اختبارتحليل الشخصيت (DISC)؛

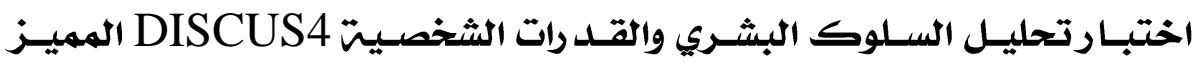

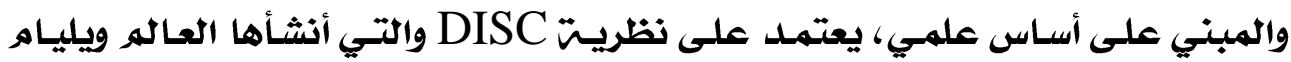

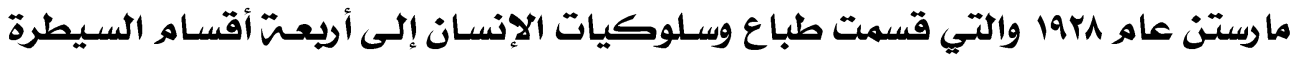

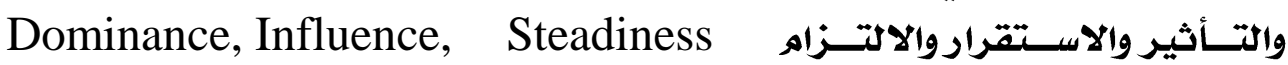
, Compliance ثانيًا : سلوك المعلى

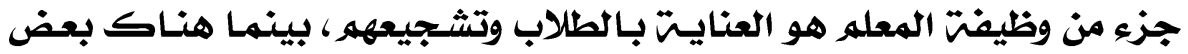

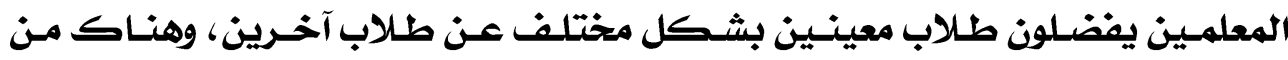

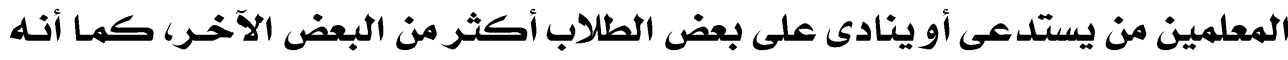

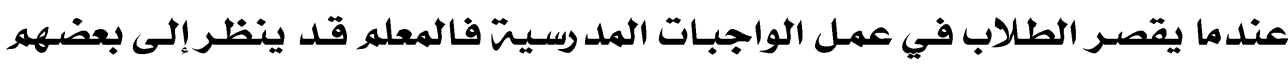
نظرة معينت بينما يعاقب آخرين منهم.

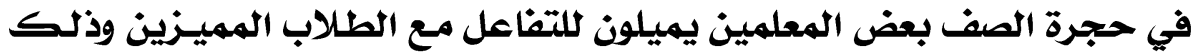

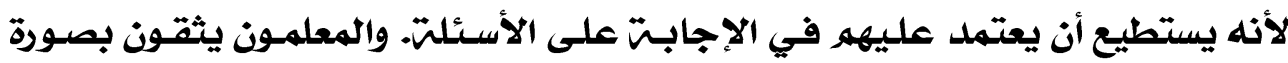

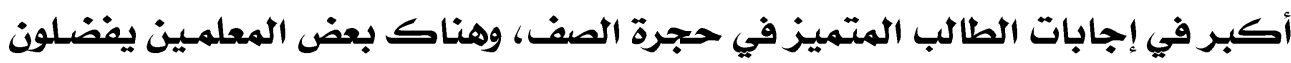

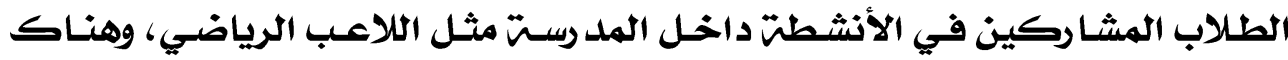

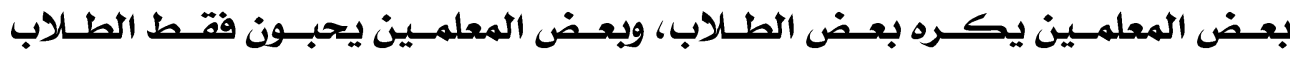

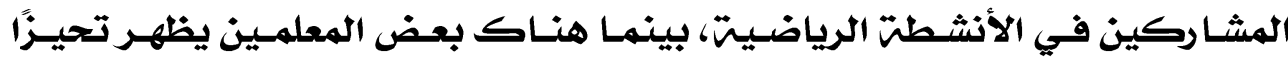

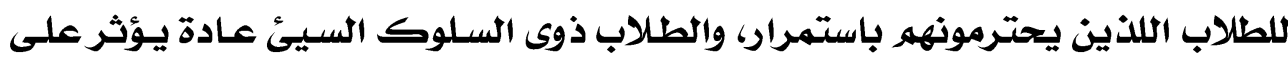

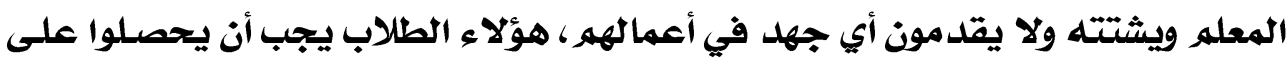

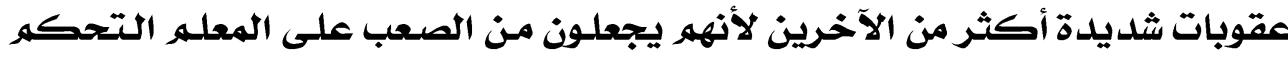

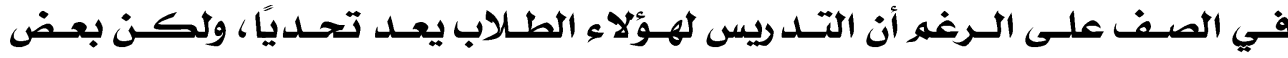

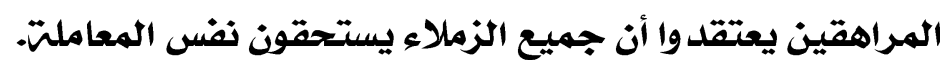

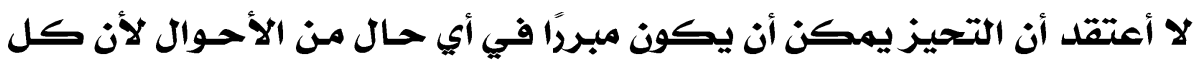

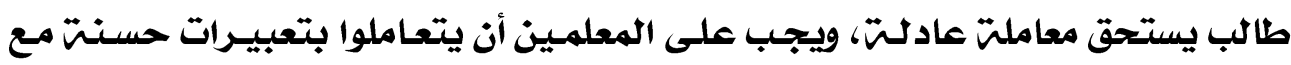

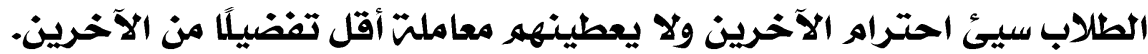

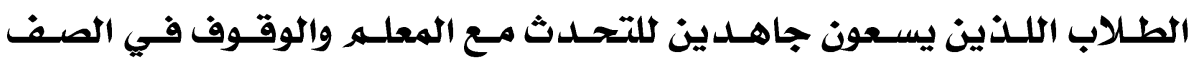

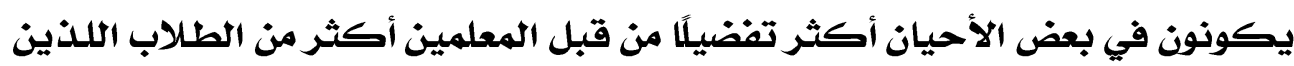
يحاولون الجلوس في آخر الفصل.

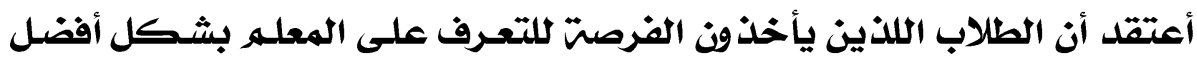

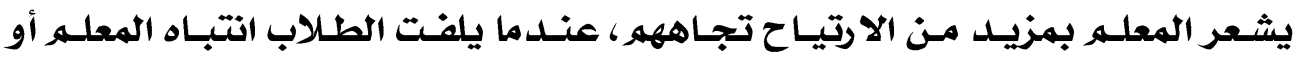

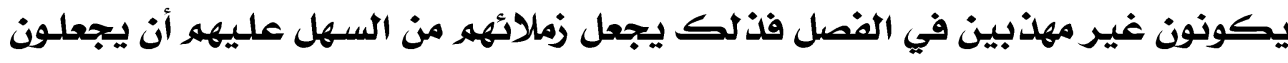

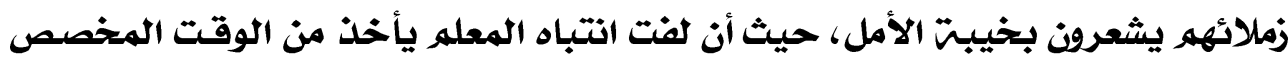


للحصت ويضايق الطلاب الآخـرين اللذين يفضلون الاستمرار في المهامر، فالمعلمون

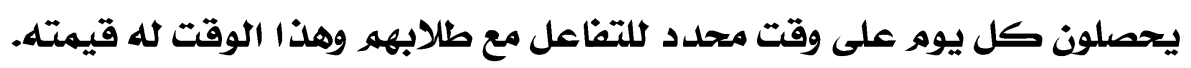

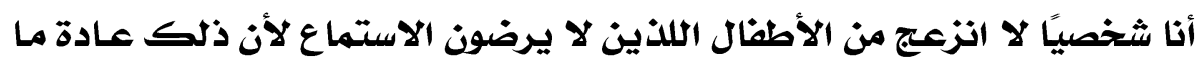

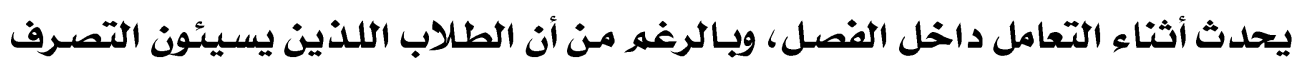

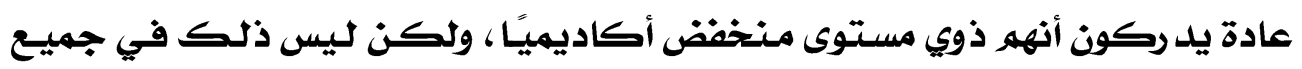
الأحوال.

بعض الطلاب يحترمون أعضاء هيئت التد ريس، ولكن من الصعب أيضًا حصـول

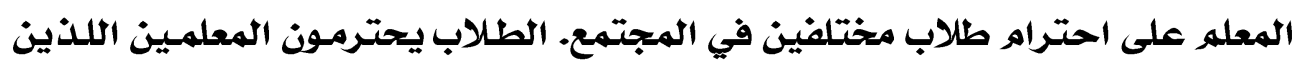

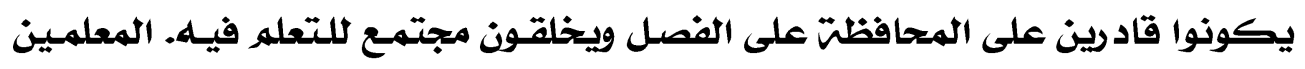

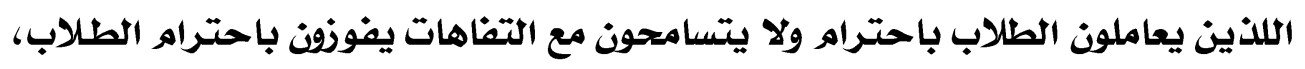

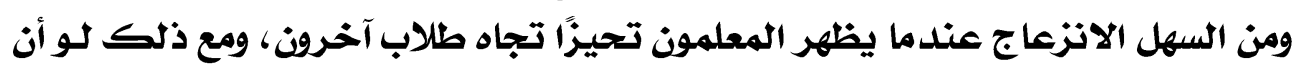

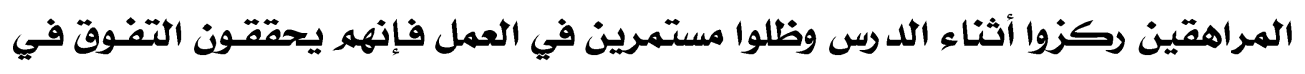
الفصل سواء كانوا على علاقت جيدة بالمعله أه لا. (Kovacs, J. 2012)

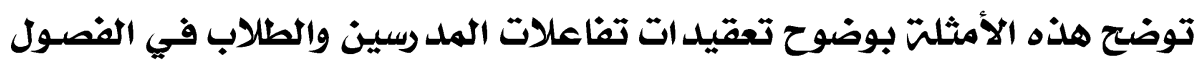

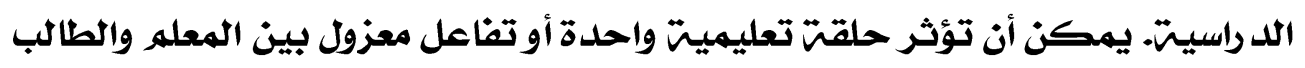

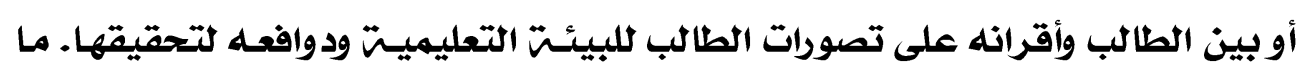

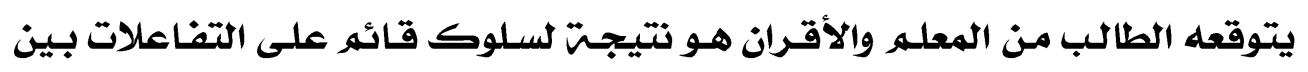

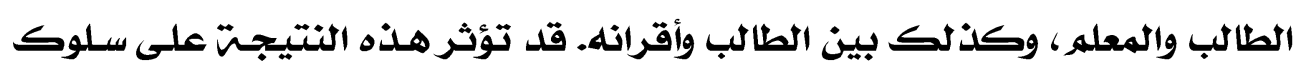
المستقبل أوخيارات الحياة.

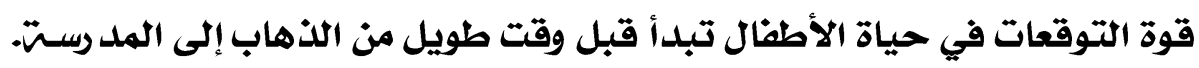

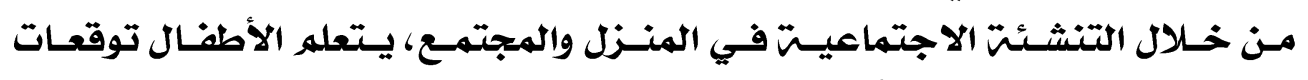

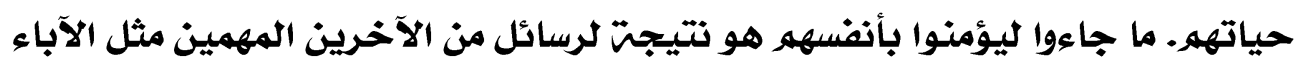

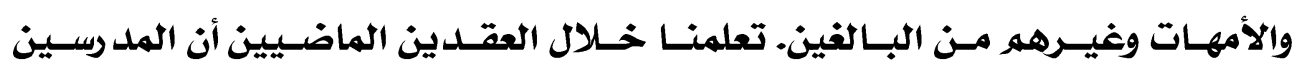

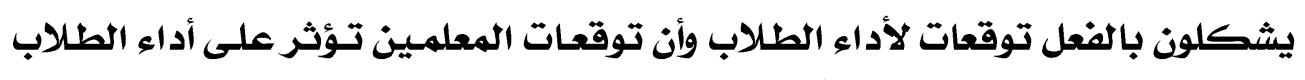

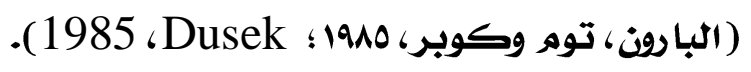

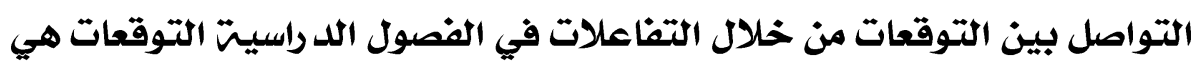

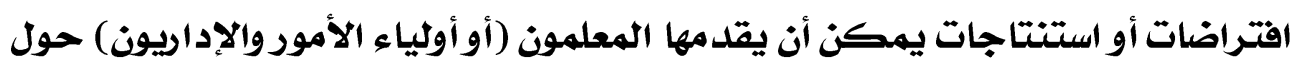

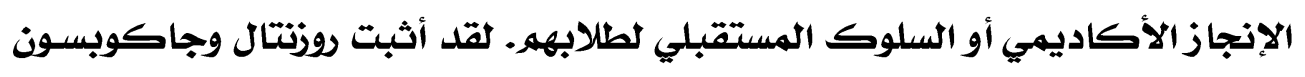

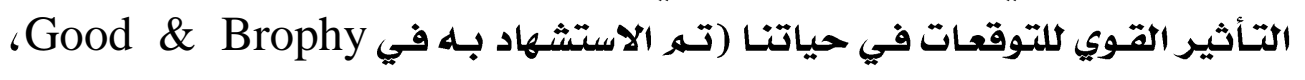

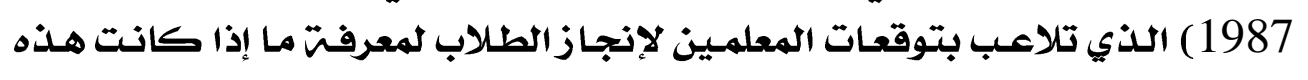

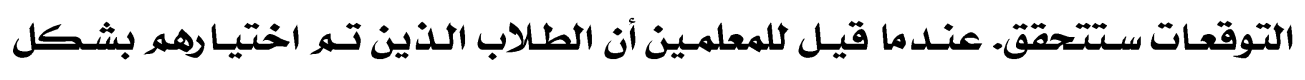

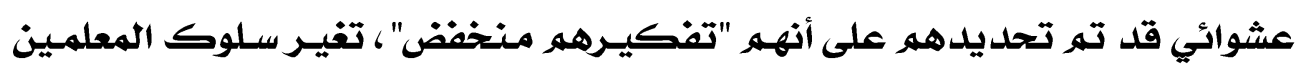

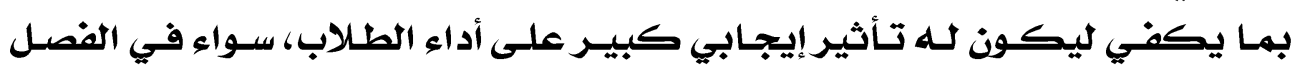


الدراسي أو في اختبارات التحصيل. وقد ته تفسير النتائج من حيث التأثيرات القويتة

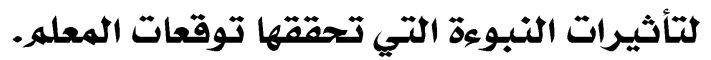

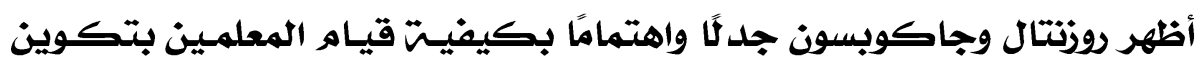

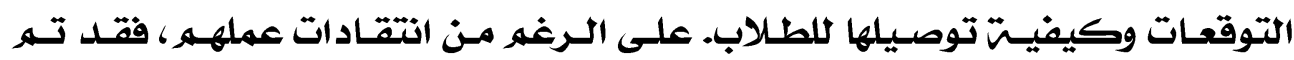

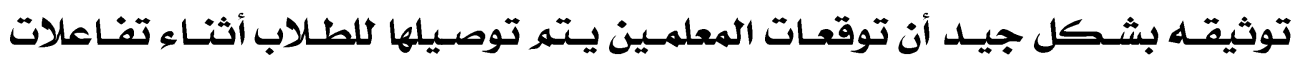

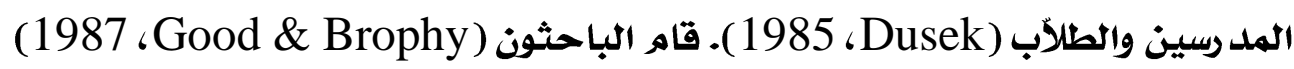

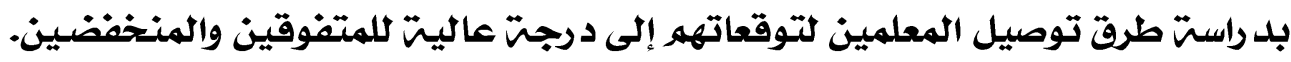

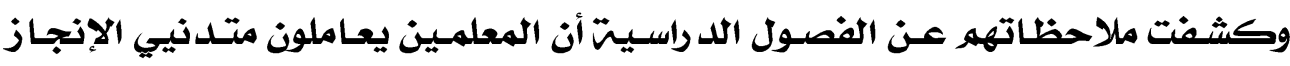

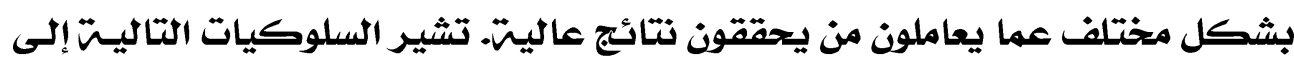

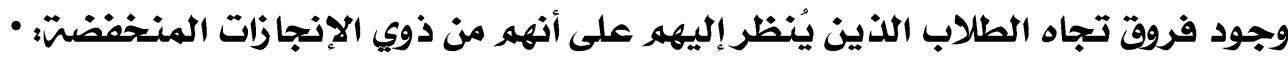

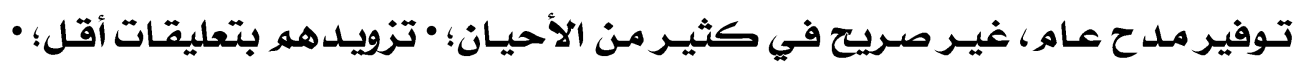

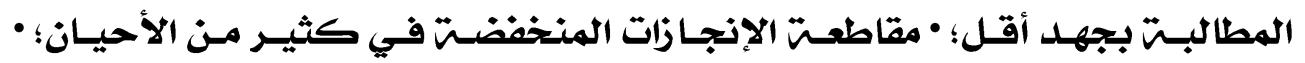

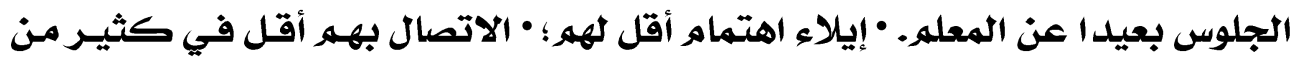

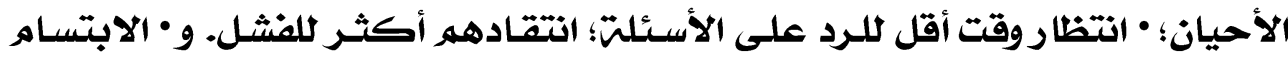

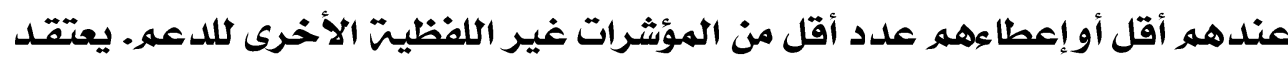

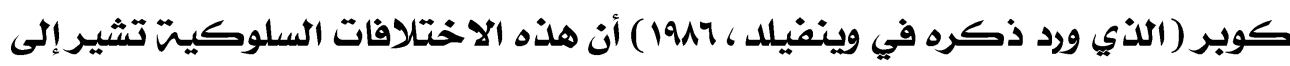

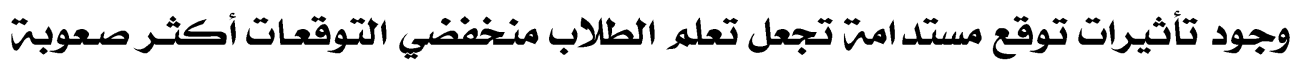

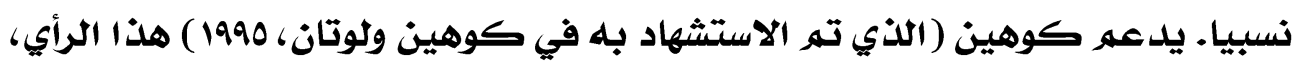

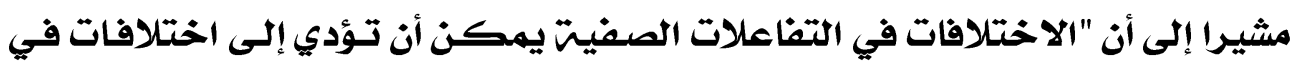

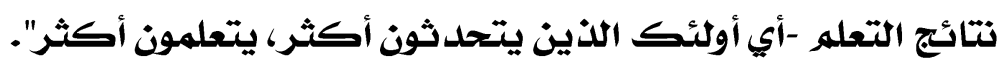
http://www.mcrel.org/products/noteworthy/noteworthy/loyc

ec.asp.

\section{إد راك الطلاب لتوقعات المعلمين:}

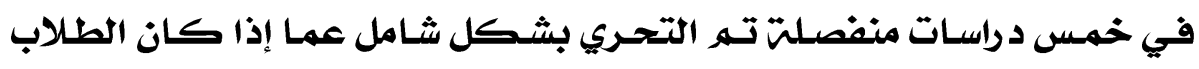

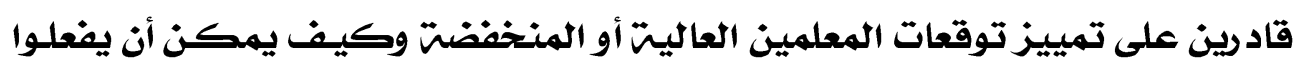

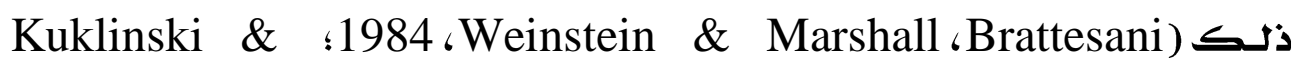
Weinstein et 1979 ،Weinstein \& Middlestadt 2000 ،Weinstein

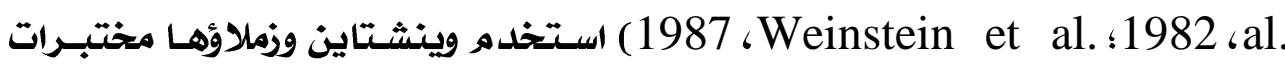

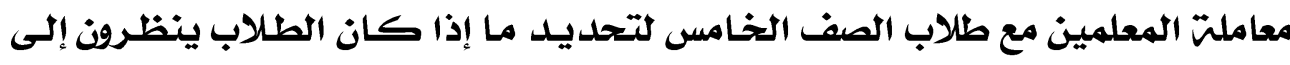

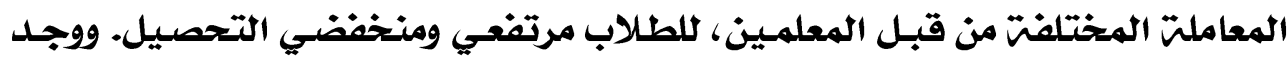

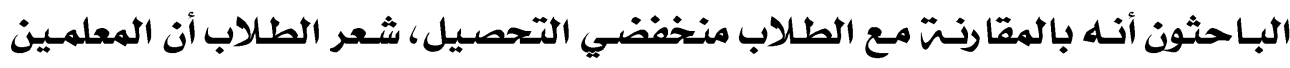

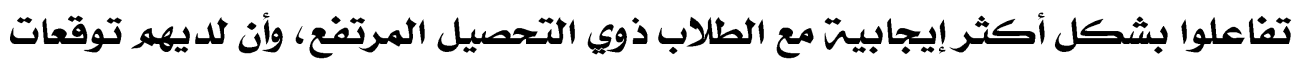




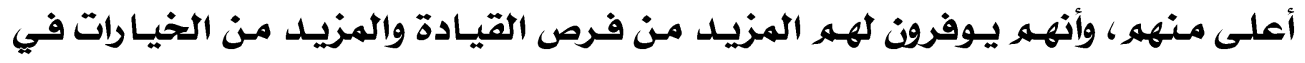

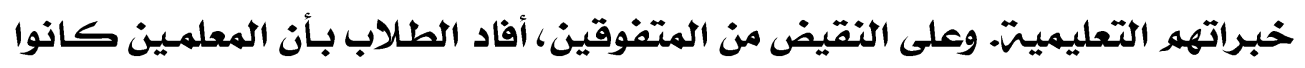

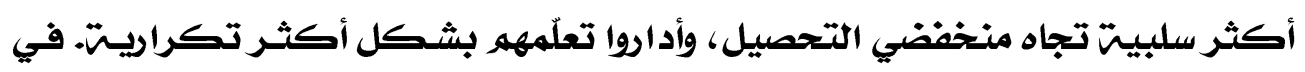

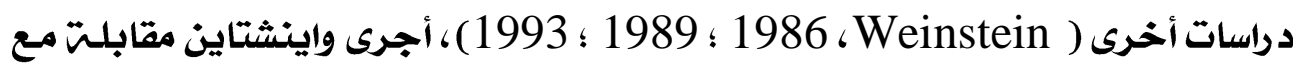

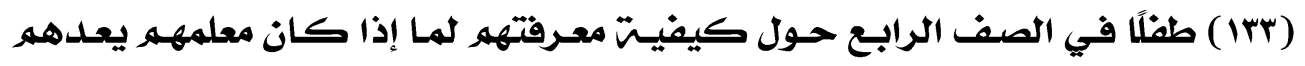

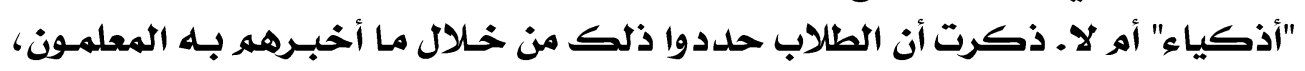

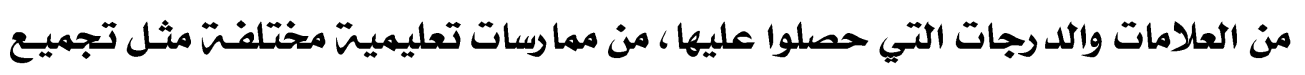

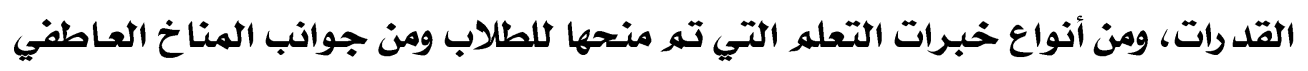

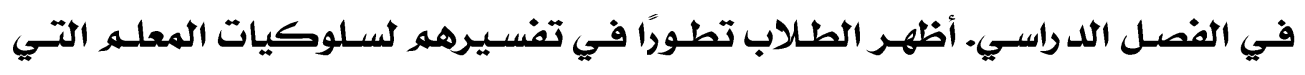

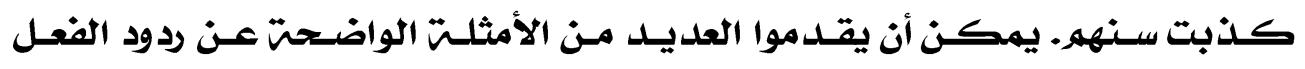

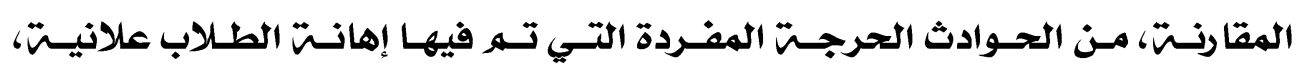

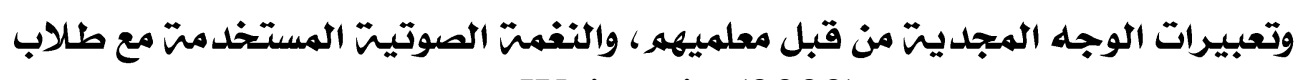

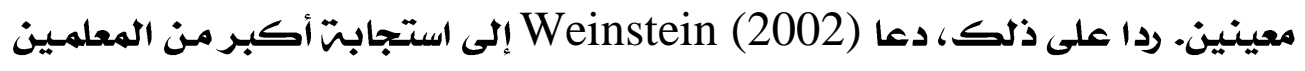

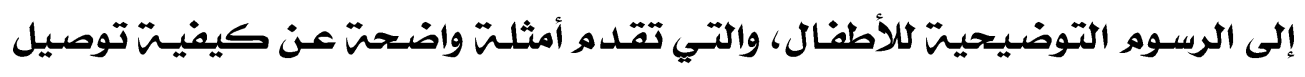
التوقعات إلى الأطفال. الترون التوضيحيت.

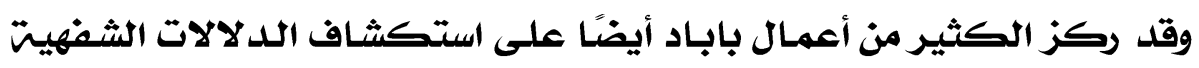

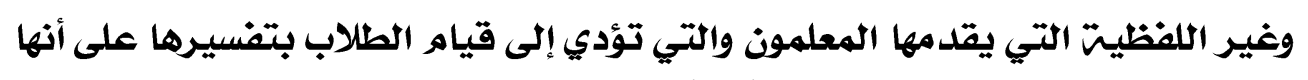

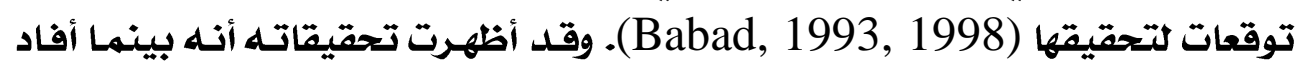

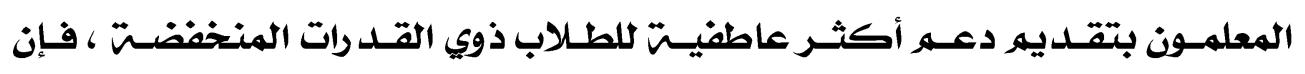

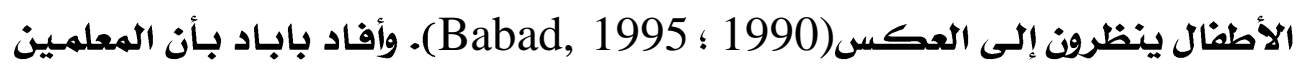

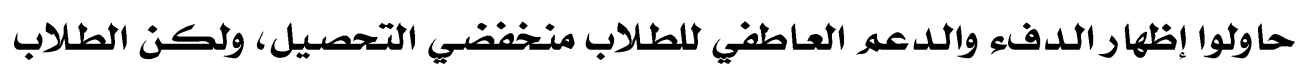

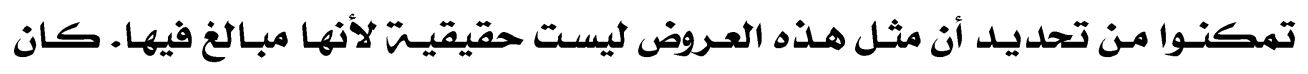

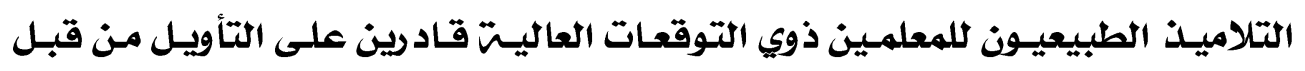

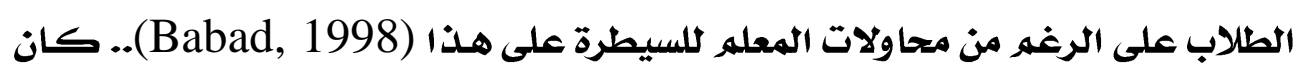

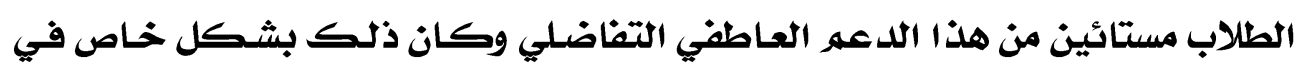
الفصول الد راسيته.

كما قـاهو بابـاد بـالتحقيق في تفسير الطلاب لسـلوكيات المعليه باستخداهر

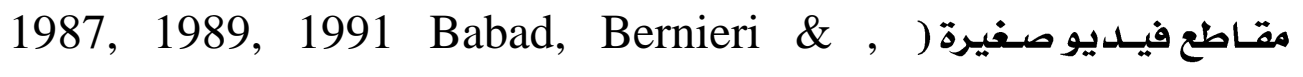
(Rosenthal,

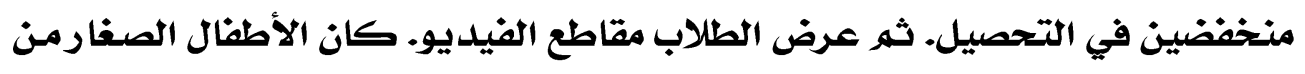

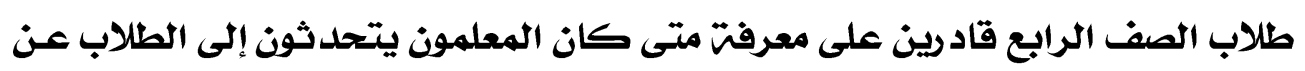

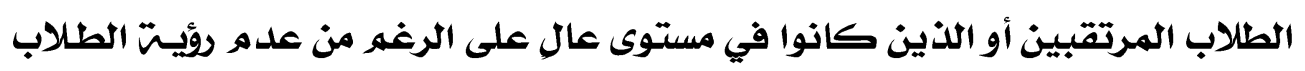

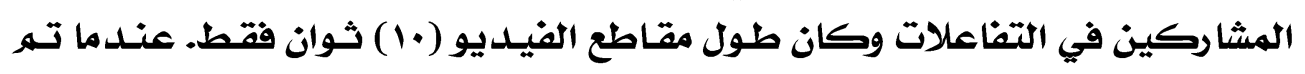




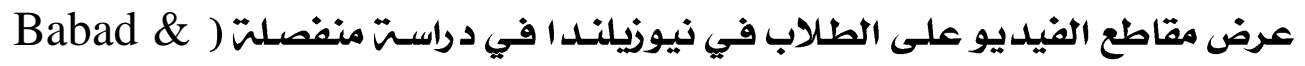

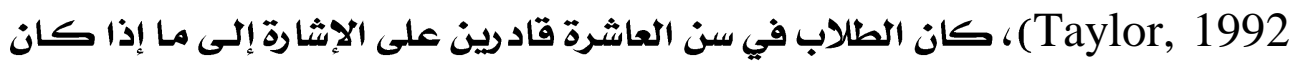

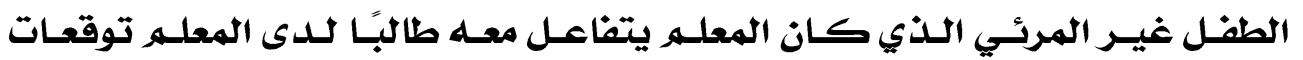

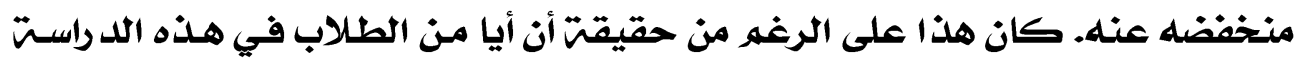

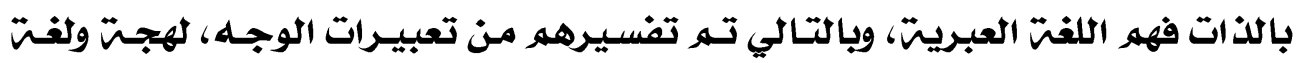

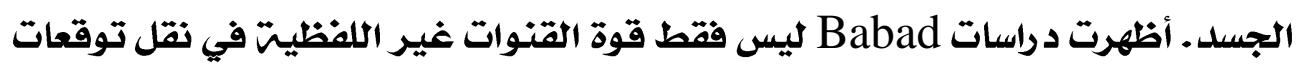

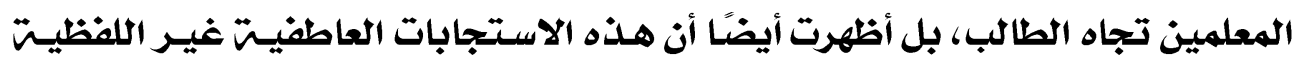

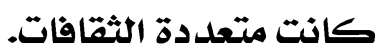

يبدو واضحا من العمل المكثف لكل من وينشتاين وباباد أن الطلاب قاد رون التون

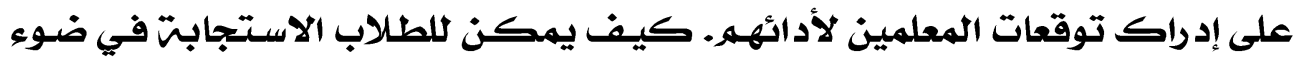

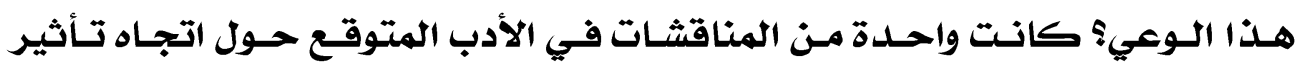

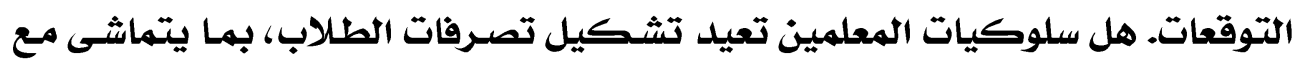

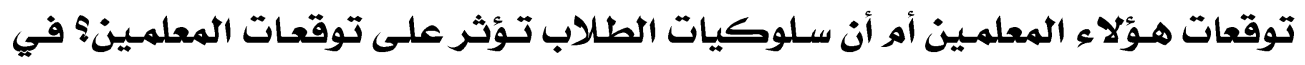

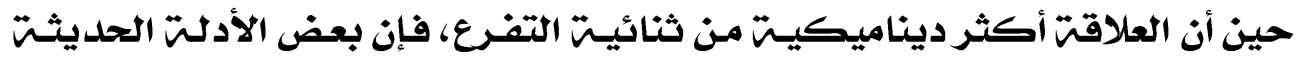

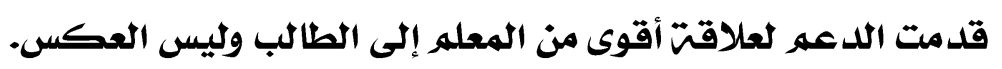

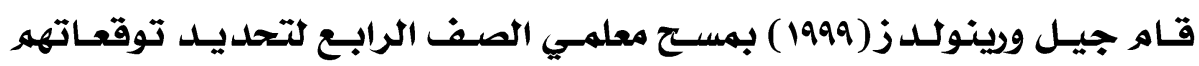

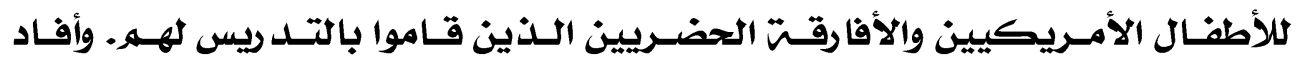

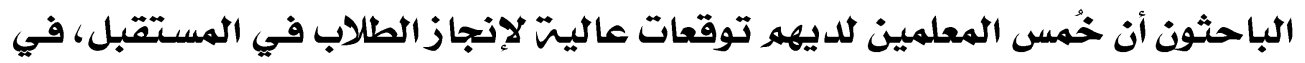

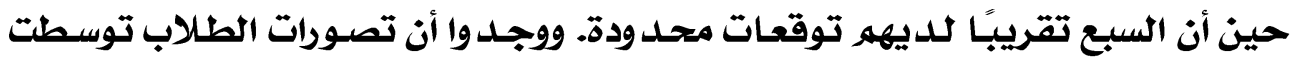

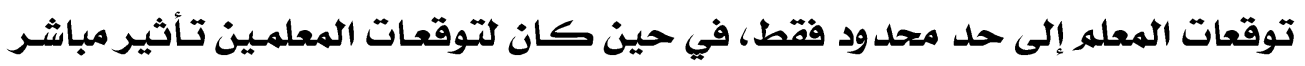
كبير على درجات الطاب في كل من المعل القراءة والرياضيات.

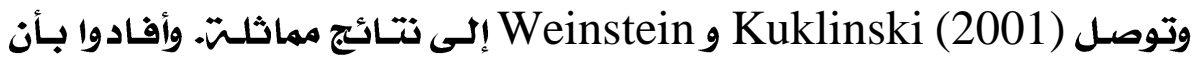

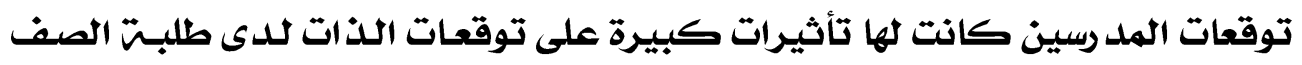

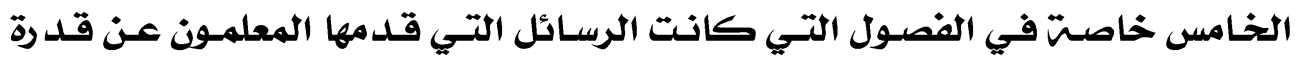

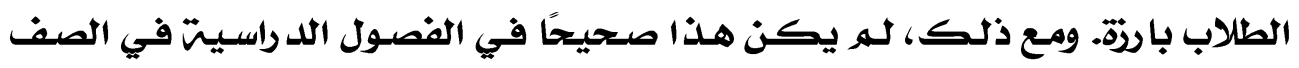

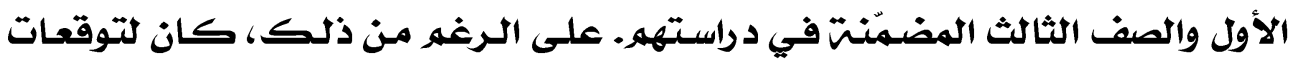

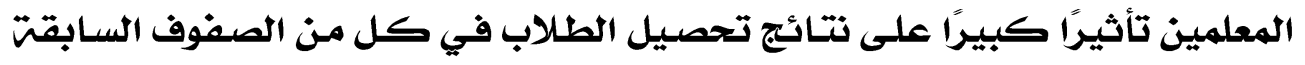

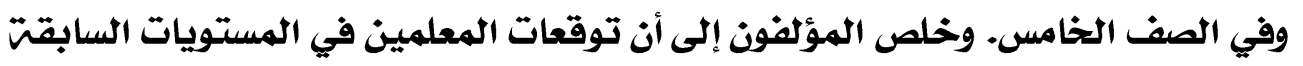

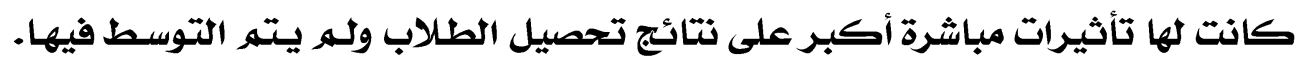

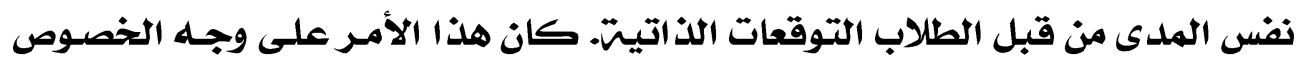

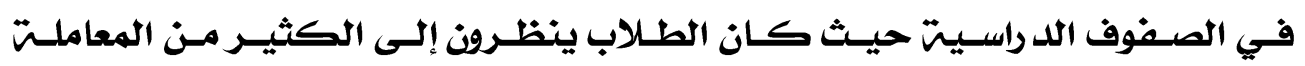
التفضيليت نحو طلاب التوقعات العاليت والمنتخفضيت. 


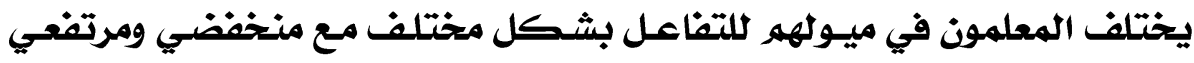

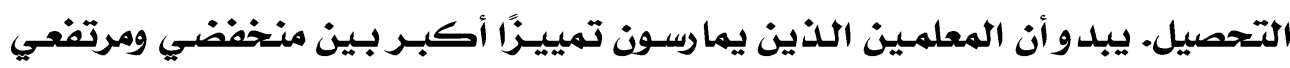

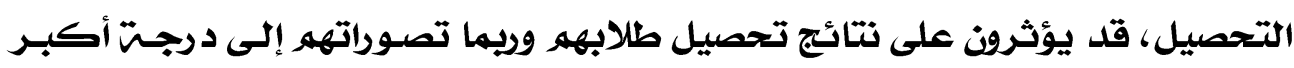

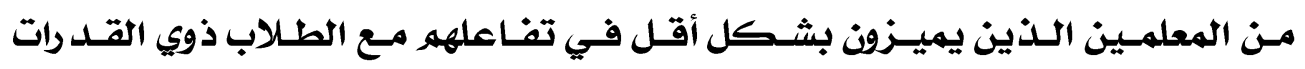

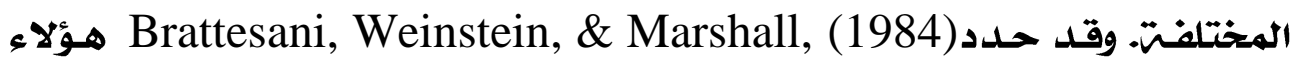

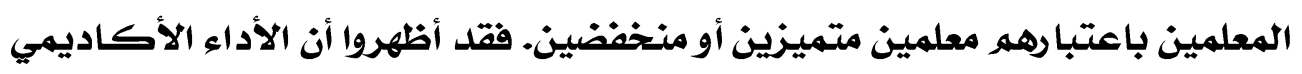

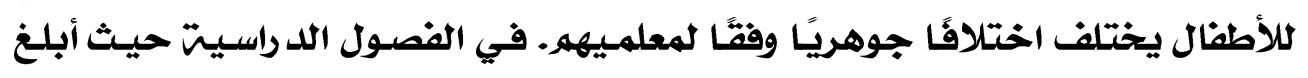

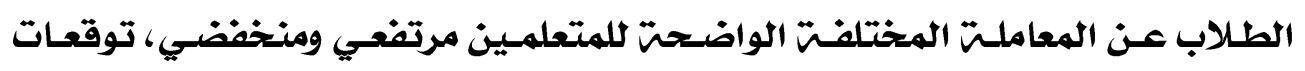

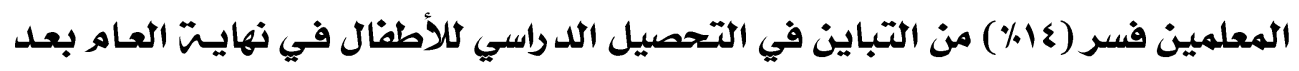

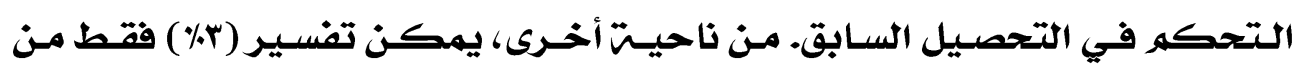

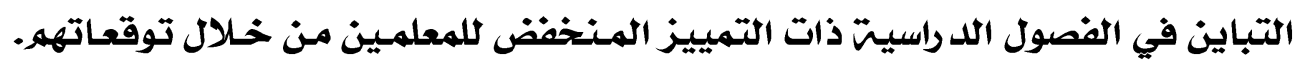

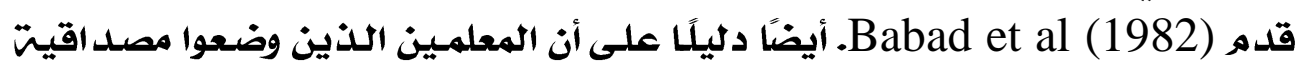

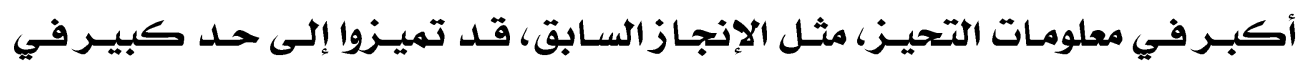

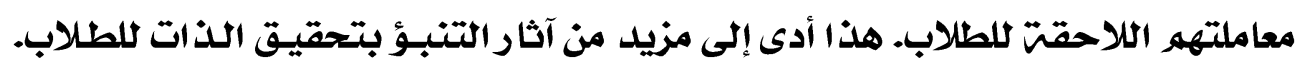

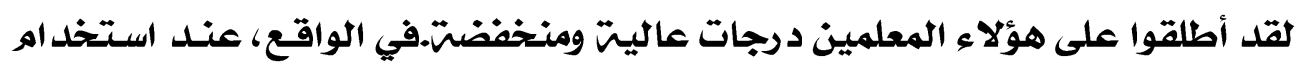

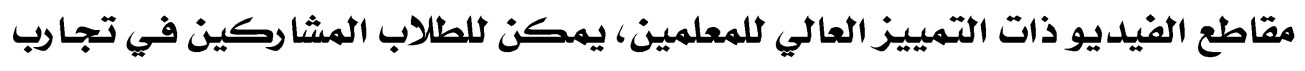

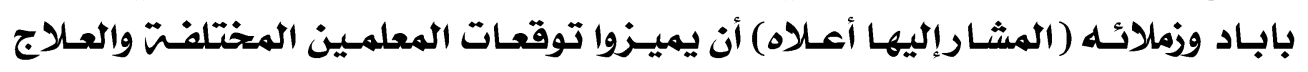

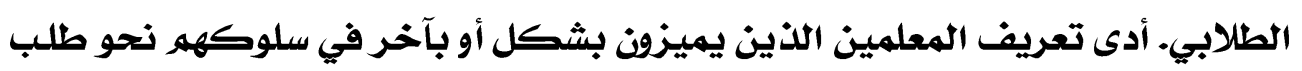

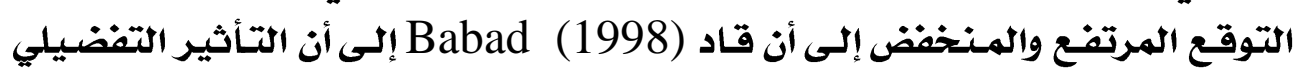
كان في صميه قضيت توقعات المعله.

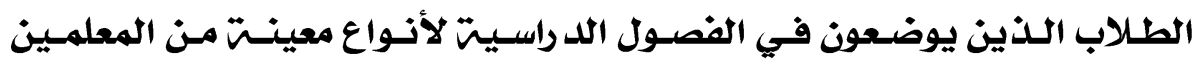

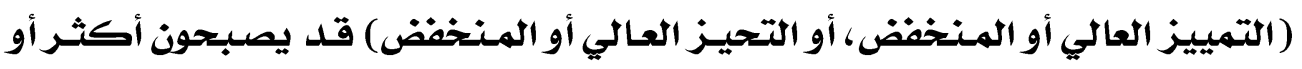

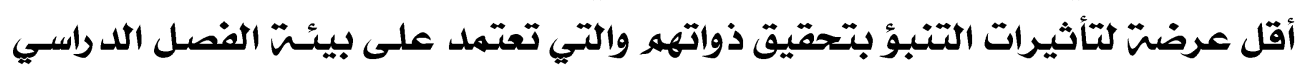

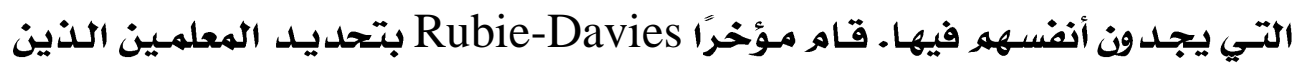

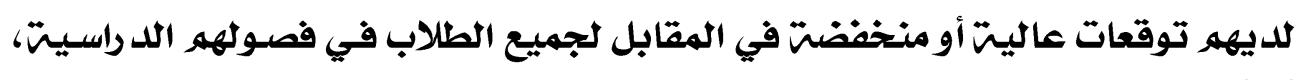

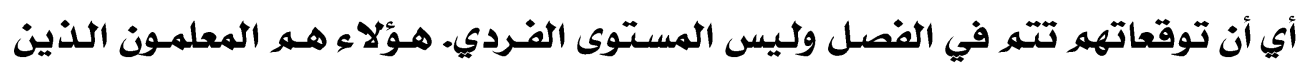

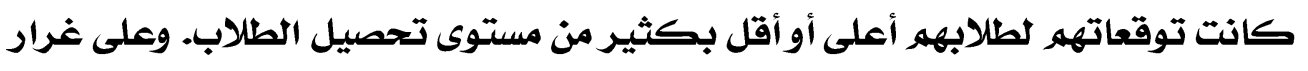

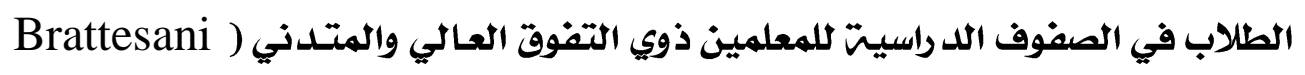

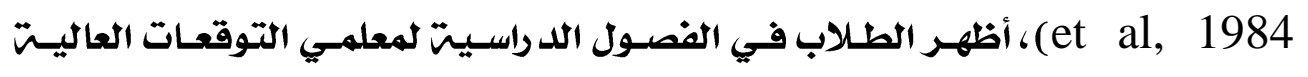

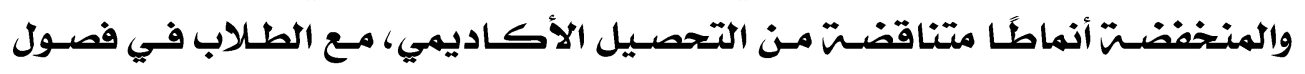

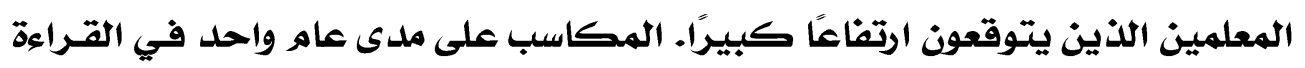

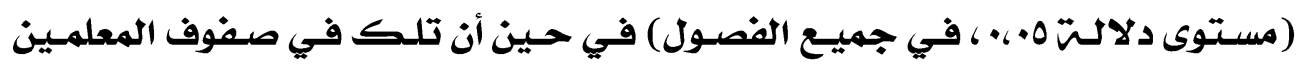

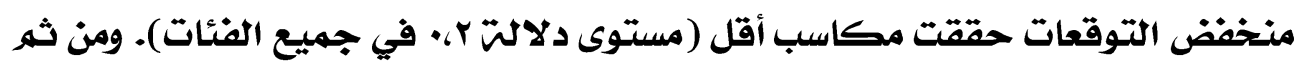


هناك بعض الد راسات التـي تبين التحصيل المتغيـر للطلاب وفقًا لخصـائص المعلـه

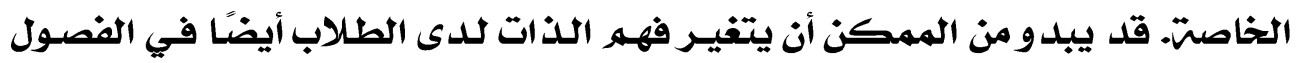

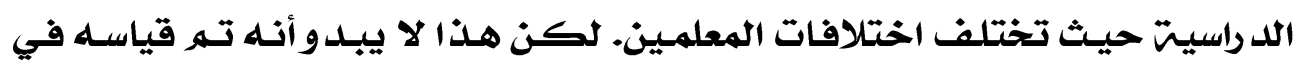
البحث التجريبي. منذ أن أبلى بعض الباحثين إدراكهمر للذات فيما يتعلق بالإنجاز

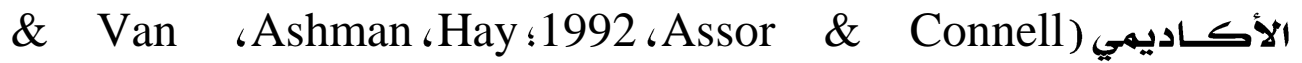

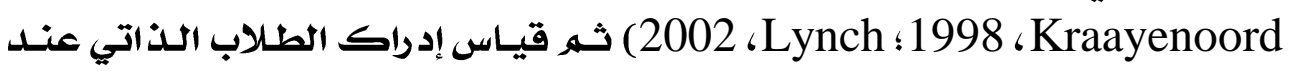

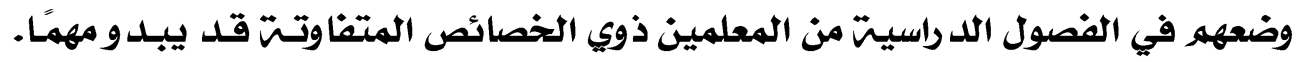

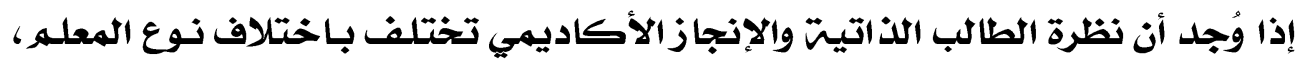

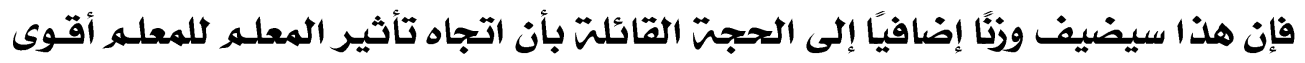

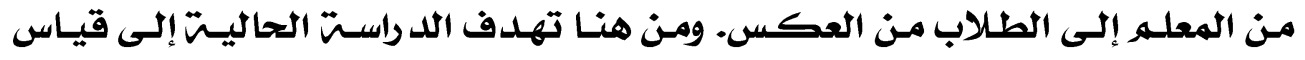

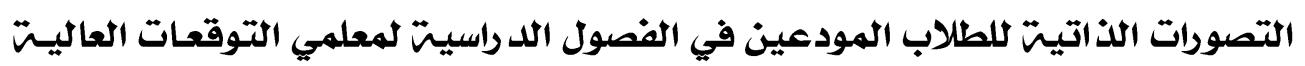

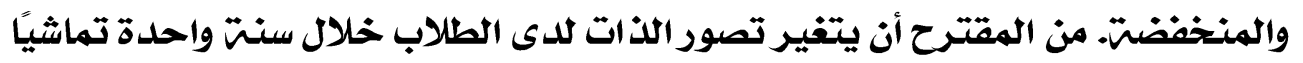
مع توقعات المعلمين المتهحورة حول المقترح انتئر الفصورل. ثالثًاء الطالبات ذوات صعوبات التعلهر: تعريف صعوبات التعلم:

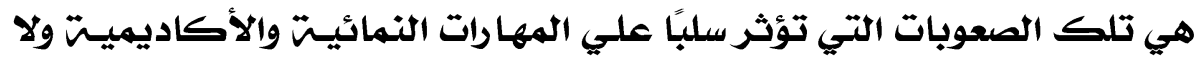

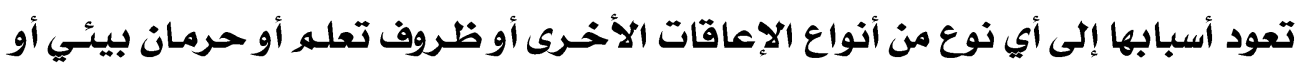

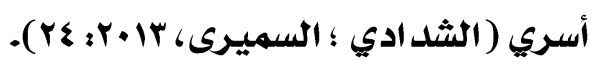

\section{أنواع صعوبات التعله:

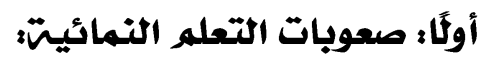

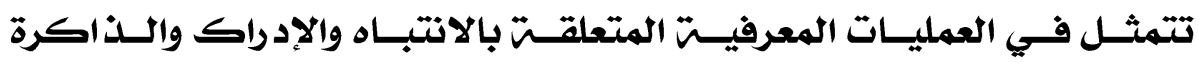

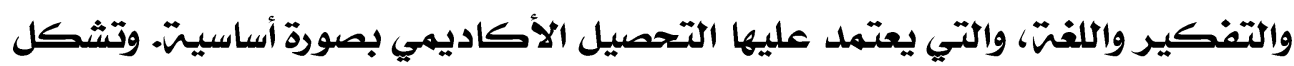

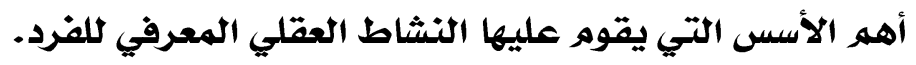

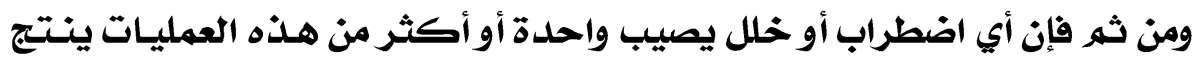

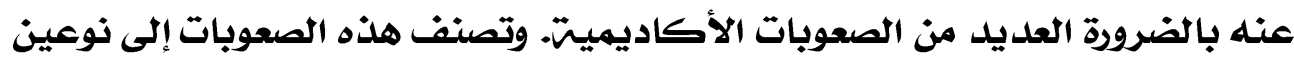
أساسيين هما:

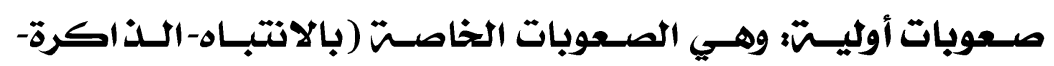

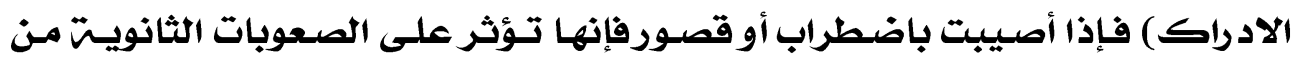
الصعوبات النهائيت.

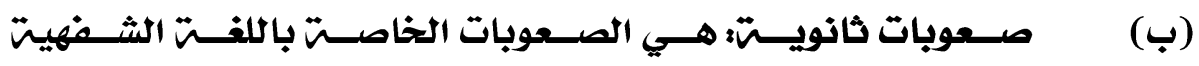

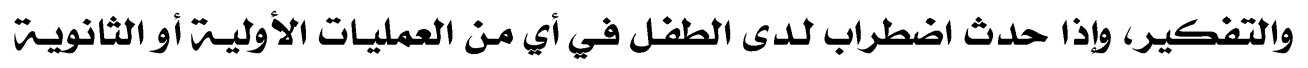


بلد رجـت كبيـرة وواضـحتة، ويعجـز عـن تعويضـها مـن خـلال وظـائف أخـري، عندئدن تكون لديه صعوبت في تعله الموضوعات الأكاديميتة.

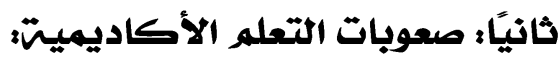

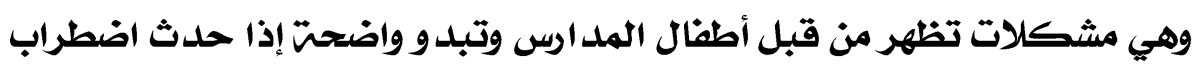

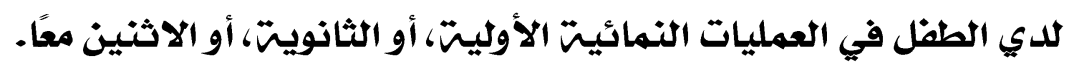

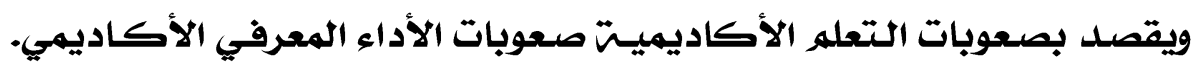

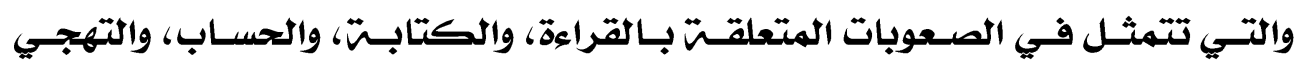

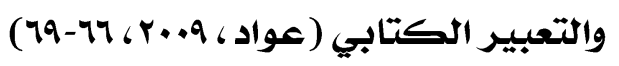

$$
\text { مستويات صعوبات التعله: }
$$

المستوي الأول: مرحلتّ ما قبل المدلتوريت (Pre-School)

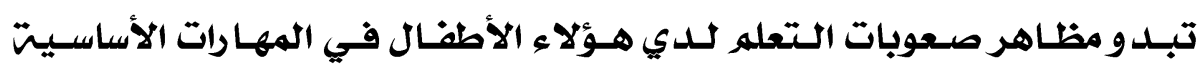

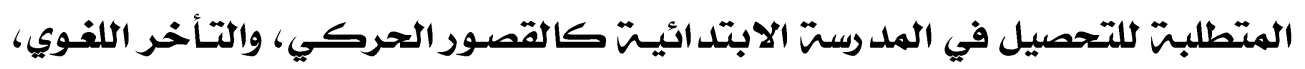

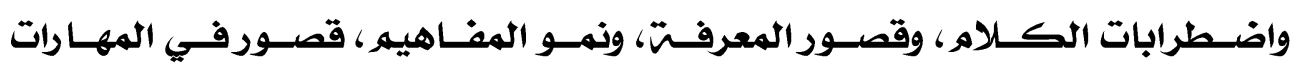

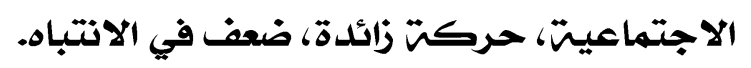

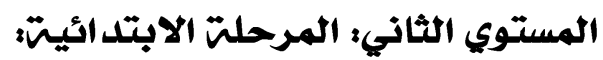

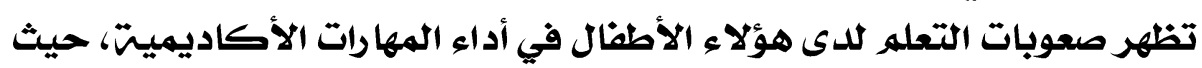

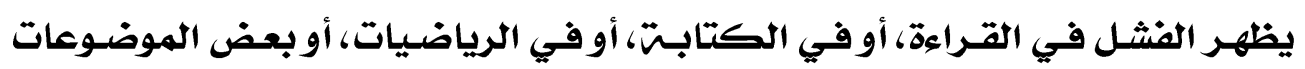

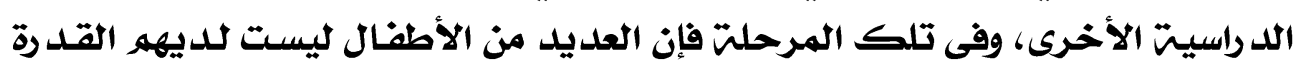

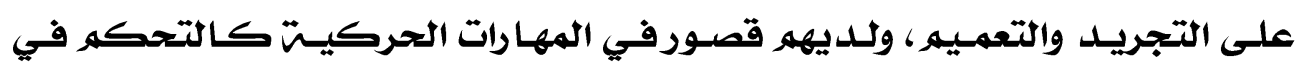

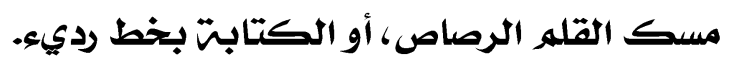

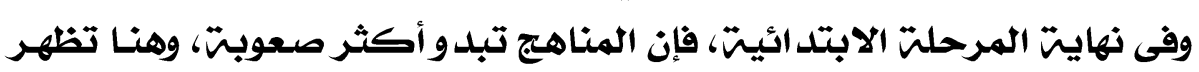

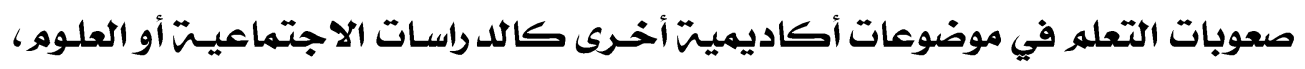

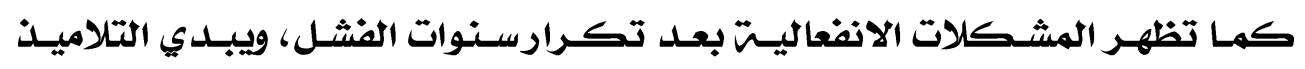

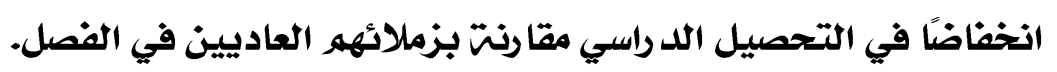

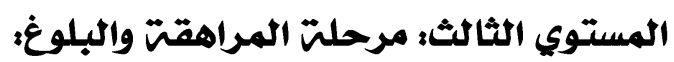

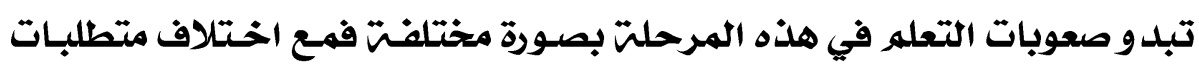

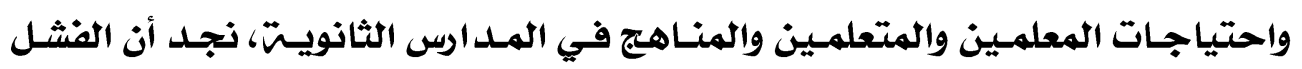

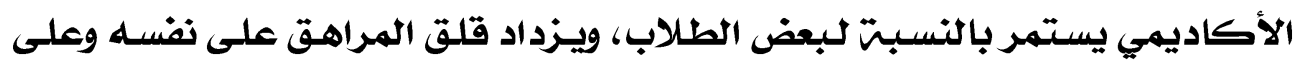

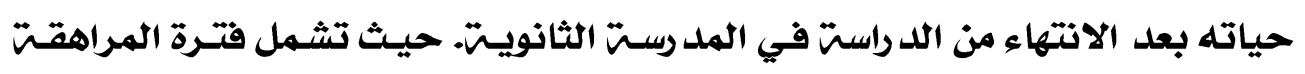

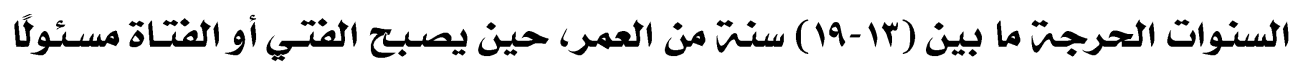
عن نفسله وهو ما يزال تحت المظلت العائليت من التوجيه ماتين والعنايتة. 
الخصائص المميزة للبالغين ذوي صعوبات التعلم:

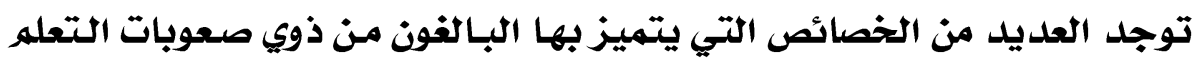

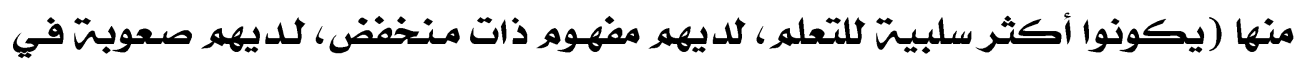

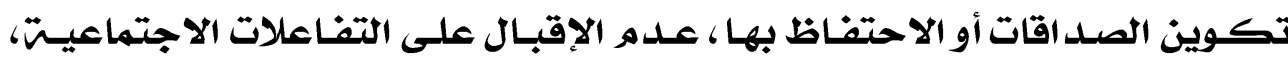

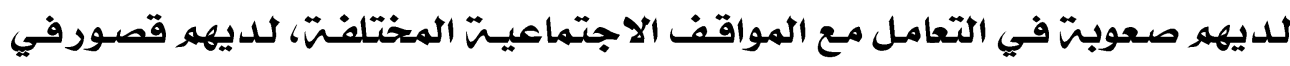

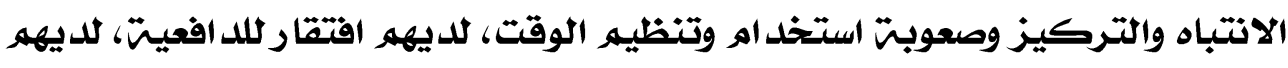

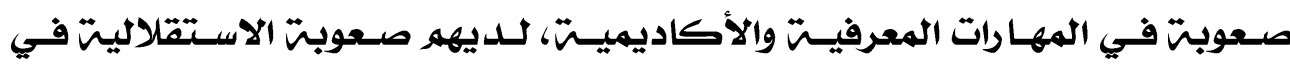

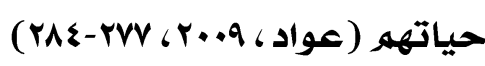

النماذج النظريت المفسرة لصعوبات التعله:

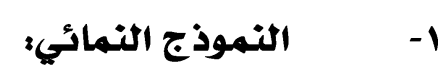

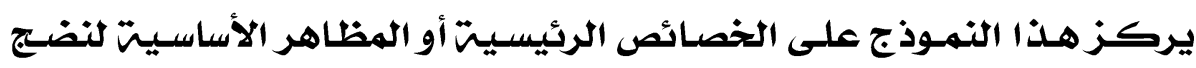

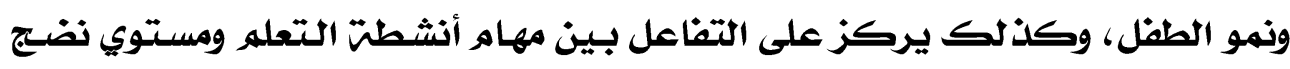

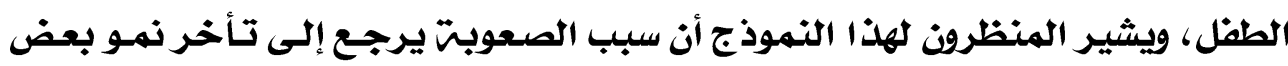

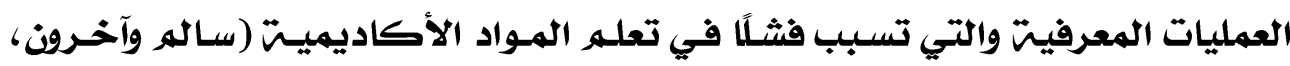

( \& $r$, r...r

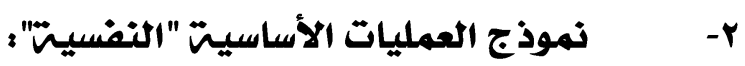

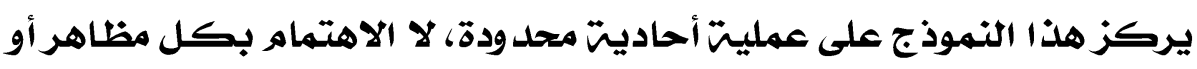

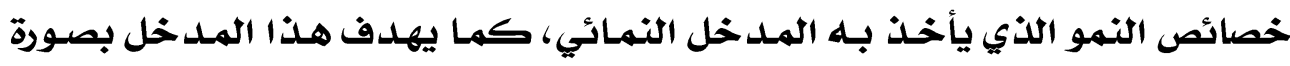

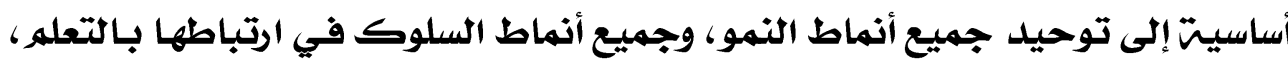

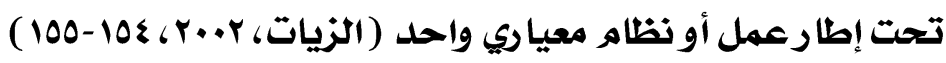

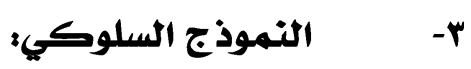

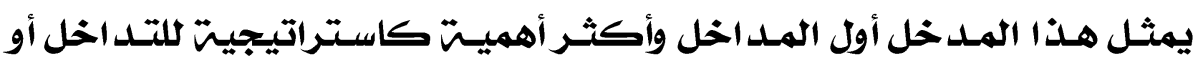

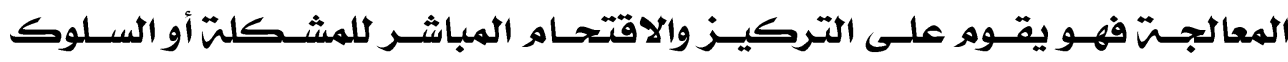

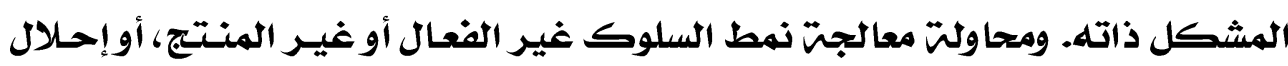

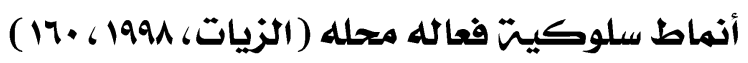

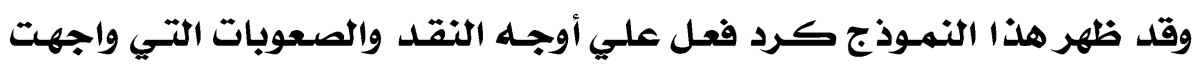

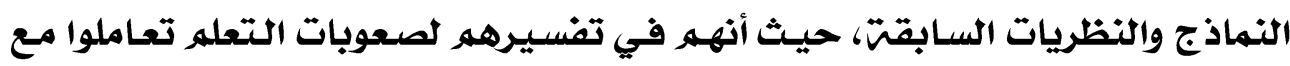

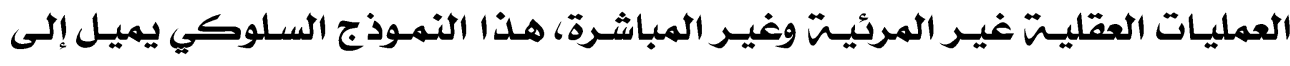

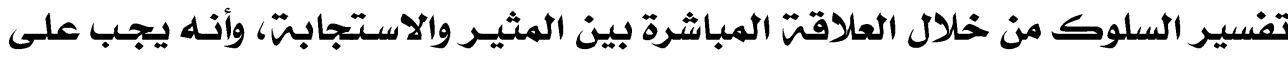

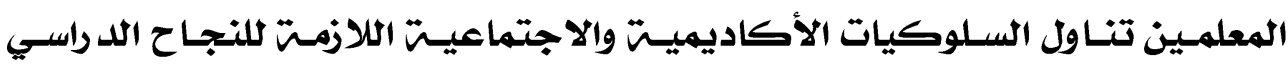

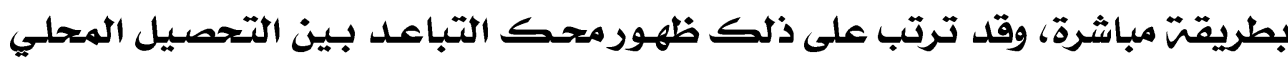

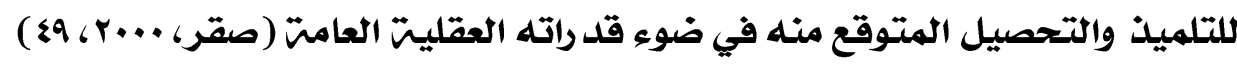




$$
\text { ع - النموذج النفسي العصبي: }
$$

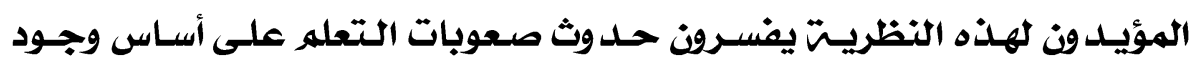

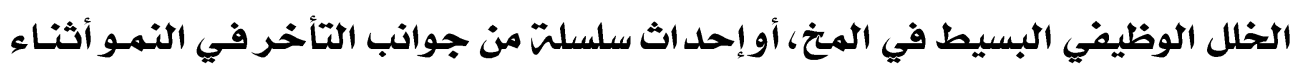

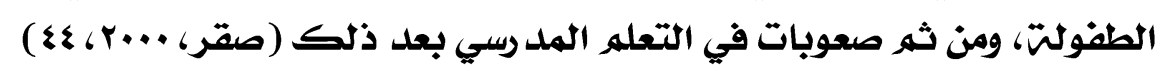

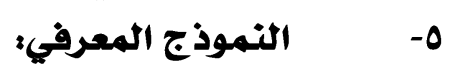

لقد أدي قصور النماذج والنظريات السابقت التي حاولت تفسير صعوبات التعله

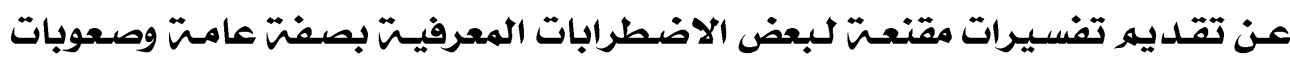

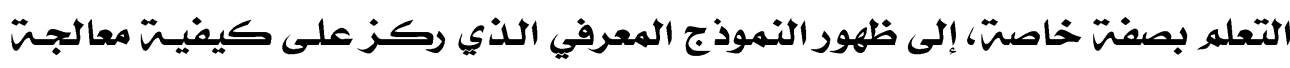

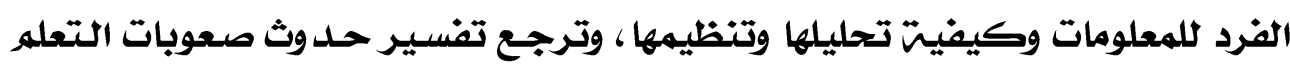

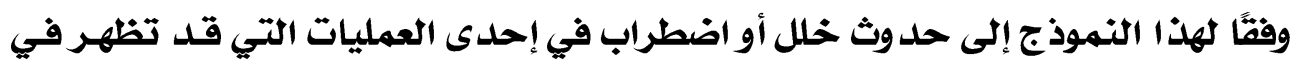

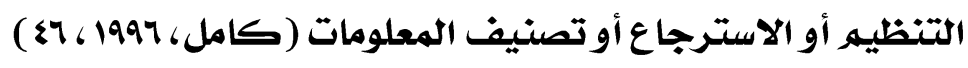

\section{مراحل تشخيص صعوبات التعلم:}

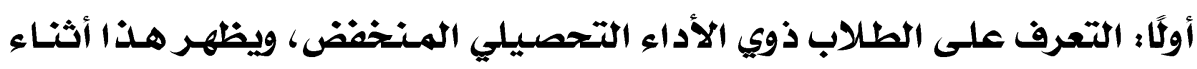

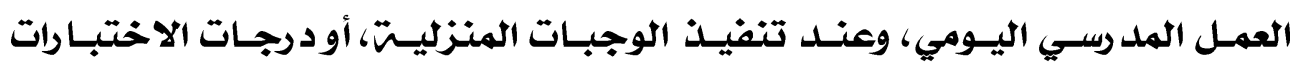
الشهريته.

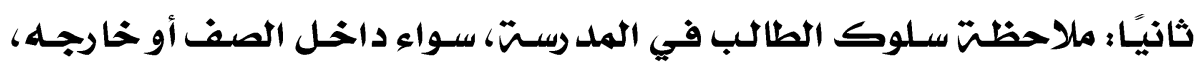

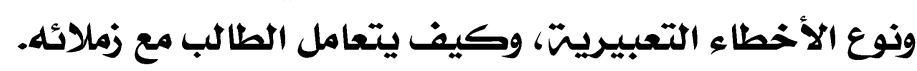

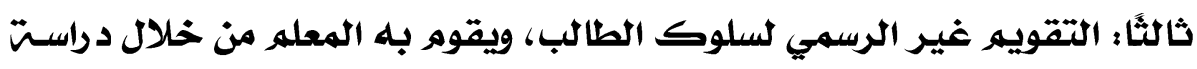

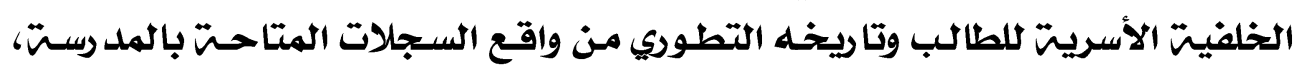

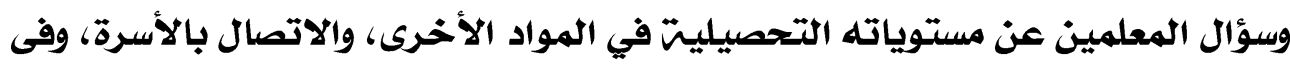

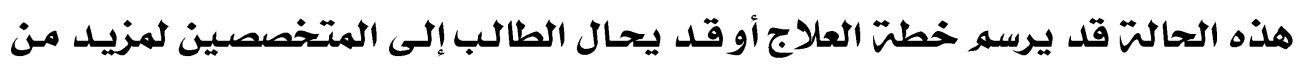
الد راستّ. رابعًا قياهر فريق الاخصائيين ببحث حالت الطالب، ويتكـون الفريق من معلـه

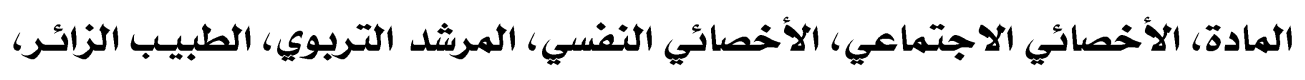

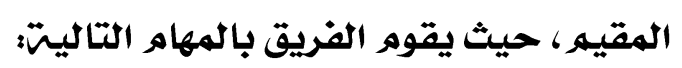

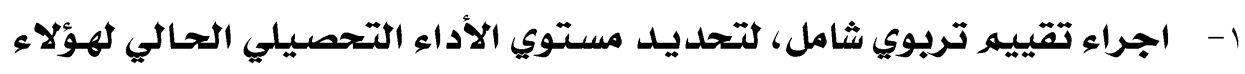

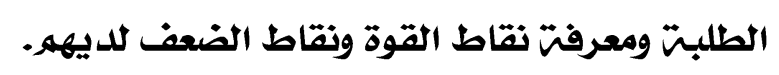

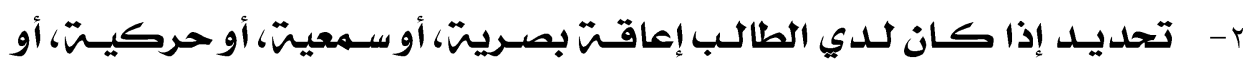

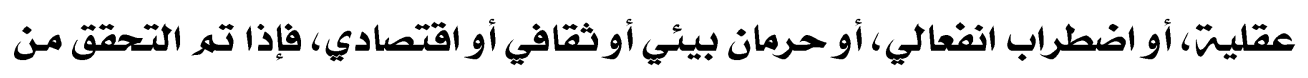

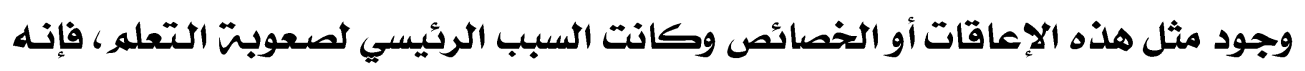

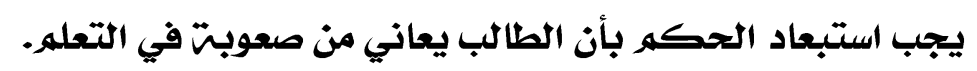

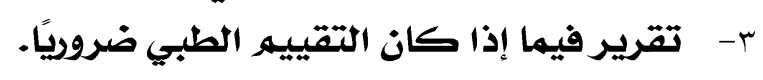




$$
\text { ع - حديد فيما إذا كانت الخبرات التعليميت مناسبت لعمر الطالب. }
$$

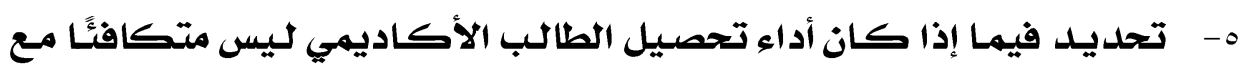

عمره وقد رته.

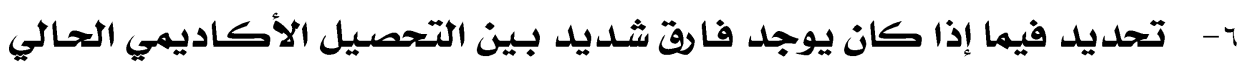

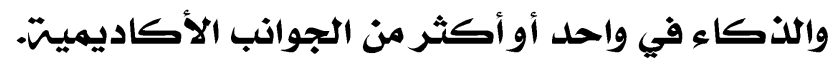

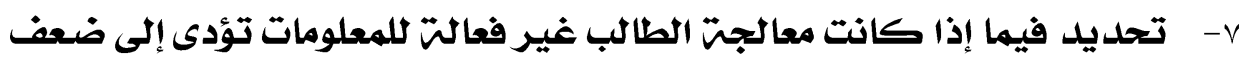
التحصيل الأكاديمي.

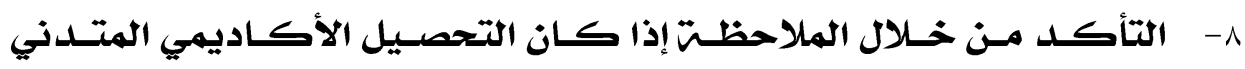

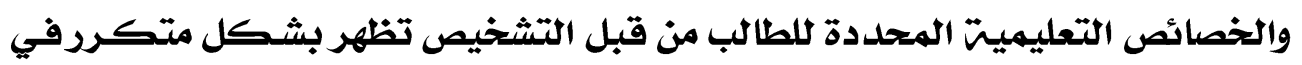

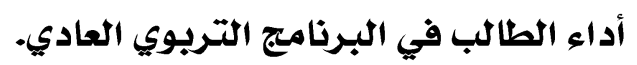

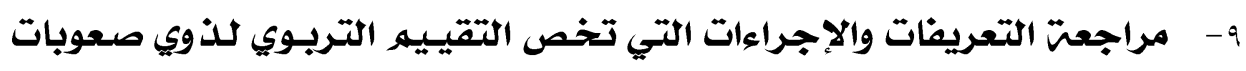
التعله.

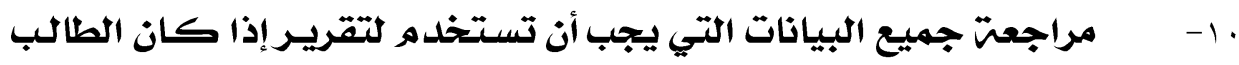
معوقًا أهر لا.

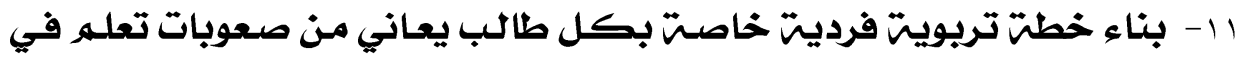

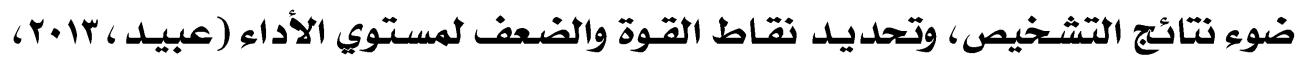

\section{بحوث ودراسات سابقت:}

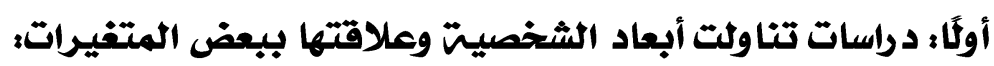

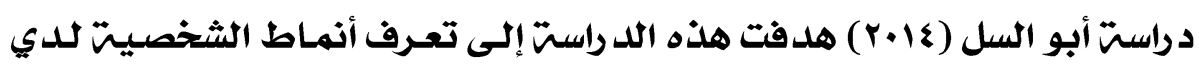

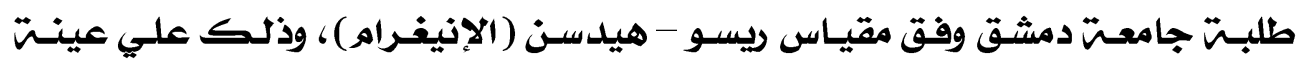

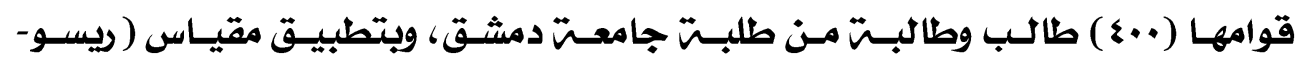

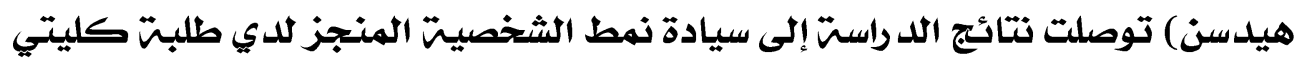

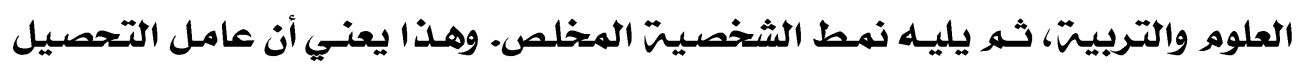

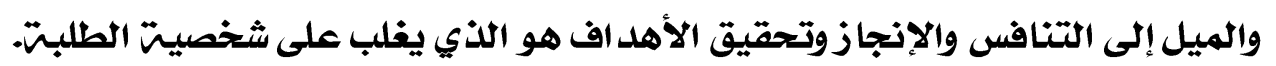

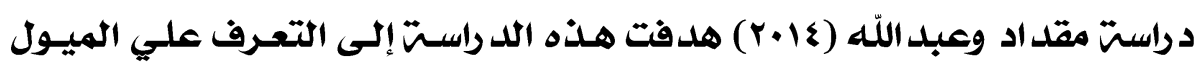

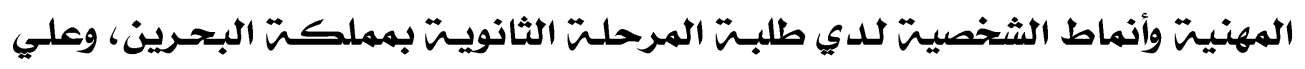

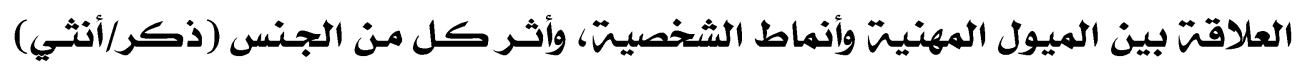

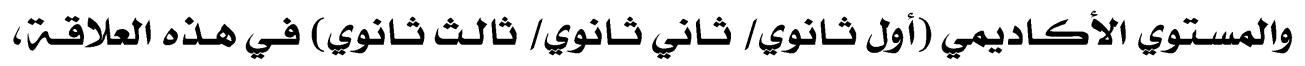

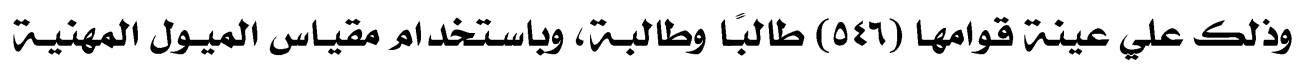

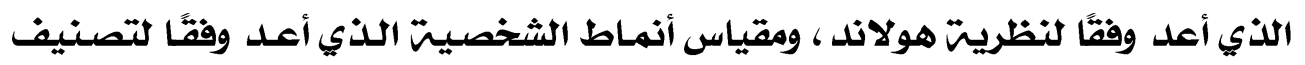

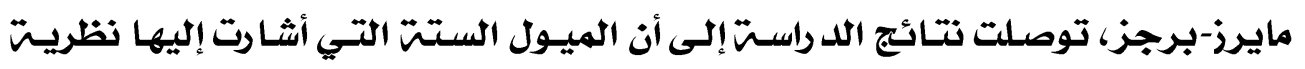




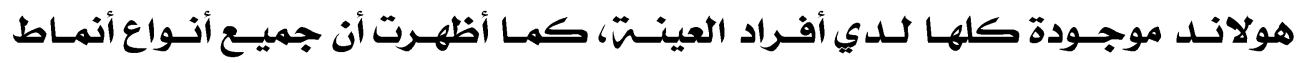

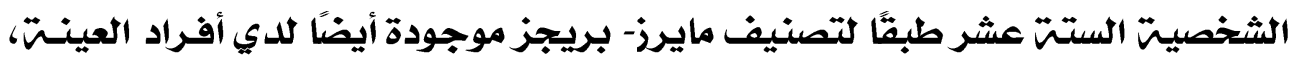

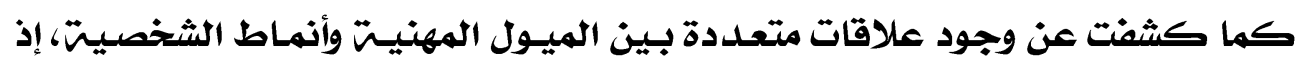

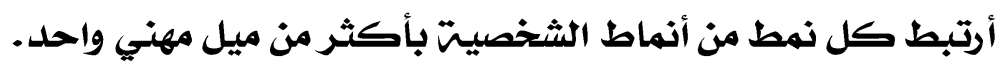

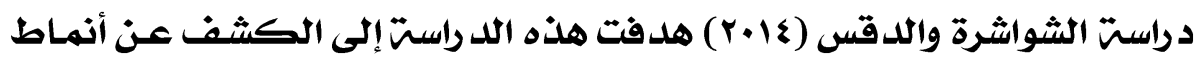

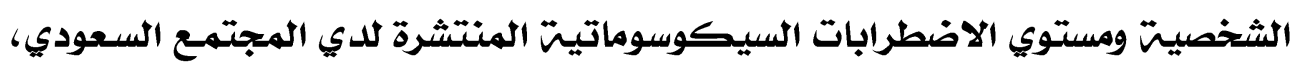

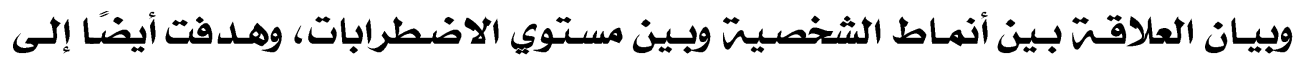

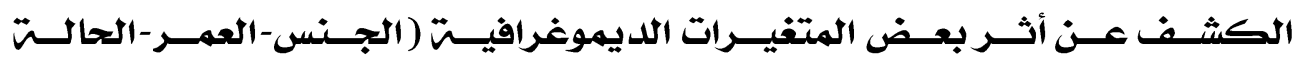

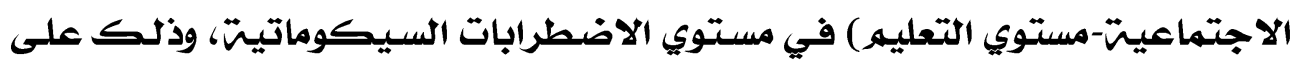

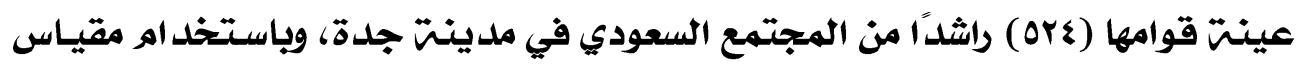

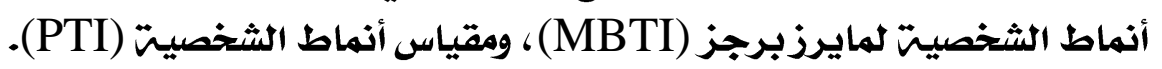

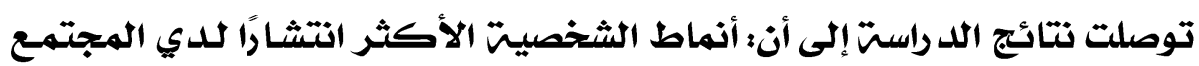

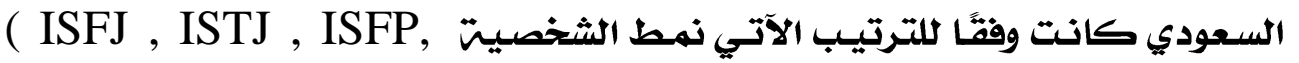
.ESTJ, INFP )

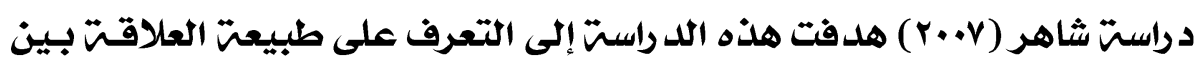

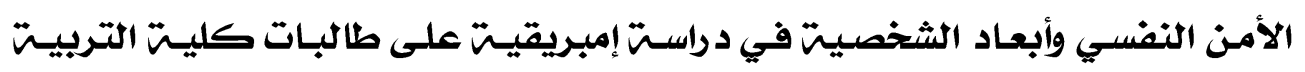

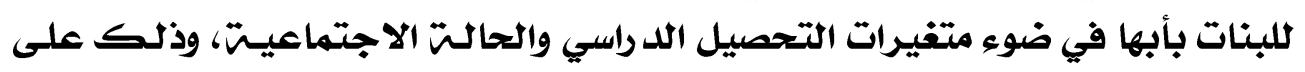

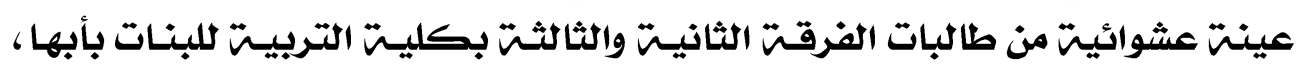

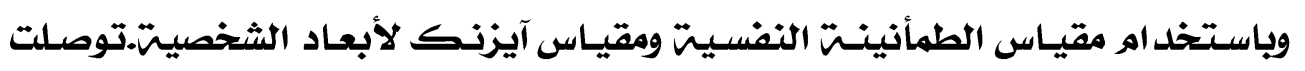

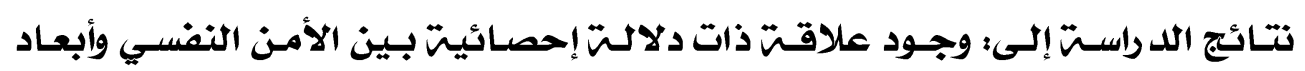
الشخصيت لدى طالبات كليت التربيت للبنات بأبها.

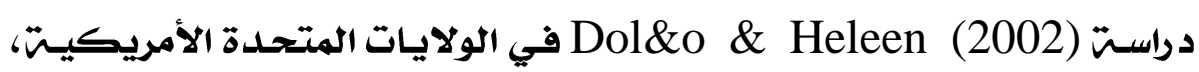

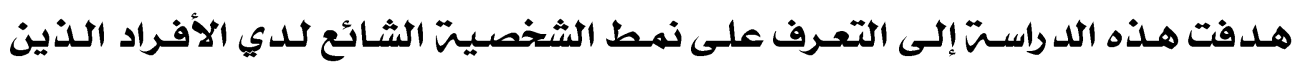

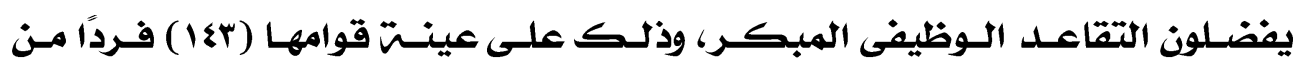

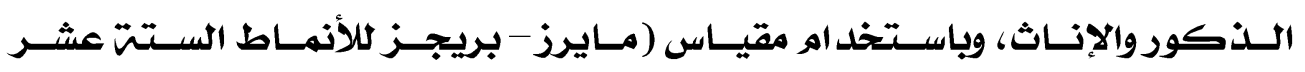

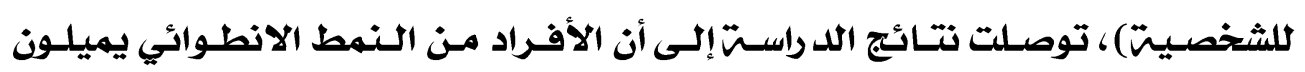
ويفضلون التقاعد المبكر أكثر من غيرهئ.

ثانيًا دراسات تناولت سلوك المعلم وعلاقته ببعض المتغيرات؛

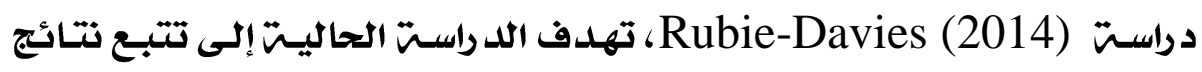

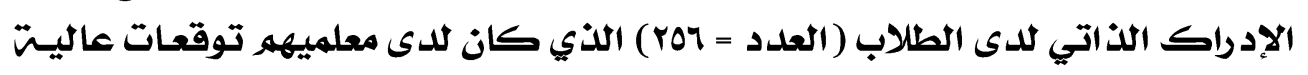

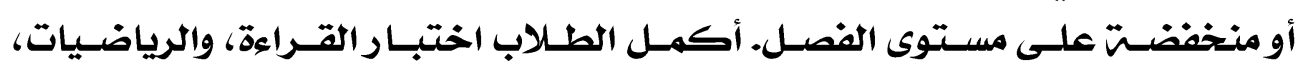

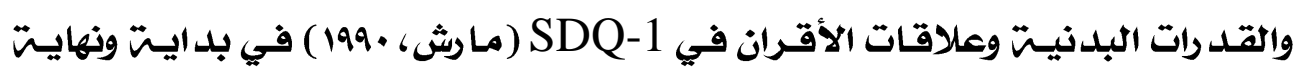




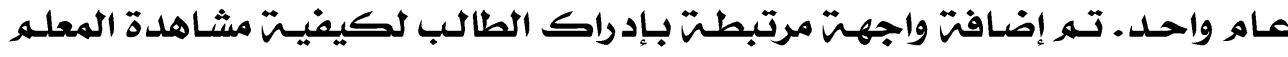

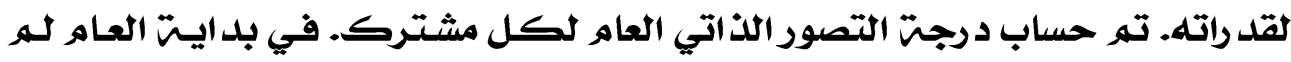

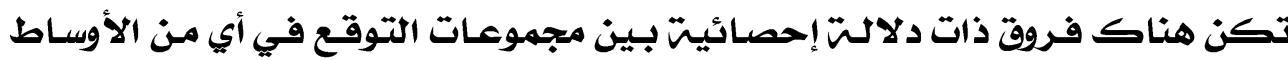

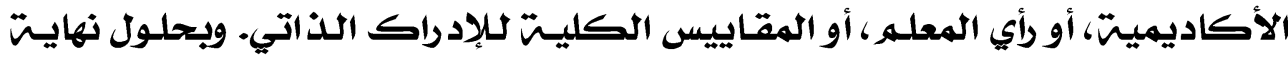

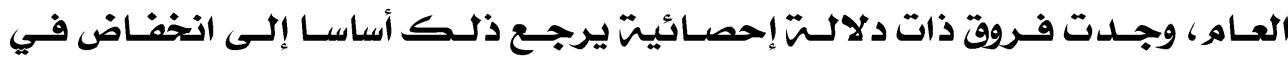

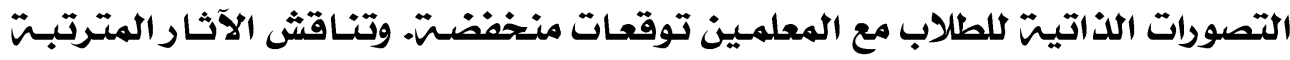
على مما وستخ المعله. دراست (2012) Monteiro; Almeida. \& Vasconcelos فإن إدراكات

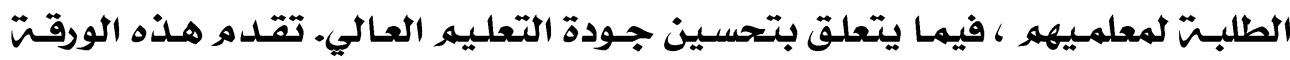

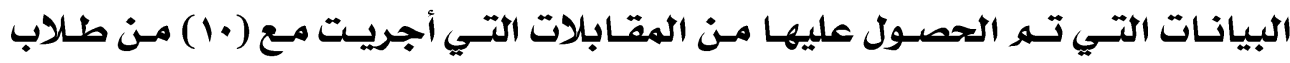

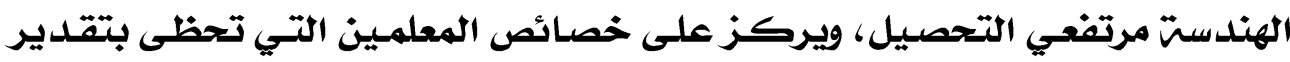

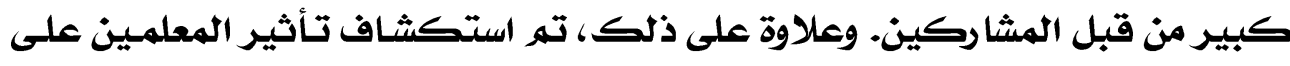

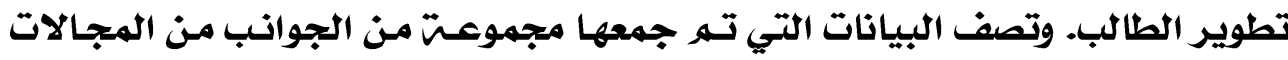

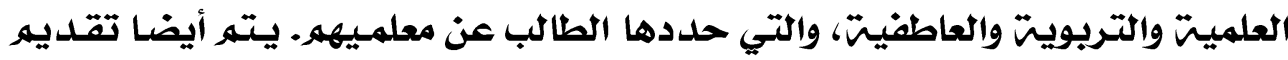

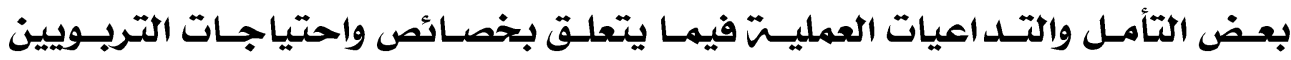
المتفوقين.

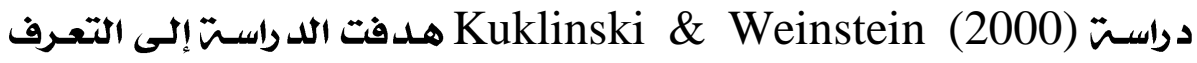

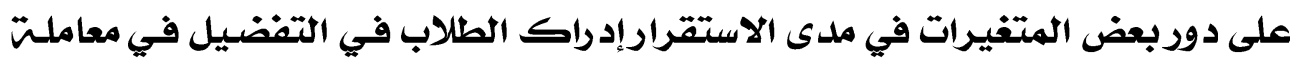

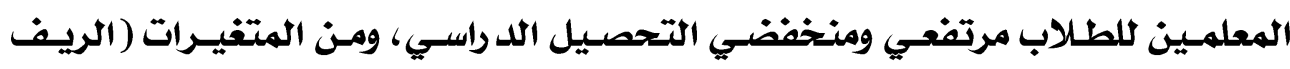

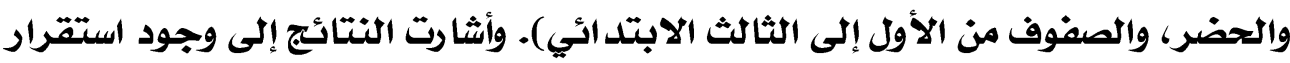

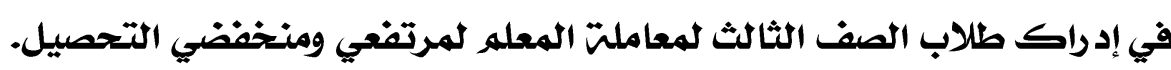

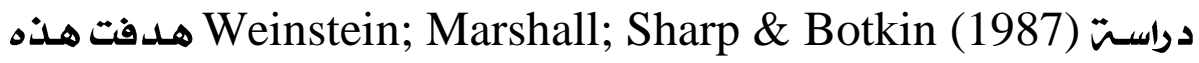

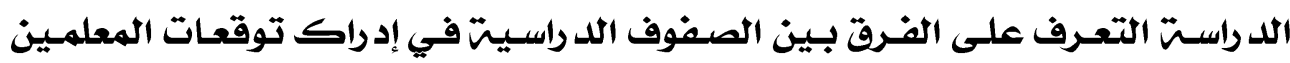

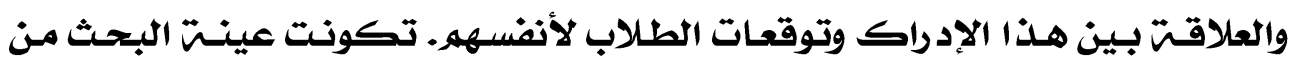

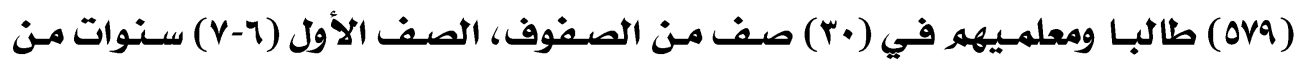

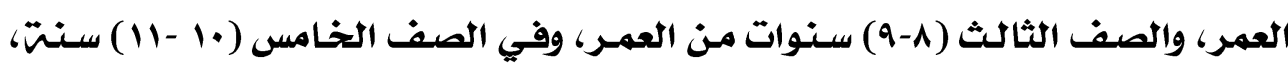

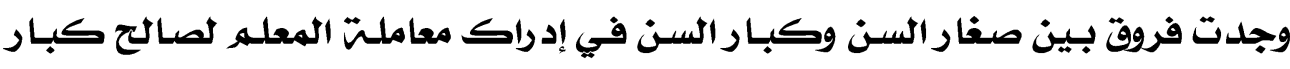

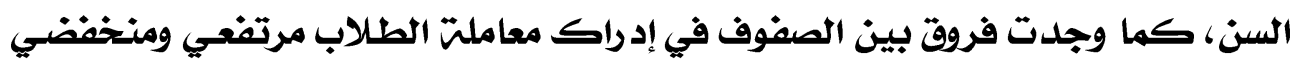

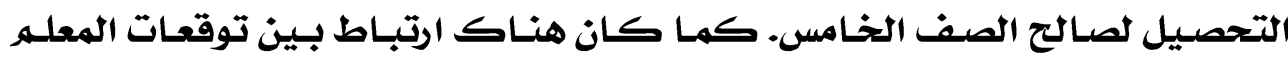

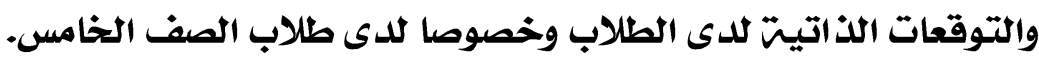

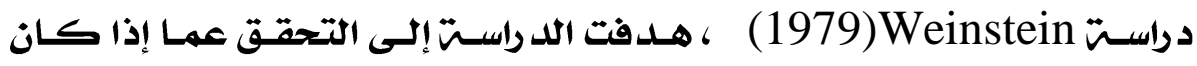

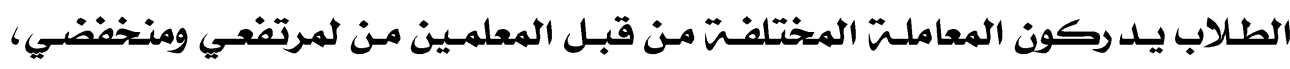

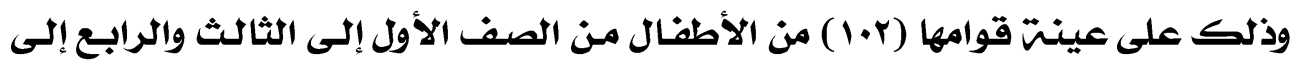




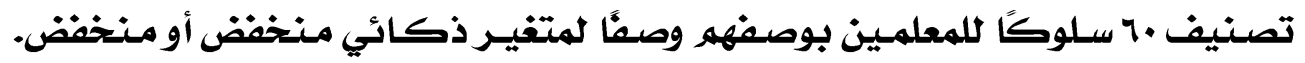

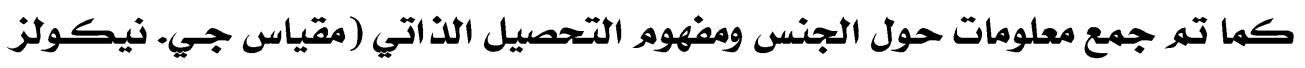

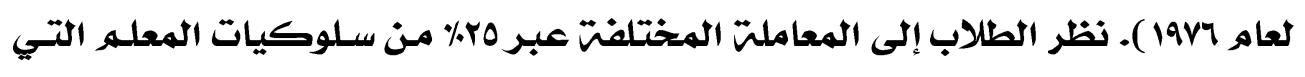

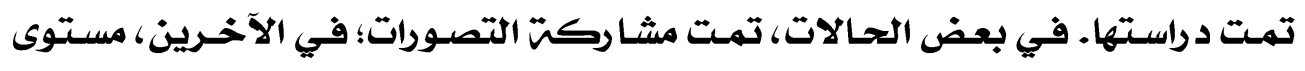

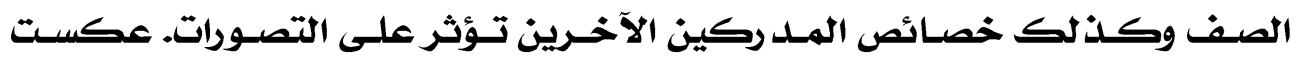

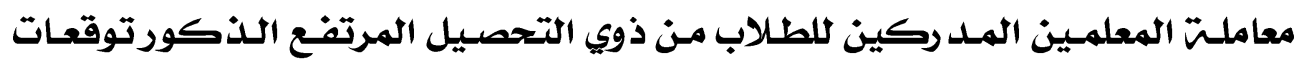

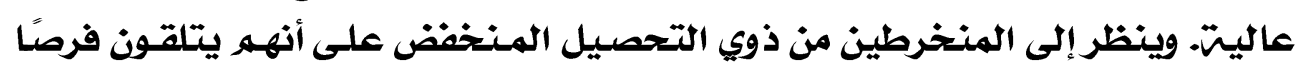
أقل ولكنهه يشعرون بقلد رأكبر من القلق.

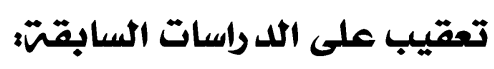

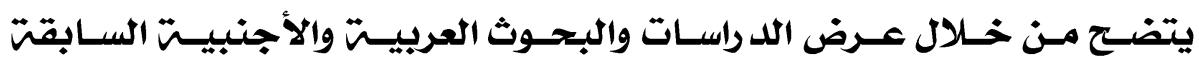

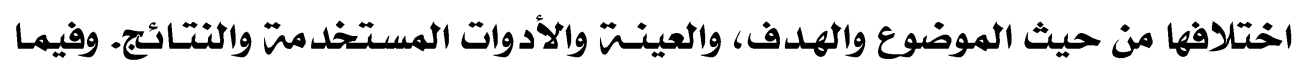

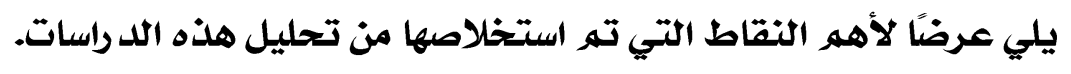

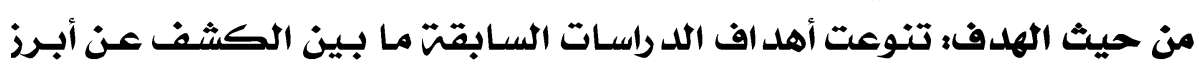

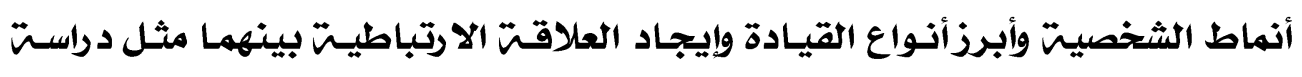

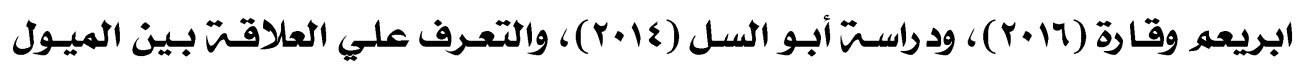

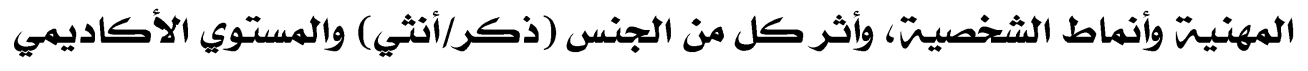

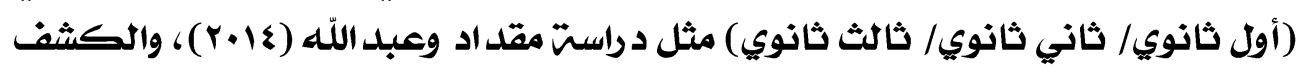

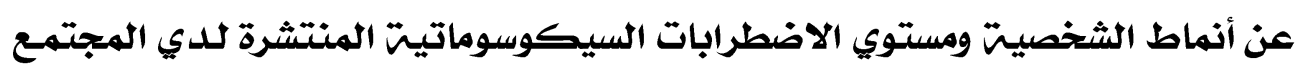

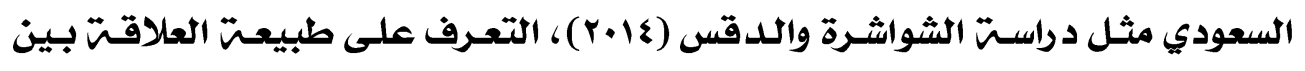

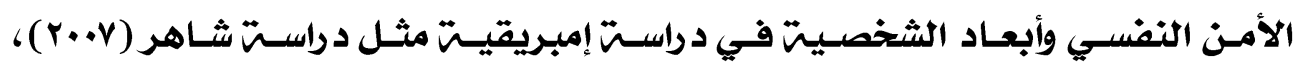

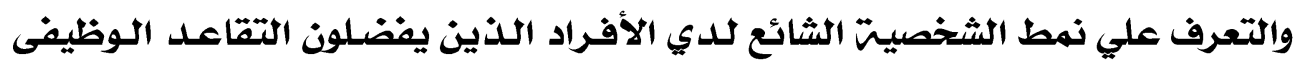

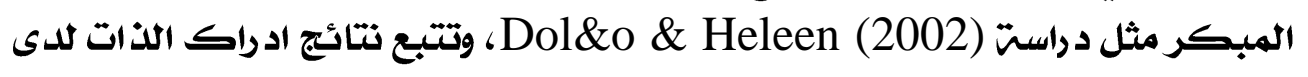

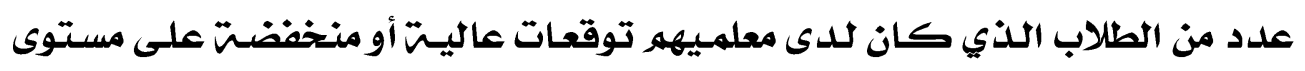

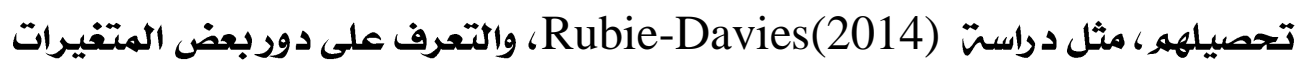

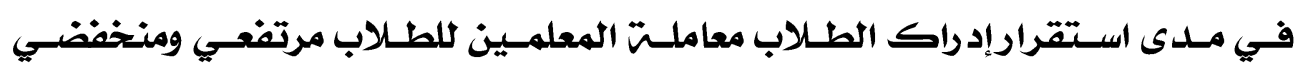

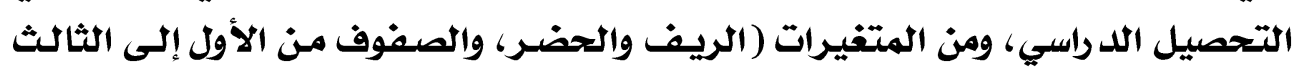

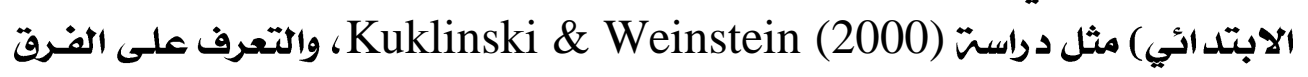

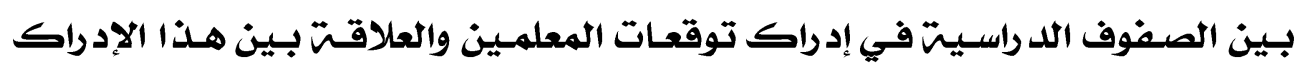

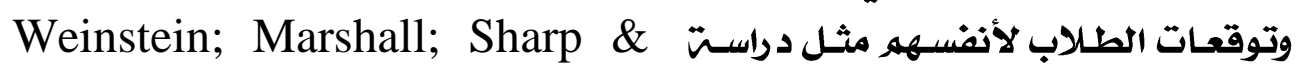

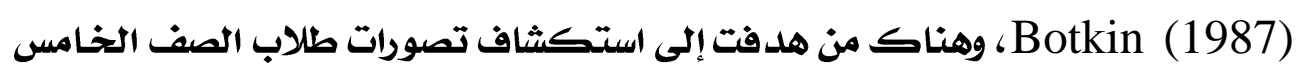

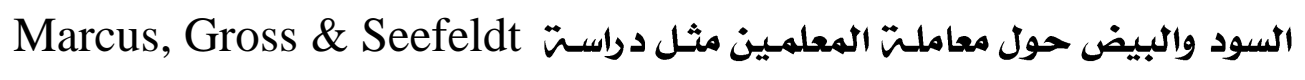

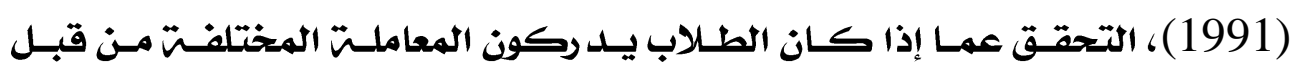

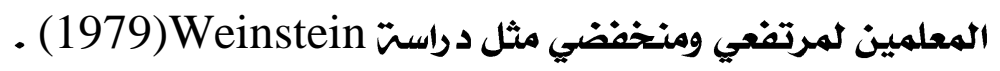




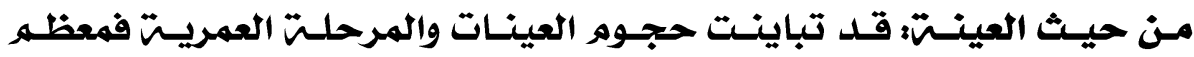

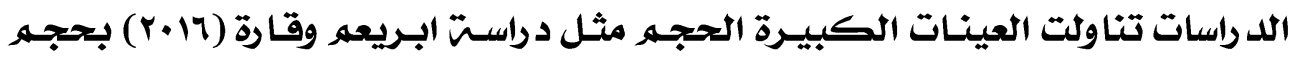

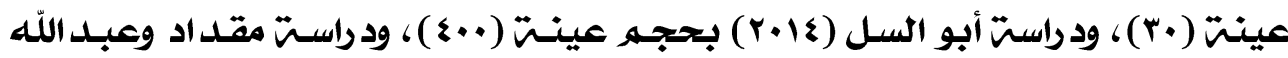

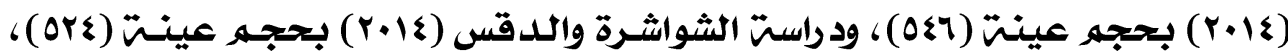

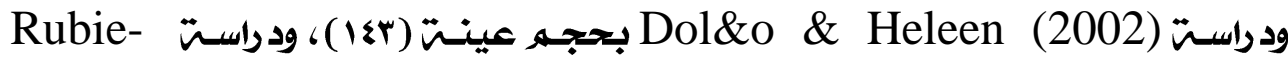

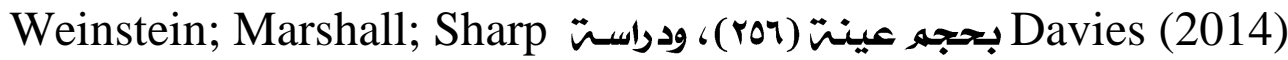

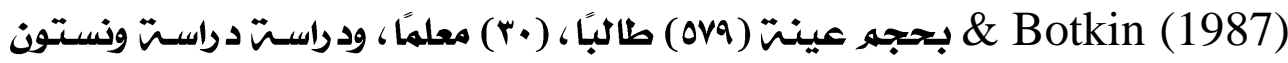
(1979)Weinstein

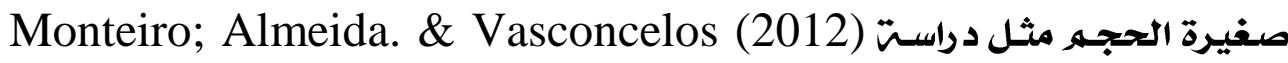

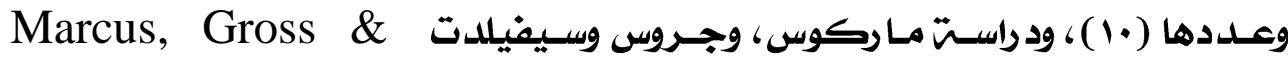

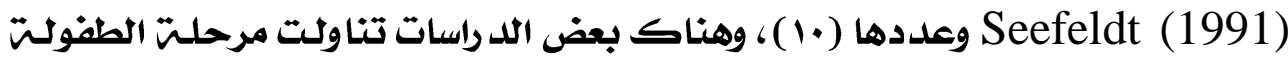

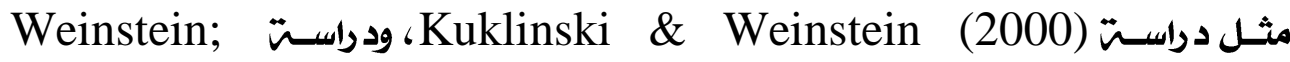
Marcus, Gross \& Marshall; Sharp \& Botkin (1987)

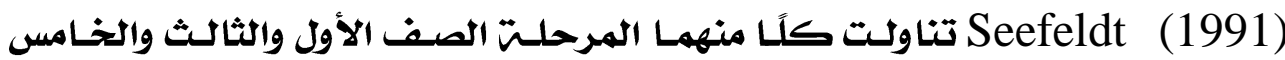

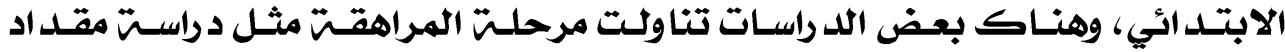

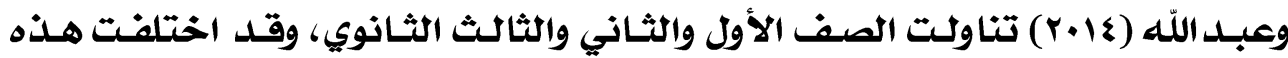

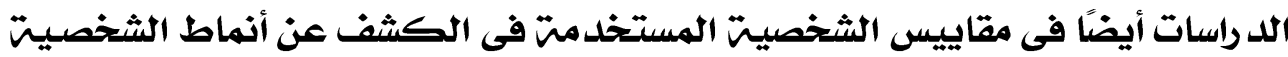
وسلوك المعله تجاه الطالبات المرتفعات في التحصيل.

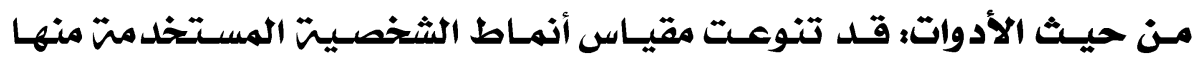

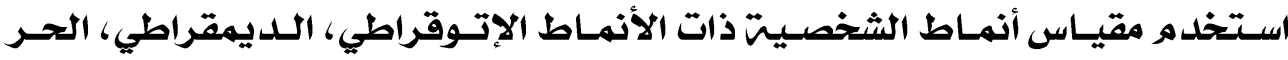

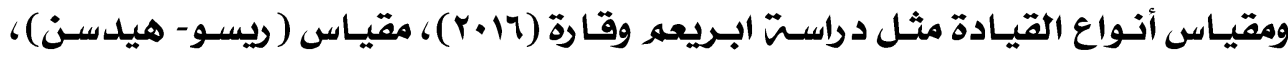

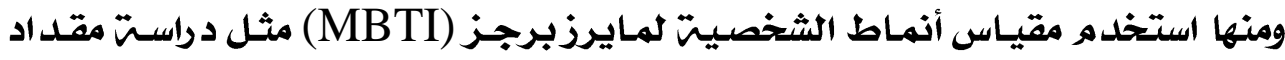

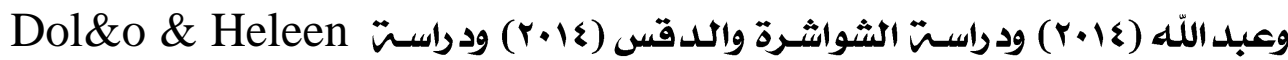

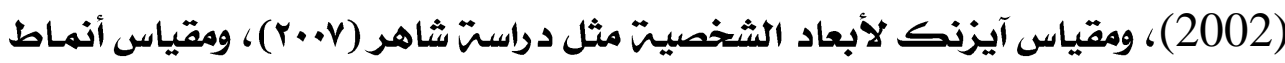

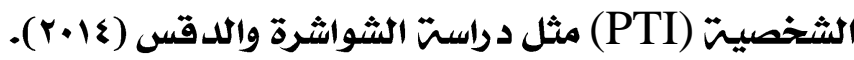

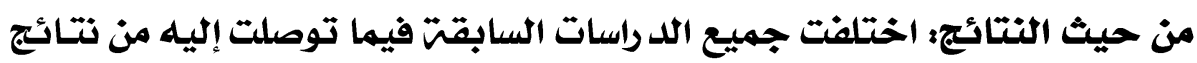

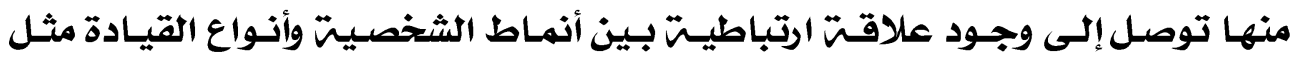

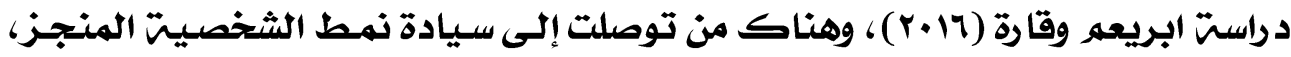

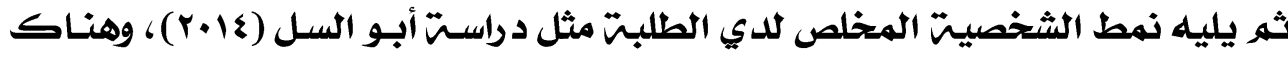

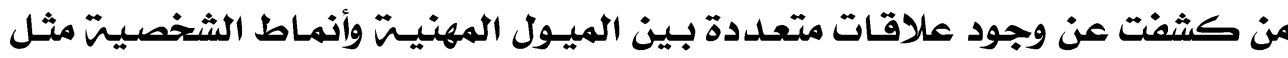

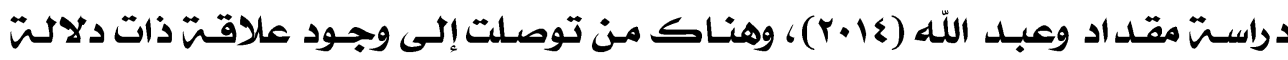

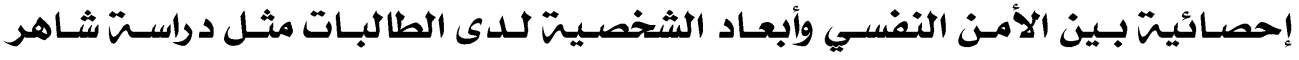

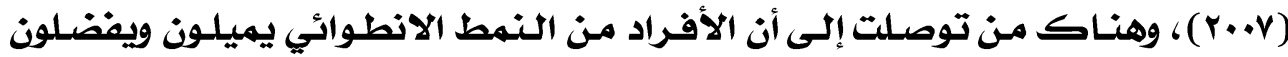




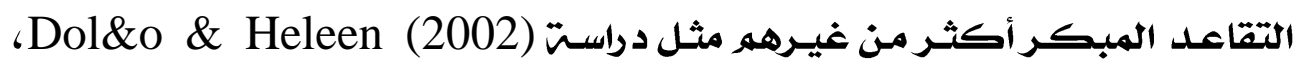

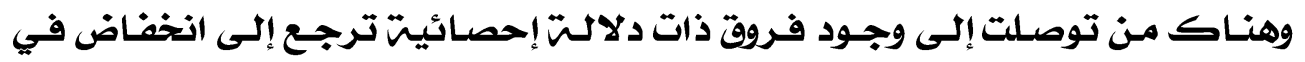

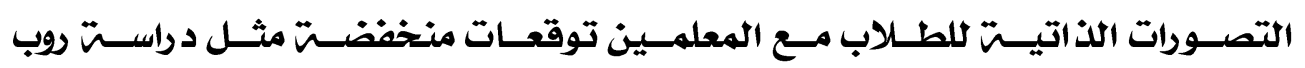

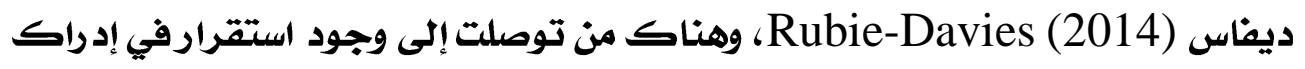

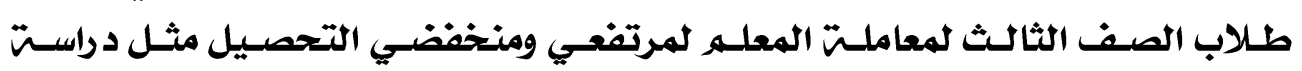

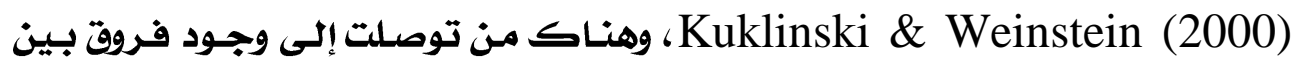

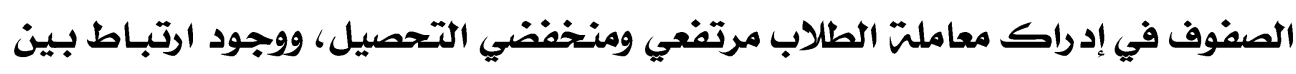

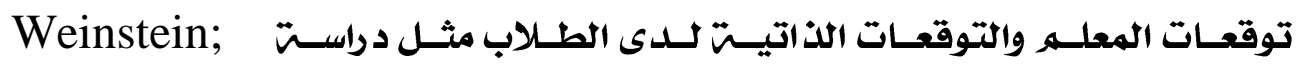

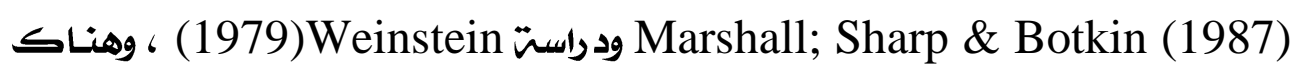
من توصلت إلى أن أدرك الذكور السود أن معلميهـ عاملوهه بطرق، وكأنهه الأقل

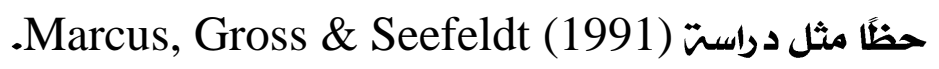

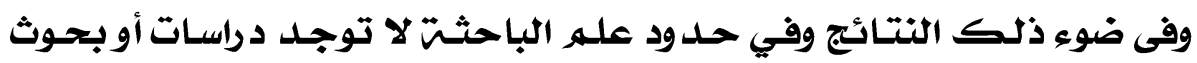

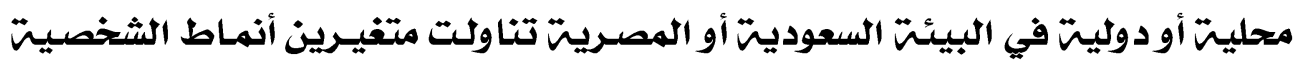

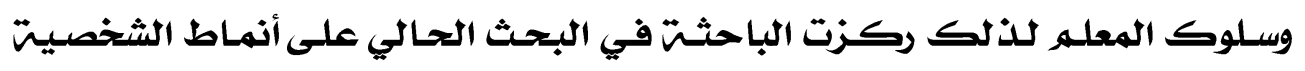

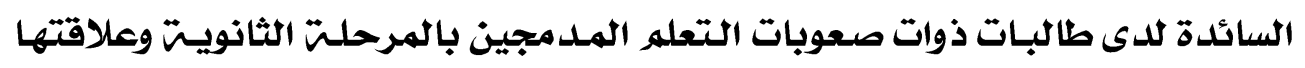

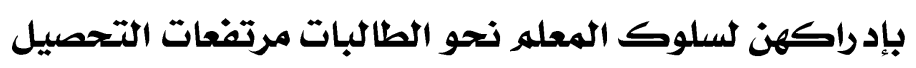

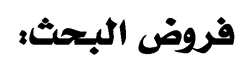

في ضـوء الإطار النظري والدراسـات السابقنت التـي تـه عرضها يمكن طرح

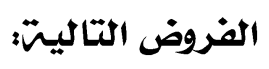

(1) التـأثير الاجتمـاعي هـو الــنمط السـائد لــدى طالبـات ذوات صـعوبات الـتعله بالمرحلت الثانويتة.

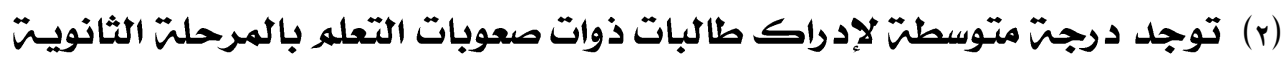
لمعاملت المعله للطالبات مرتفعات التحات التحصيل.

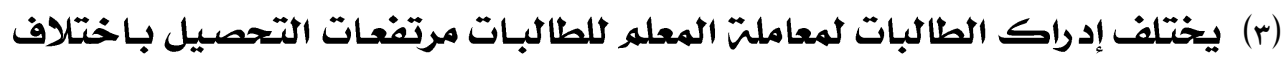
نمط الشخصيتة. (ع يختلف إدراك الطالبات لمعاملت المعله للطالبات مرتفعات التحصيل باختلاف نوخلة

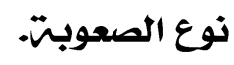

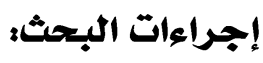

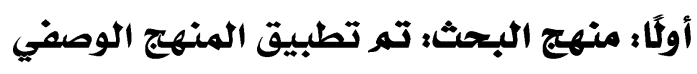

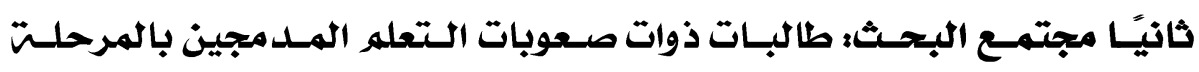
الثانويتة 


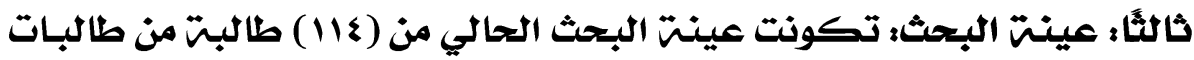

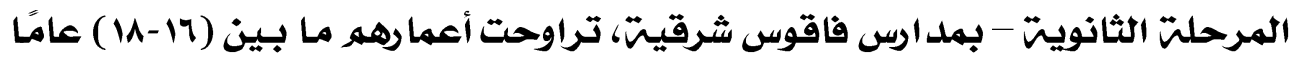

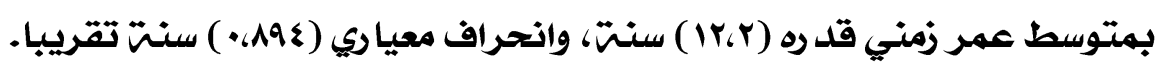

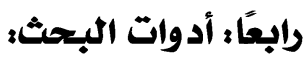

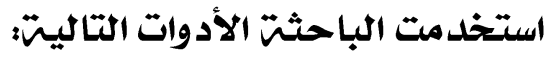

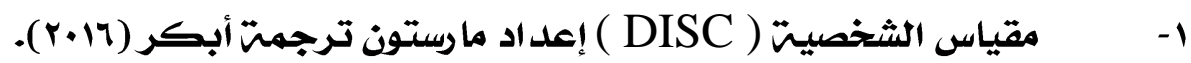

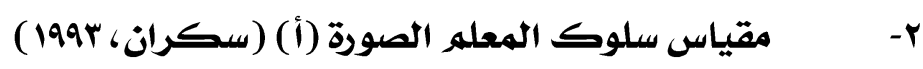

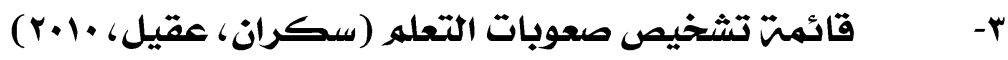
أوكَاء مقياس الشخصيت ( DISC) يهدف هذا المقياس إلى التعرف على أنماط الشخصيت في ضوء DISC

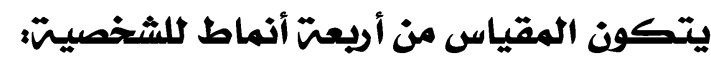

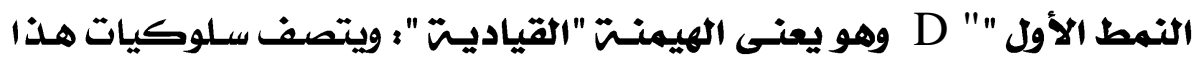

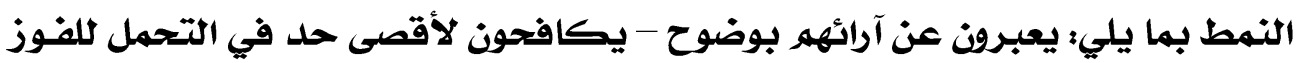

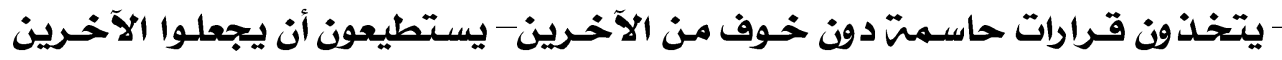

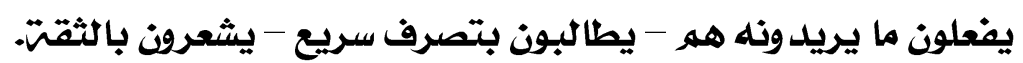

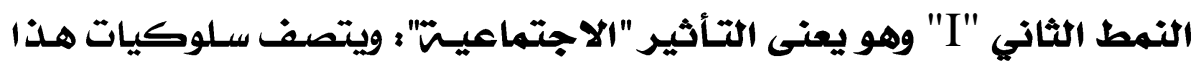

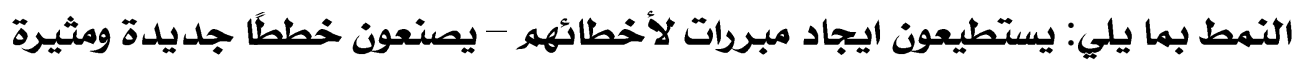

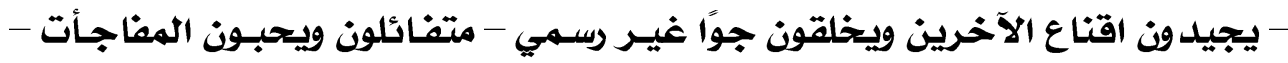

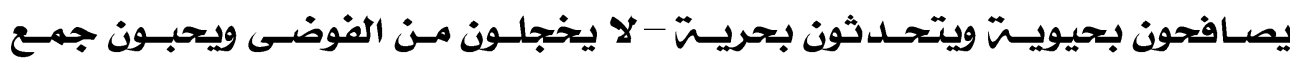

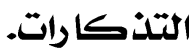

النمط الثالث " S " وهـو يعنى الثبـات "المتزنـت" : ويتصف سـلوكيات هـذا

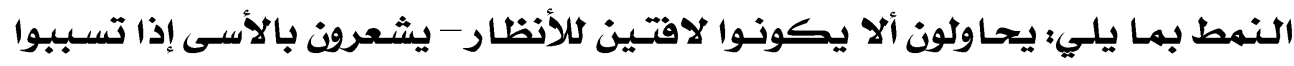

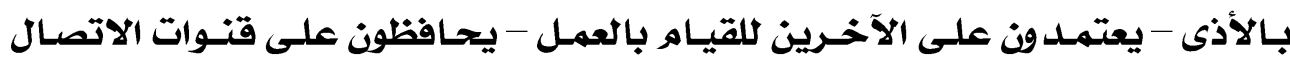

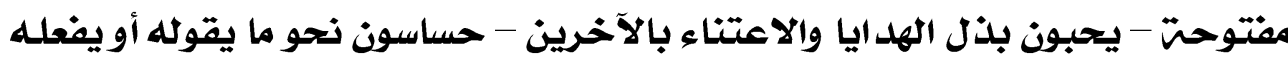

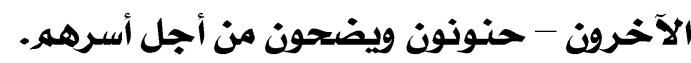

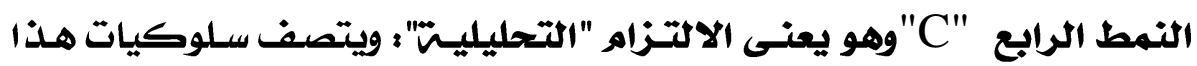

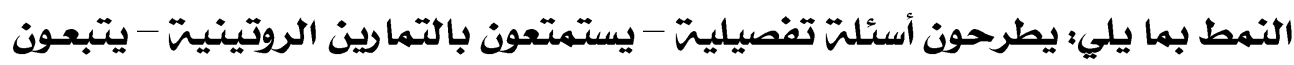

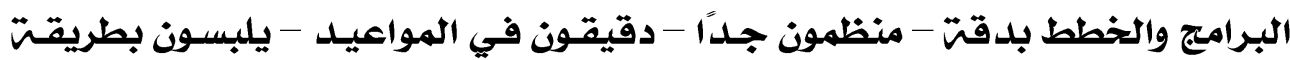

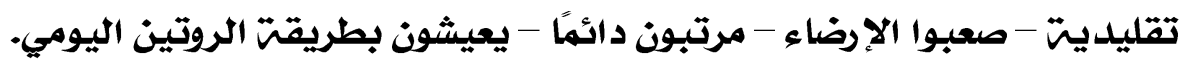
الخصائص السيكومتريتّات

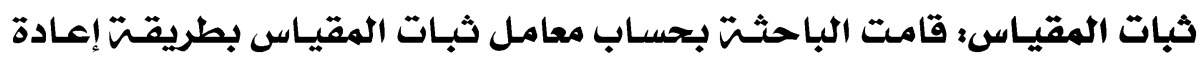
الاختبار ووكانت النتائج كما كياني: 


\begin{tabular}{|c|c|c|c|c|c|}
\hline \multicolumn{6}{|c|}{ جلول ( ) نتائج إعادة اختبار مقياس أنماط الشخصيت } \\
\hline 0 & $\varepsilon$ & $r$ & $r$ & 1 & التطبيق الأول \\
\hline \multirow[t]{2}{*}{ 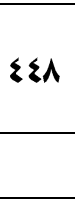 } & 001 & $\wedge \leqslant \wedge$ & 0.0 & rVO & أعلي صفت في التطبي \\
\hline & $\mathrm{C}$ & $\mathrm{S}$ & I & $\mathrm{D}$ & \\
\hline 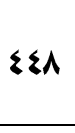 & or. & $\wedge \leqslant \vee$ & olr & TrV & أعلى صفت في التطبي الثاني \\
\hline 0 & $\varepsilon$ & r & r & 1 & \\
\hline \multirow[t]{2}{*}{ olr } & $\varepsilon \wedge \uparrow$ & rra & orr & ATr & أقل صفت في \\
\hline & $\mathrm{C}$ & $\mathrm{S}$ & I & $\mathrm{D}$ & \\
\hline$\Sigma 99$ & sit & $\varepsilon \cdot r$ & oOr & AVI & أقل صفت في \\
\hline
\end{tabular}

يتضح من الجدول السابق أن التطبيق القبلي والتطبيق البعدي كانتي

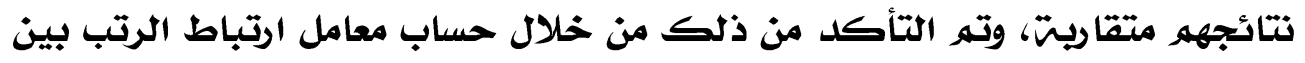

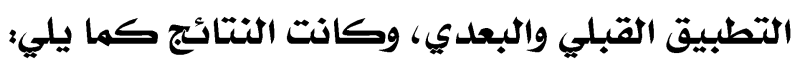

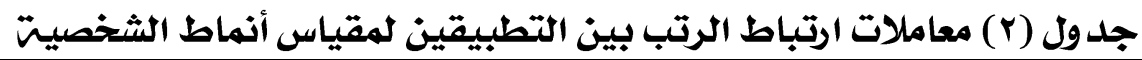

\begin{tabular}{|c|c|}
\hline معامل الارتباط بين التطبيقين & الصفت \\
\hline$* * 16 \cdots$ & أقل صفت \\
\hline$* * * \cdots$ & أعلى صفت \\
\hline
\end{tabular}

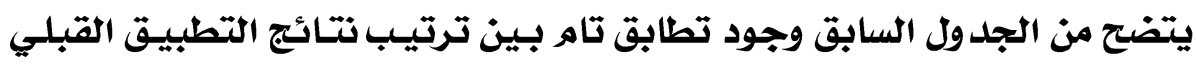

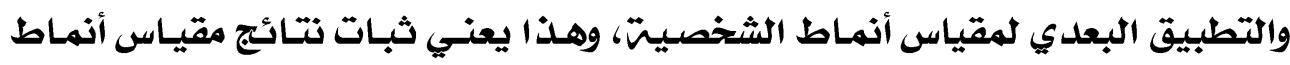
الشخصيته.

صلدق المقياس:

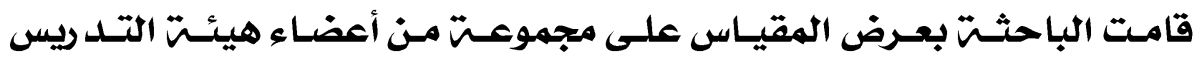

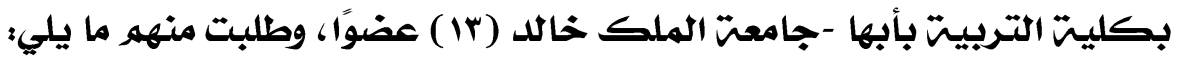

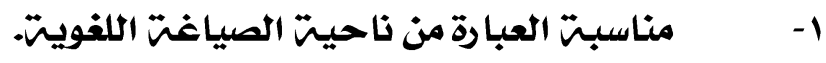

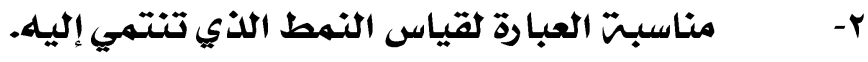

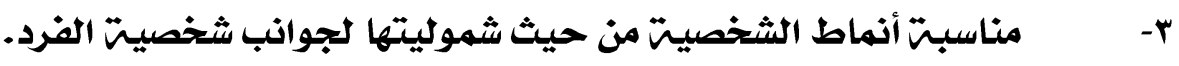

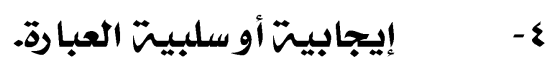

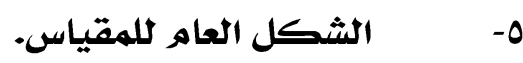

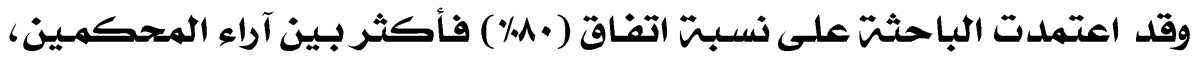

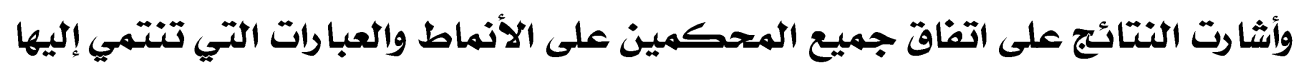


ولكن وجلد إعادة صياغت لبعض العبارات وقامت الباحثت بالتعدليل إلى الصياغات

طريقت الإجابت على المقياس:

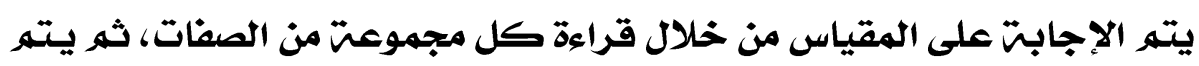

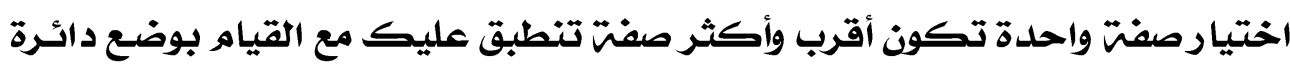

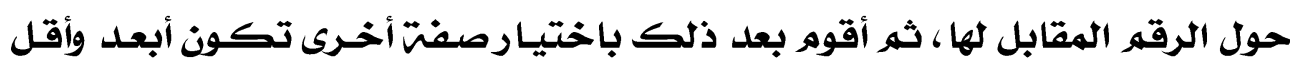

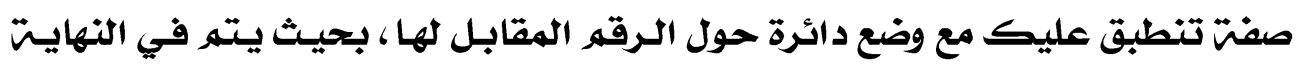

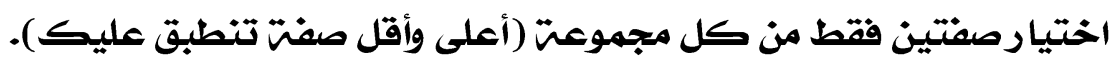
تصديع المقياسء

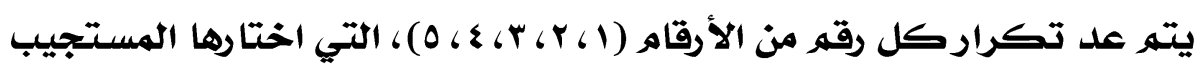

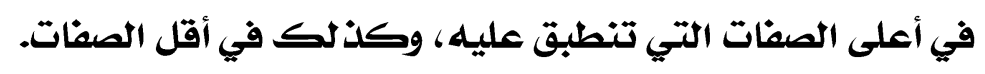

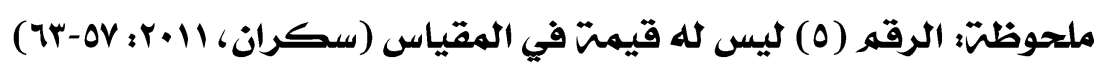

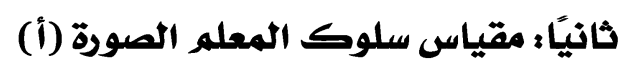

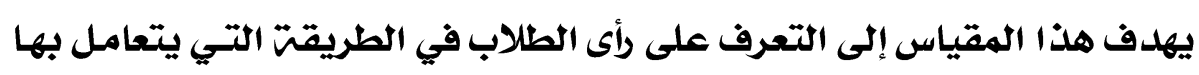
المعله مع الطالبات مرتفعات التحصيل الد راسئ.

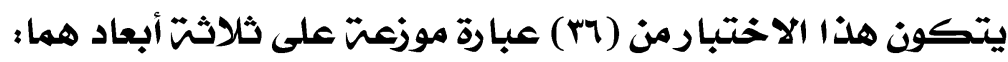

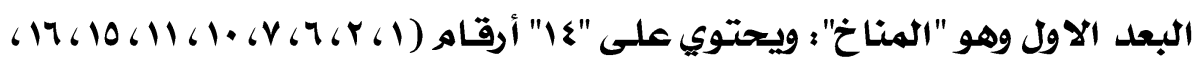

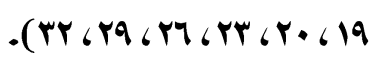

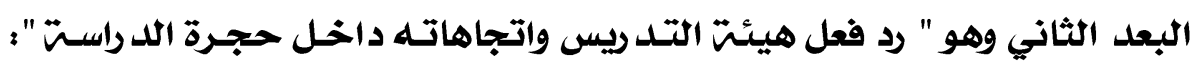

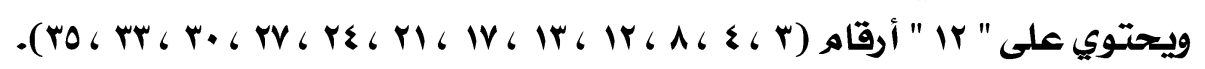

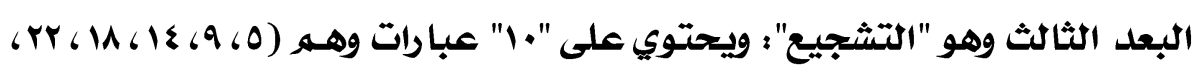

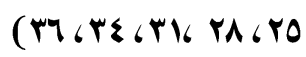

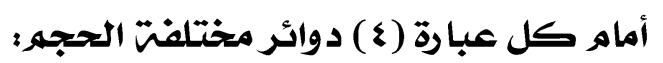

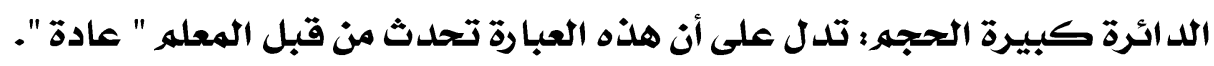

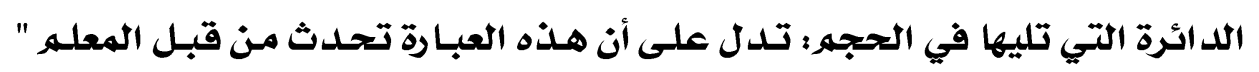
غالبًا".

الد ائرة التي تليها في الحجهر : تـدل على أن هـذه العبـارة تحـدث من قبـل المعلـه " أحيانًا".

الد ائرة صغيرة الحجهم : تلد على أن هذه العبا رة تحدث من قبل المعله " نادرًا".

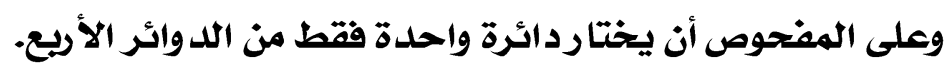

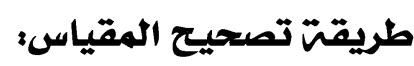

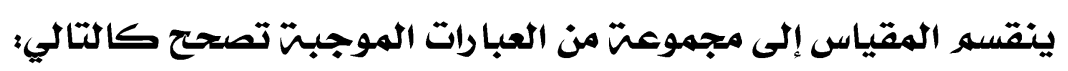

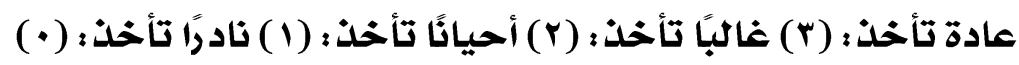




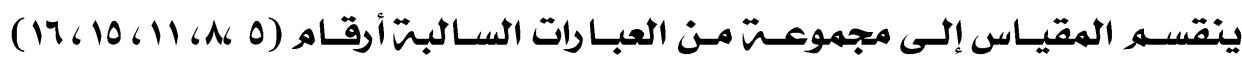
تصحت كالتالي:

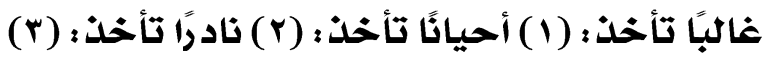

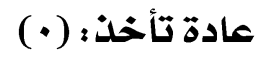

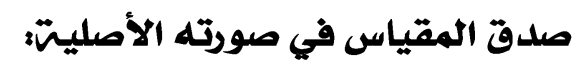

(1) الصدق الظاهري: حيث تم عرض المقياس على مجموعت من المتخصصين في مجال

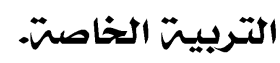

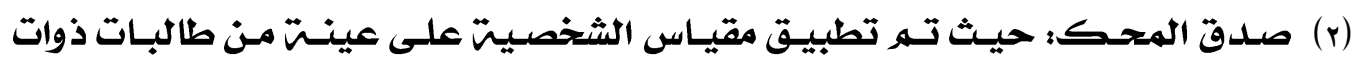

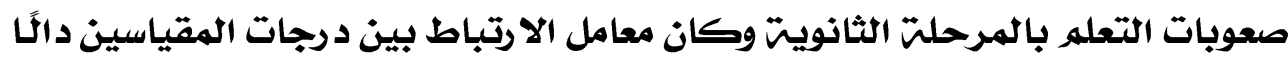

ومرتفعًا.

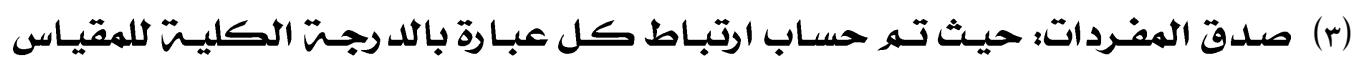

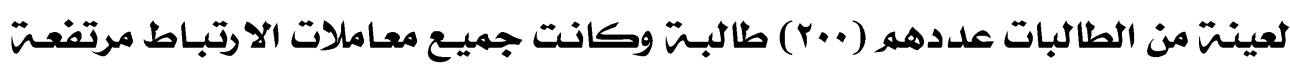

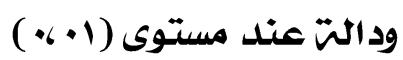

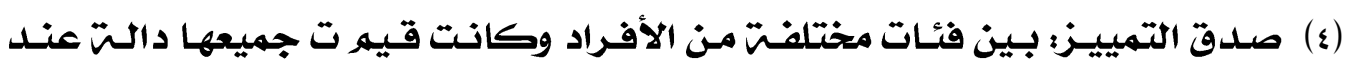

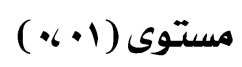

$$
\text { ثبات المقياس في صورته الأصليت: (اهت }
$$

ا-طريقت إعادة التطبيق

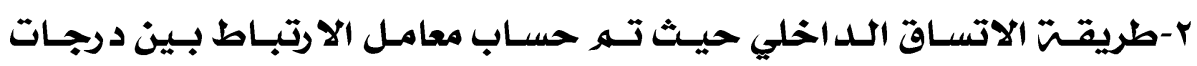

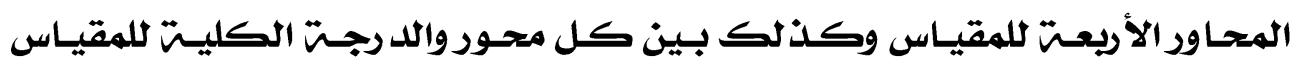

$$
\begin{aligned}
& \text { وكانت جميع معاملات الارتباط دالت وموجبت عند مستوى ( ( • • ) } \\
& \text { الخصائص السيكو متريت للمقياس في البحث الماتئ الحالي: }
\end{aligned}
$$

\begin{tabular}{|c|c|}
\hline معامل الثبات & أبعاد المقياس \\
\hline$\cdot 6 \cdot \varepsilon$ & البعد الأول (المناخ) \\
\hline •VTO & 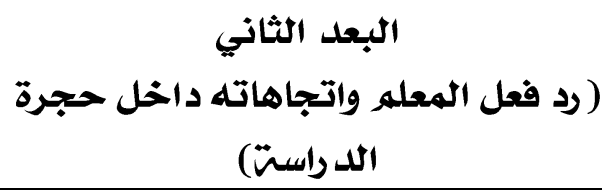 \\
\hline$\cdot v \leqslant 9$ & البعد الثالث (التشجيع) \\
\hline .6799 & ثبات المقياس ككل \\
\hline
\end{tabular}

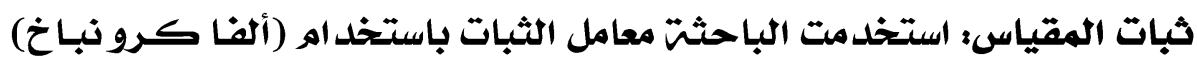

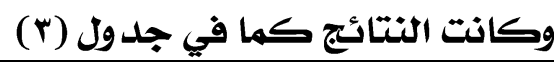

يتضح من الجدول السابق وجود معاملات ثبات مقبولثة لمقياس سلوك المعله وأبعاده الثلاثتّ. 


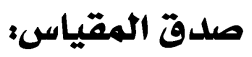

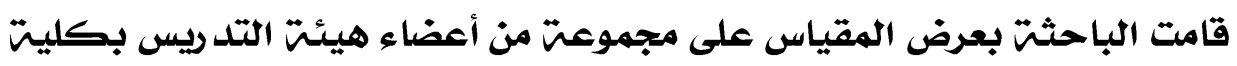

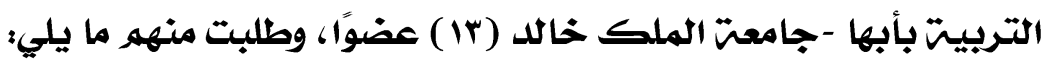

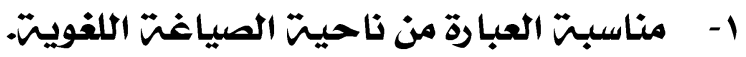

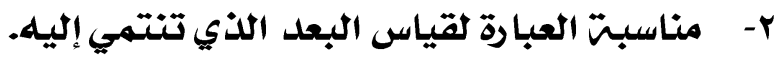

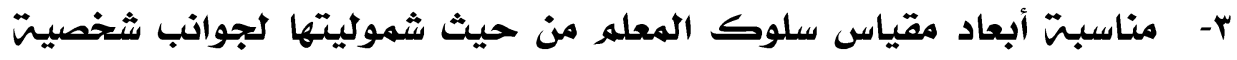
الفرد.

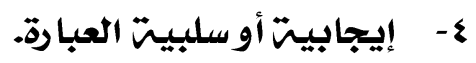
0- الشكل العاهر للمقياس.

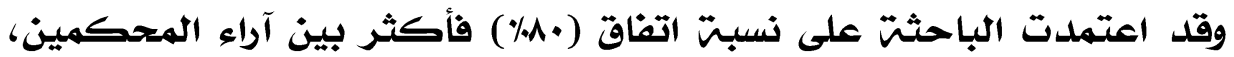

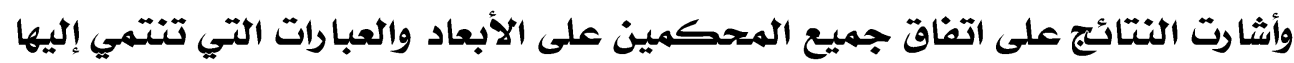

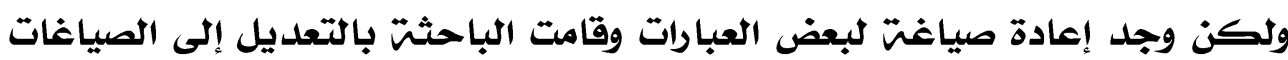
الججديدة.

(Learning Disabilities Diagnostic ائمت تشخيص صعوبات التعله Inventory) أعد Hammill \& Bryant (1991)،قائمت تشخيص صعوبات التعله LDDI

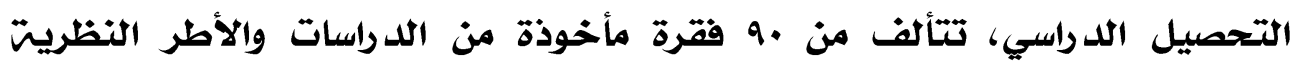

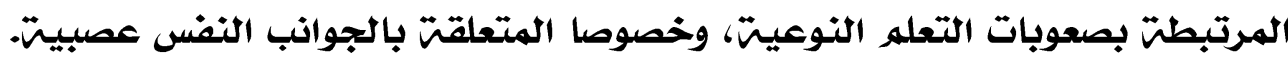

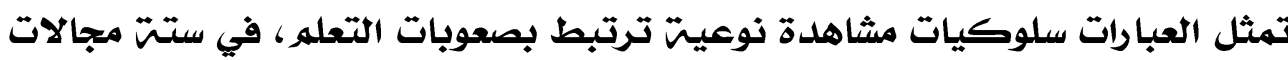

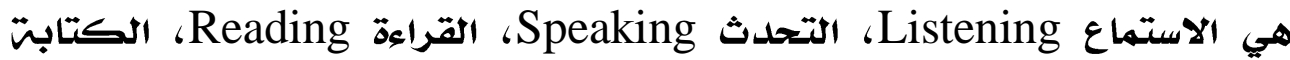

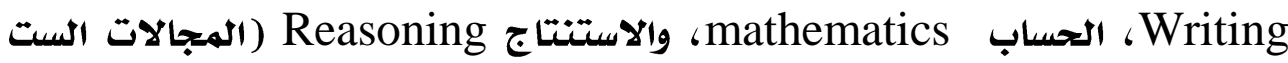

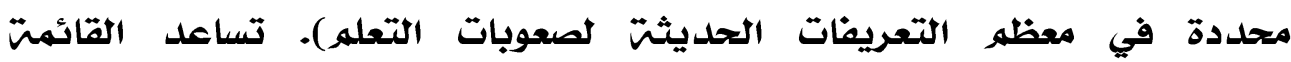

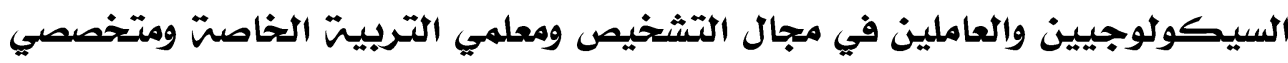

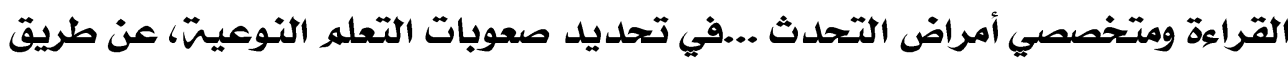

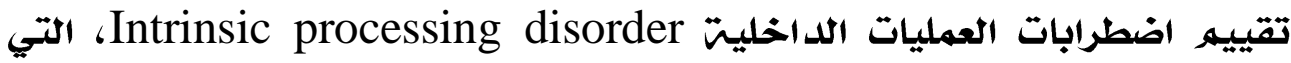
تكمن وراء تلك الصعوبات وتثيرها. وهي مناسبت للصفوف من الثالث الابتدات الصاتياتي

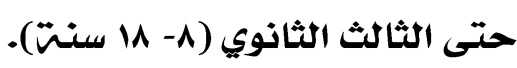

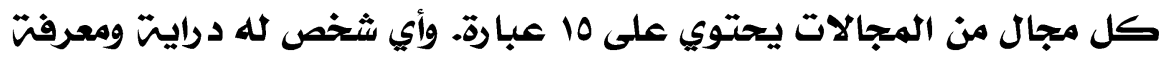

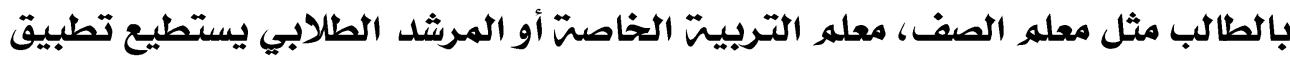

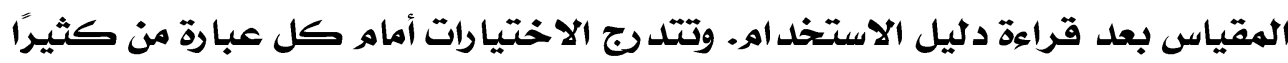

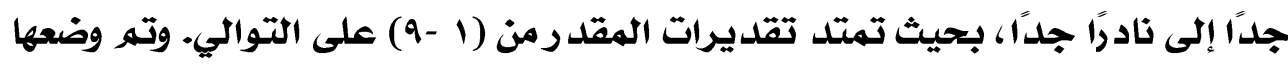

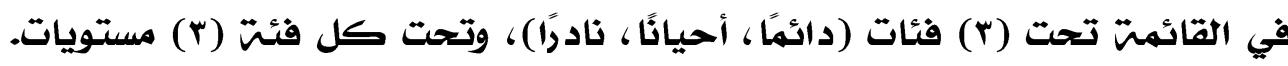




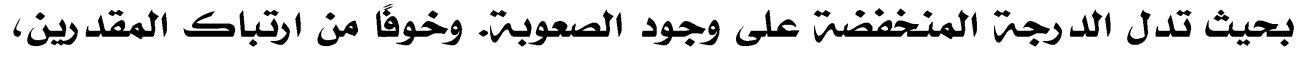

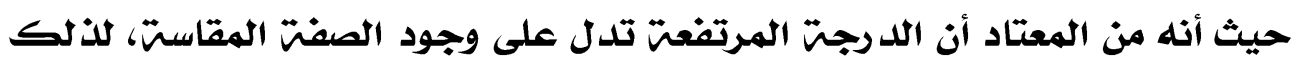
صاغ الباحثان الاختيارات بشكل عن الهعبي على ان النحو التالي:

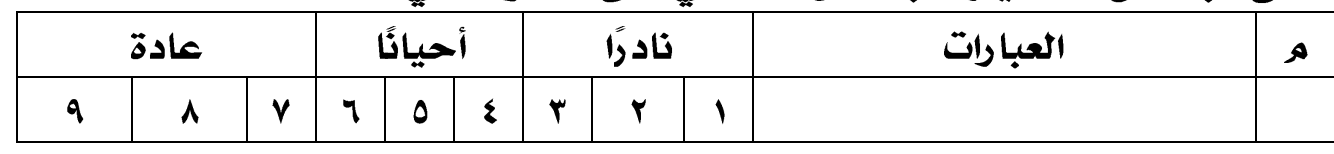

تقدير الد رجت على القائمت:

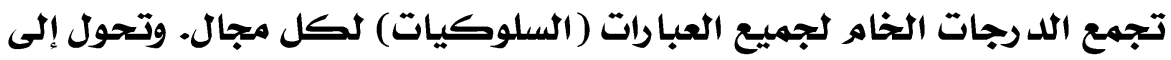
تساعيات، باستخد اهر البيانات المعيا ريتّ.

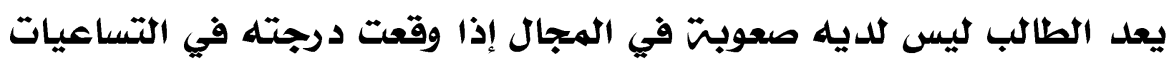

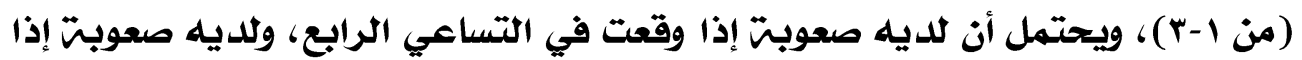

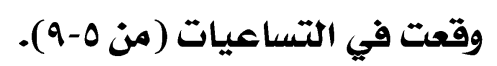

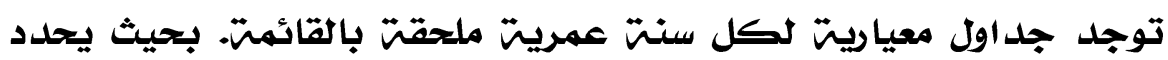

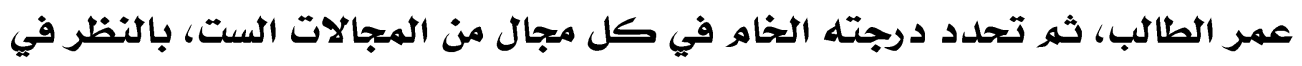

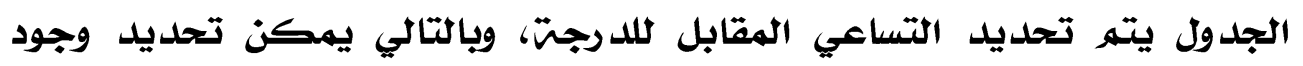
الصعوبت من عدمه. تقنين القائمتن: أولاء تقنين معدي القائمتش:

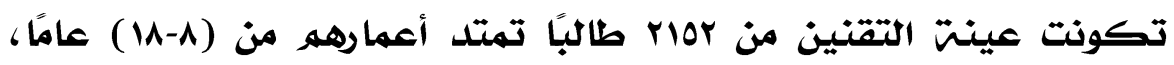

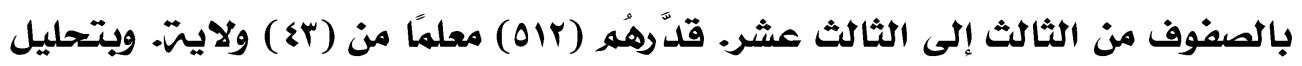

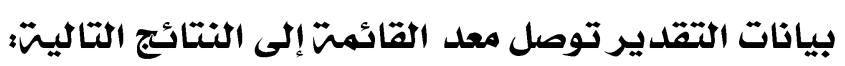
الثباته

1- لاختبار التجانس، ته حساب معاملات ألفا لهجالات القائمت لدى المستويات

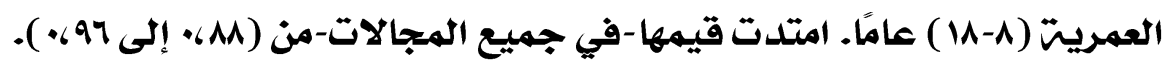

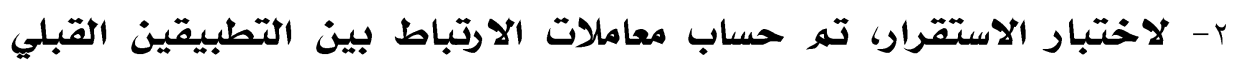

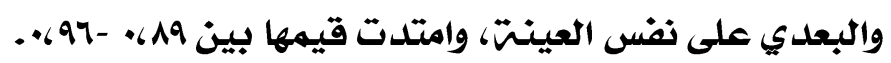

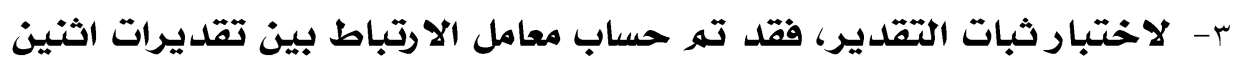

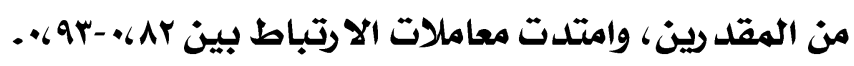
الصلدق:

استخدهر معد القائمت كل من صدق المحتوى content validity، والصدق

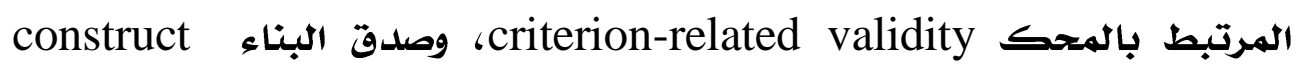
validity وتم تفصيلها في دليل القائمت ص ص

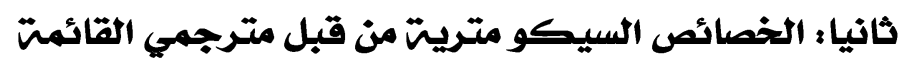




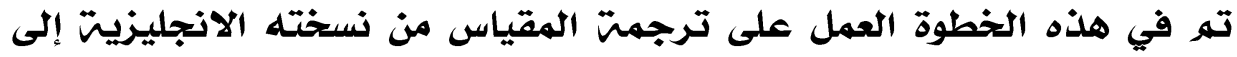

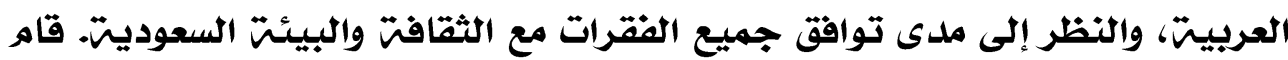

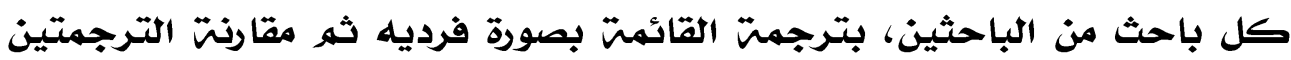

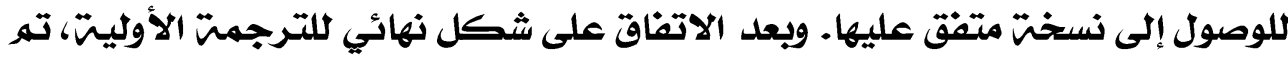
عرضها على أحد أعضاء هيئت التد ريس تخصص طرق تلد ريس لفت إنجليزيتة، لمعرفت

$$
\begin{aligned}
& \text { مدى دقت الترجمت قبل التقنين. }
\end{aligned}
$$

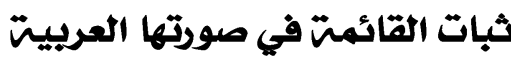

$$
\begin{aligned}
& \text { ثبات مجالات القائمتش: }
\end{aligned}
$$

ته حساب معامل ألثا كرونباخ لمجالات القائمت كمؤشر على الثبات،

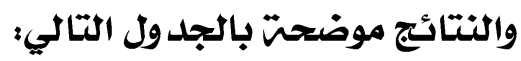

\begin{tabular}{|c|c|c|}
\hline معامل ألثا كرونباخ & عدد العبارات & المجالات \\
\hline .918 & 10 & الاستماع \\
\hline .880 & 10 & التحدث \\
\hline .932 & 10 & القراءة \\
\hline .948 & 10 & الكتابن \\
\hline .959 & 10 & الحساب \\
\hline .961 & 15 & التفكير \\
\hline
\end{tabular}

جلد ول ( ع ) معاملات ثبات قائمت تشخيص الهيص صعوبات التعله

يتضح من الجدول السابق أن القائمت لها درجت مقبولتم من الثبات ثبات مفردات القائمتر:

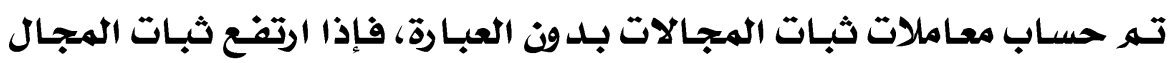

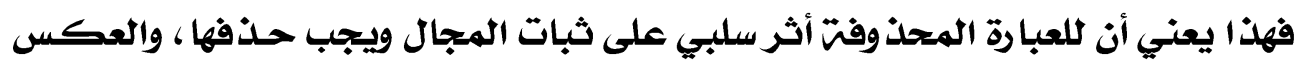

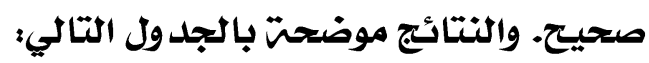

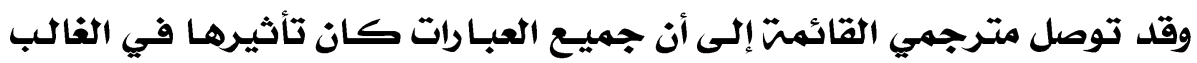

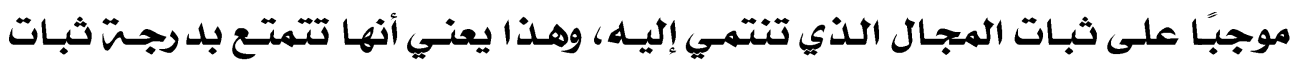
مقبولن. الاتساق الد اخلي:

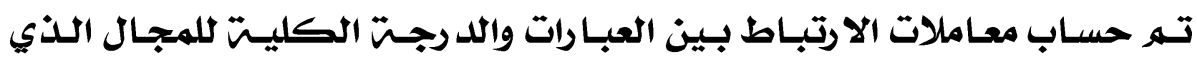

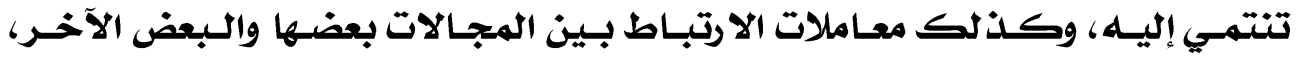
وكانت النتائج كما يلي: والئه

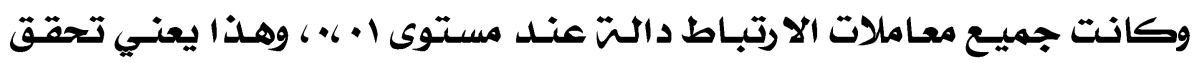
درجت مقبولتم من الاتساق الد اخلي للقائمتة. 


\section{صدق القائمت في صورتها العربيت

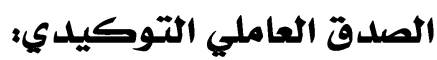

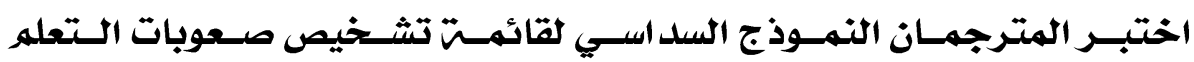

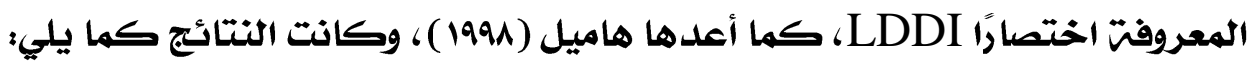

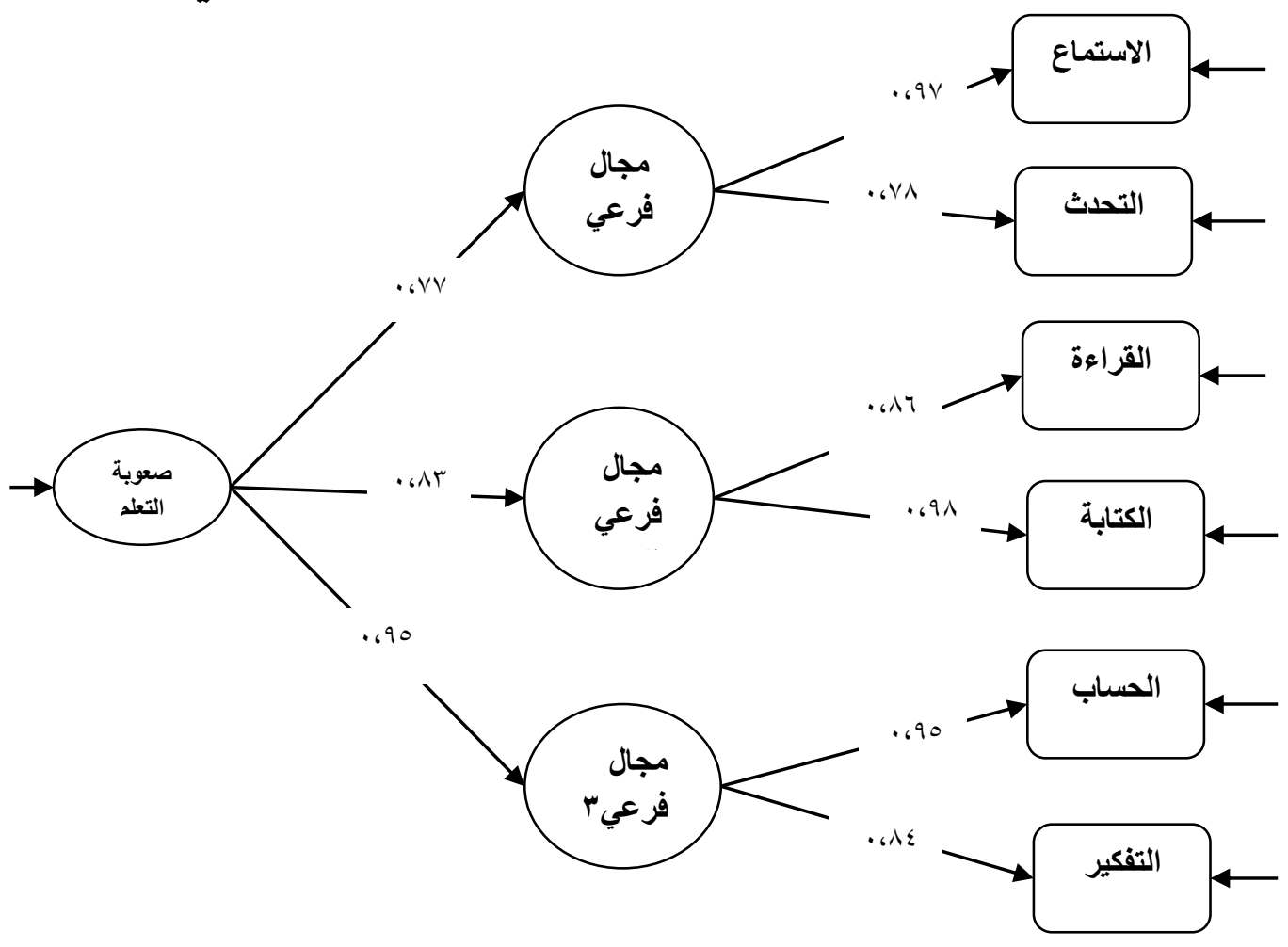

شكل ( 1 ) النموذج السداسي لقائمة تثخيص صعوبات التعلم

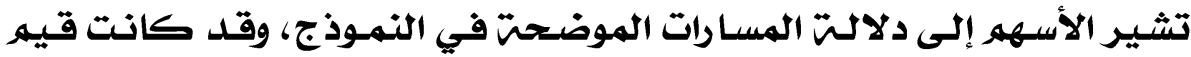

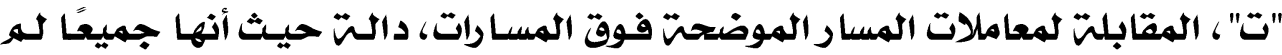

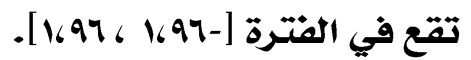

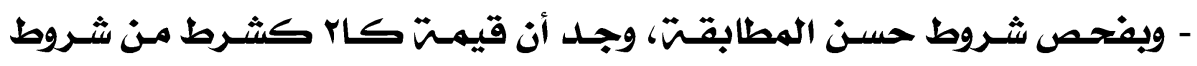

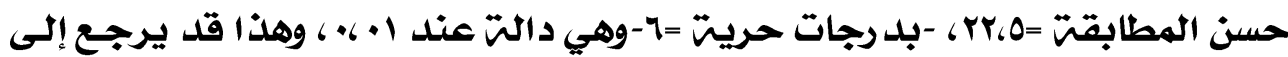

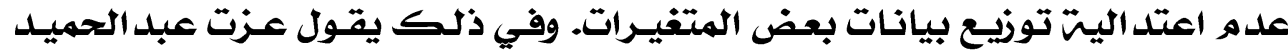

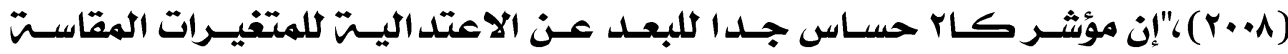

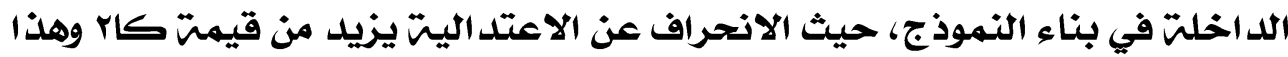

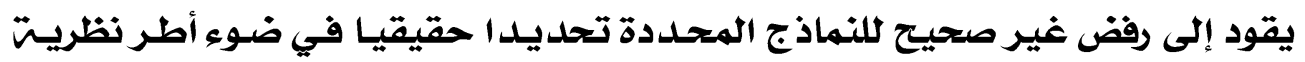


وبالتالي تكون قيمته معبـرة عن مطابقت النهـوذج إذا تـوفر شـرط الاعتد اليـتة، لأن

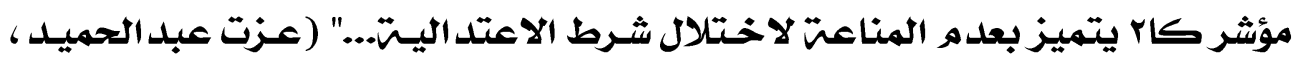

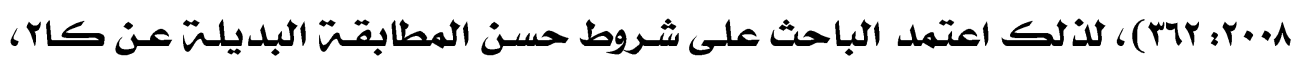
وكانت على النحو التالي:

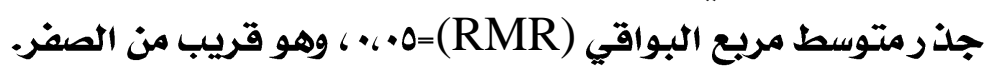

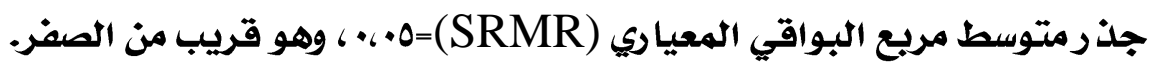

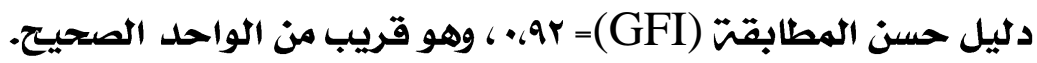

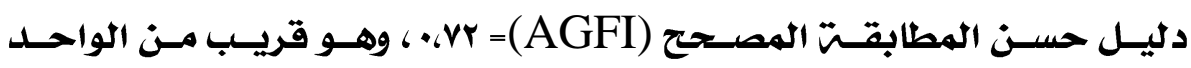

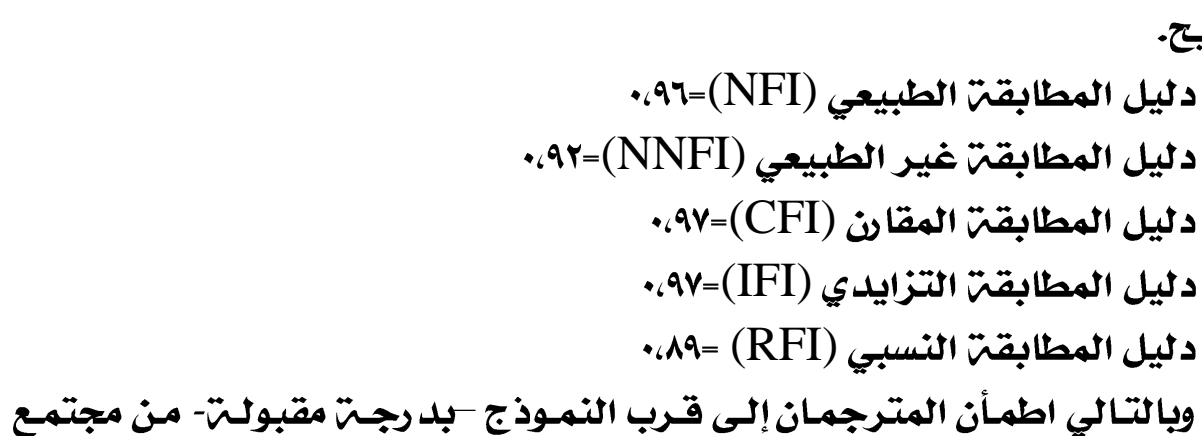
الصحيح. العينتة.

وقد اكتفت الباحثت بما قاهر المترجمان من اختبار للخصائص السيكومتريت للقائمتة، كما اقتصرت فقط على ثلاث صعوبات (القراءة والكتابت والحساب).

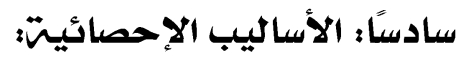

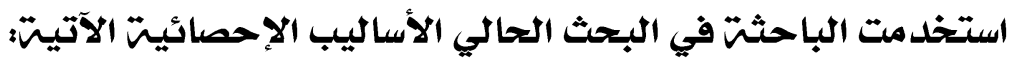

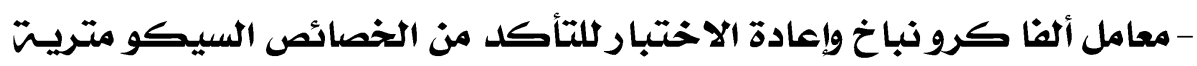
للمقاييس. واستخدمت الباحثت لاختبارصحت الفروض الأساليب الآتيت:

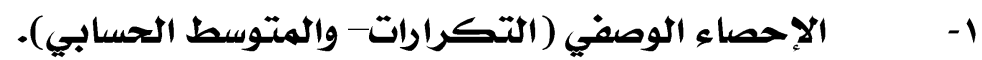

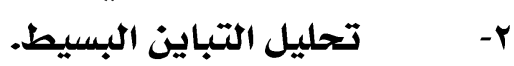

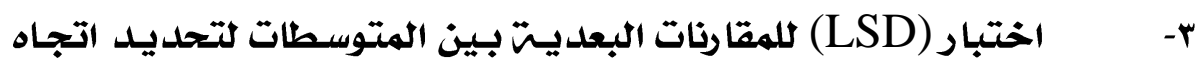
الفروقة.

\section{تتائج البحث وتفسيره:

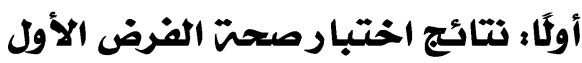

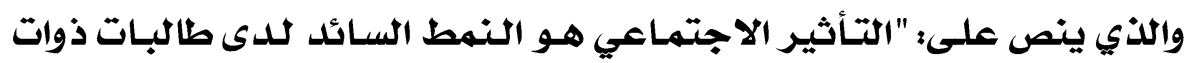

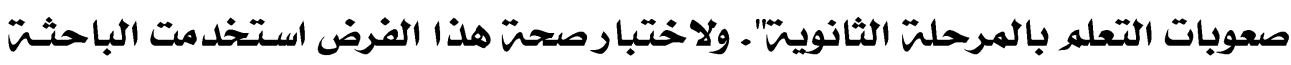

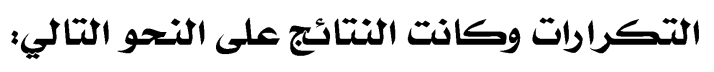


جدول (0) تكرار أنماط الشخصيت لدي عينت البحث (أعلي صفتر)

\begin{tabular}{|c|c|c|c|c|c|}
\hline \multicolumn{5}{|c|}{ التكرارات في المقياس } & \multirow{2}{*}{ الصفات } \\
\hline 0 & $\varepsilon$ & $r$ & $r$ & 1 & \\
\hline 1. & Ir & $r \wedge$ & 18 & - & 1 \\
\hline$r$. & Tr & 18 & - & $\wedge$ & $r$ \\
\hline$\varepsilon r$ & - & - & $\varepsilon \varepsilon$ & $r \wedge$ & $r$ \\
\hline$\varepsilon$ & \&1 & $\leqslant 9$ & 1 & 19 & $\varepsilon$ \\
\hline rr & - & $7 r$ & $r$. & $\wedge$ & 0 \\
\hline- & 0 & 17 & 7. & rr & 7 \\
\hline$r V$ & 1 & r & ir & 1 & $\checkmark$ \\
\hline- & $M \Lambda$ & ar & rr & $r$ & $\wedge$ \\
\hline$v$. & $r \cdot$ & 1 & - & ir & 9 \\
\hline$r \wedge$ & - & or & $\Lambda$ & rq & 1. \\
\hline IV & 10 & rq & - & 07 & 11 \\
\hline IV & $r \wedge$ & - & or & $r$ & ir \\
\hline 11 & - & m & 77 & $\varepsilon$ & ir \\
\hline- & $\varepsilon$ & or & $\varepsilon$ & iv & $1 \varepsilon$ \\
\hline- & ov & $r \varepsilon$ & $r$ & $r \cdot$ & 10 \\
\hline ir & $r q$ & or & $r_{1}$ & - & 17 \\
\hline ro & - & $r \cdot$ & $r r$ & $r V$ & iv \\
\hline rV & 0. & - & - & $r V$ & $M$ \\
\hline$\wedge$ & - & ro & ar & $\wedge$ & 19 \\
\hline- & $r V$ & 01 & 19 & $\checkmark$ & $r \cdot$ \\
\hline 1. & $r$ & $v \wedge$ & $v$ & iv & rI \\
\hline 0 & $r \wedge$ & $v$. & - & 11 & rr \\
\hline 19 & 1 & 70 & rq & - & rr \\
\hline$m$ & ro & - & rr & $r \cdot$ & $r \varepsilon$ \\
\hline$\varepsilon \leqslant \Lambda$ & 001 & $\Lambda \leqslant \Lambda$ & 0.0 & rVo & الهجموع \\
\hline
\end{tabular}

جلدول (1) تكرار أنماط الشخصيت لدي عينت البحث (أقل صفتر)

\begin{tabular}{|c|c|c|c|c|c|}
\hline \multicolumn{5}{|c|}{ التكرارات في المقياس } & \multirow{2}{*}{ الصفات } \\
\hline 0 & $\varepsilon$ & $r$ & $r$ & 1 & \\
\hline
\end{tabular}




\begin{tabular}{|c|c|c|c|c|c|}
\hline \multicolumn{5}{|c|}{ التكرارات في المقياس } & \multirow{2}{*}{ الصفات } \\
\hline 0 & $\varepsilon$ & $r$ & $r$ & 1 & \\
\hline- & 0 & ir & rr & 70 & 1 \\
\hline 11 & - & $r \Lambda$ & 1. & $O \Lambda$ & r \\
\hline rA & rr & rr & r. & - & $r$ \\
\hline- & «o & $1 \varepsilon$ & $r \varepsilon$ & $r_{1}$ & $\varepsilon$ \\
\hline rq & rr & $1 \varepsilon$ & - & $\$ 9$ & 0 \\
\hline st & - & 1ร & $r \cdot$ & $r V$ & 7 \\
\hline$v$ & ro & - & 17 & 97 & $\checkmark$ \\
\hline 1 & «o & iv & ro & 17 & $\wedge$ \\
\hline 1 & $\varepsilon \varepsilon$ & M & 18 & rร & 9 \\
\hline 0. & rr & $M$ & - & MI & 1. \\
\hline 1. & $\Delta \Lambda$ & 1 & rr & ir & 11 \\
\hline 1. & 1 & $r \cdot$ & M & 70 & ir \\
\hline ro & ir & - & - & IV & ir \\
\hline 0 & 19 & - & $\varepsilon 9$ & $\varepsilon \cdot$ & $1 \varepsilon$ \\
\hline ir & - & 9 & rr & M & 10 \\
\hline 1. & - & $\wedge$ & st & or & 17 \\
\hline$\sum 7$ & $r$. & r & - & IV & IV \\
\hline TE & - & $r \wedge$ & rr & $r \wedge$ & 11 \\
\hline 0 & $\{\wedge$ & - & 17 & ¿0 & 19 \\
\hline$\wedge$ & 1 & IV & $\wedge$ & - & $r$. \\
\hline- & rV & 0 & st & ra & $r_{1}$ \\
\hline- & $r$. & $r$ & 19 & $7 r$ & rr \\
\hline 17 & $r$. & rr & - & so & rr \\
\hline$V \varepsilon$ & - & $r_{1}$ & 19 & - & $r \varepsilon$ \\
\hline OIr & \{1ฯ & Trq & rrr & זTr & الهجموع \\
\hline
\end{tabular}

جدول (V) تكرارات الصفات لتحديد أعلى وأقل صفن

\begin{tabular}{|c|c|c|c|c|c|}
\hline 0 & $\varepsilon$ & $r$ & $r$ & 1 & \\
\hline$\leqslant \leqslant \wedge$ & 001 & $\Lambda \leqslant \wedge$ & 0.0 & rVo & أعلي صفت \\
\hline & $\mathrm{C}$ & $S$ & I & D & \\
\hline 0 & $\xi$ & $r$ & $r$ & 1 & \\
\hline
\end{tabular}




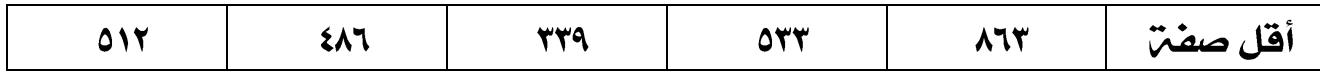

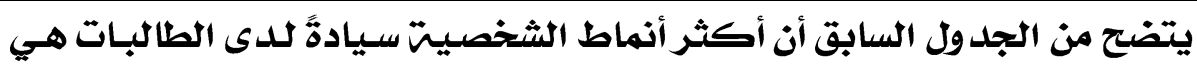

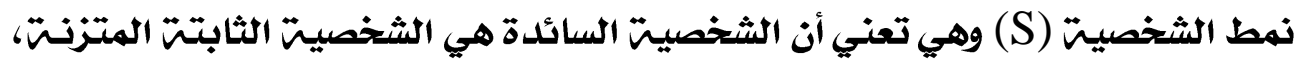

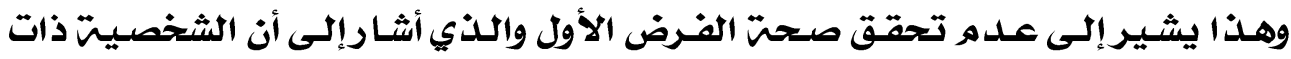

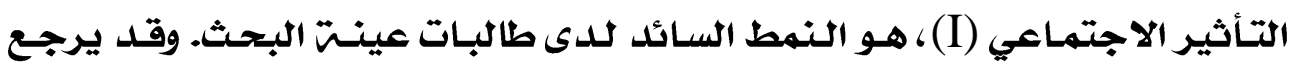

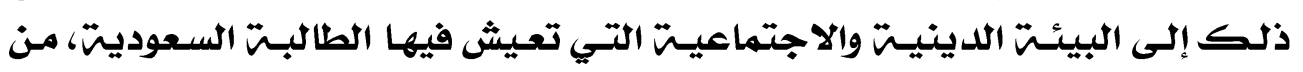

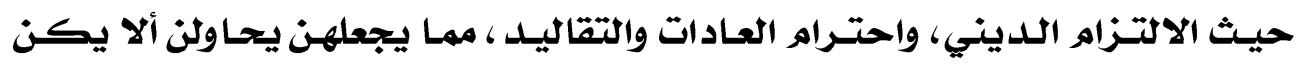

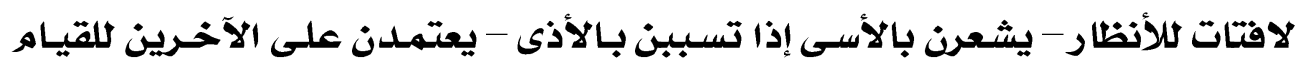

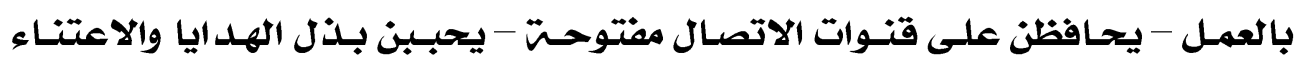

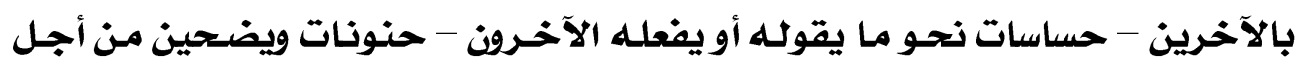

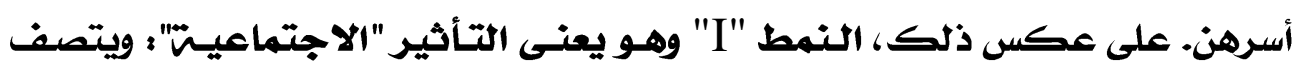

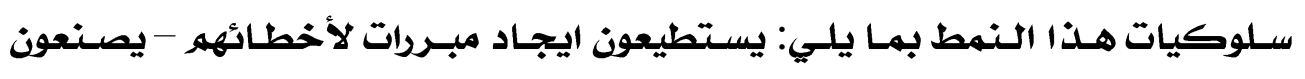

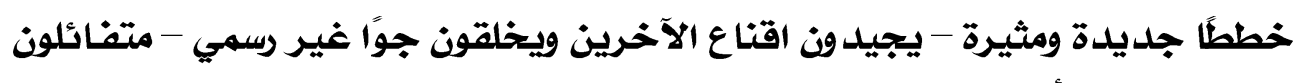

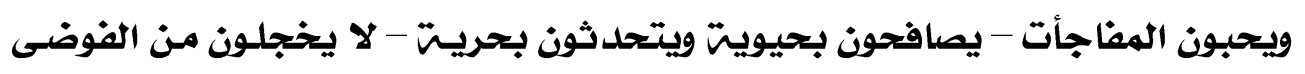
ويحبون جمع التذكارات.

$$
\text { ثانيًا: نتائج اختبارصحت الفرض الثاني }
$$

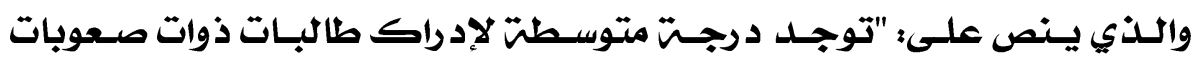

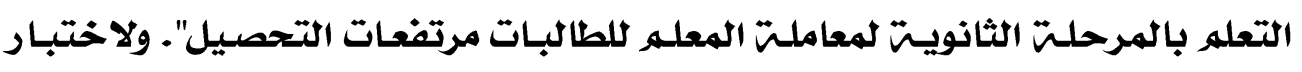

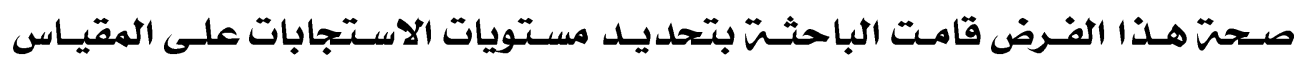

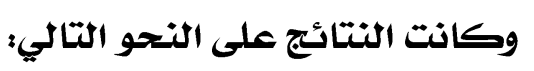

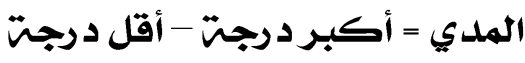

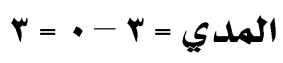

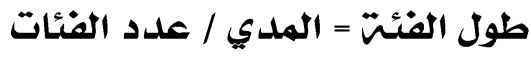

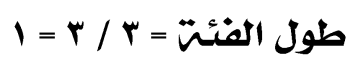

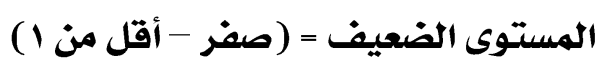

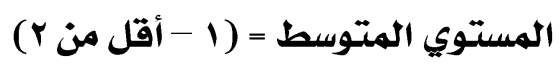

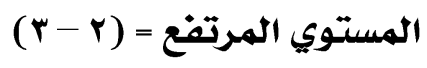

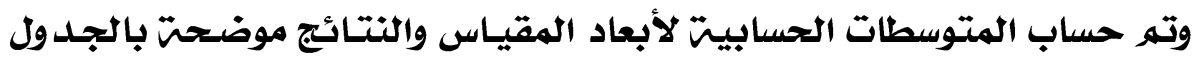


جد ول (1) المتوسطات الحسابيت لأبعاد مقياس إدراك معاملت

المعله للطالبات مرتفعات التحصيل

\begin{tabular}{|c|c|c|}
\hline مستويات إدراك & المتوسطابي الحسب & الأبعاد \\
\hline مرتفع & T.OS & البعد الأول (المناخ) \\
\hline مرتفع & r.VA & 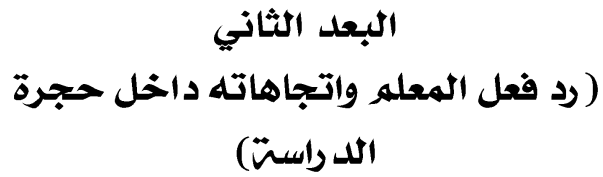 \\
\hline مرتفع & T.AV & البعد الثالث (التشجيع) \\
\hline
\end{tabular}

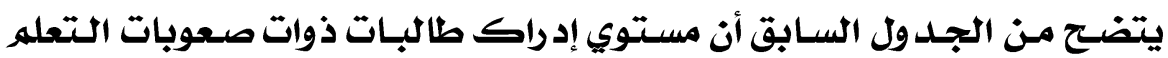

بالمرحلت الثانويت لمعاملت المعله للطالبـات مرتفعات التحصيل ككان مرتفع، وهـذا

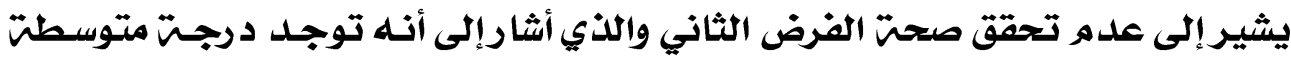

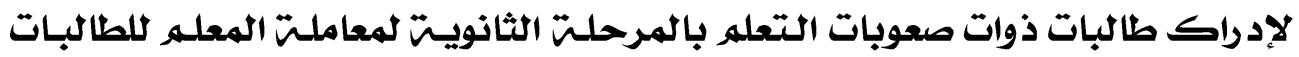

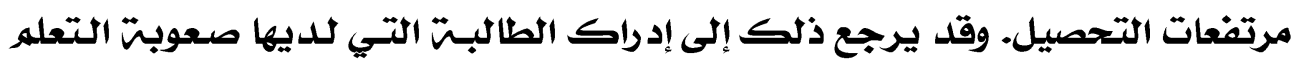

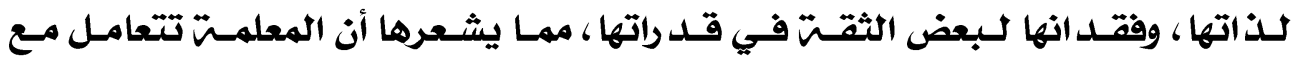

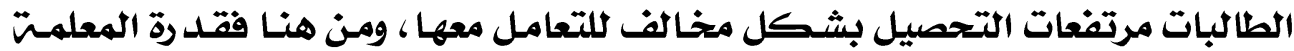

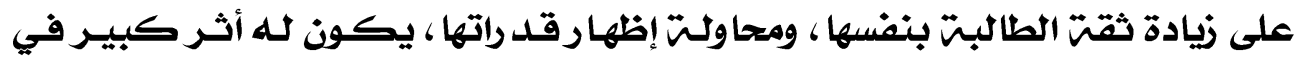

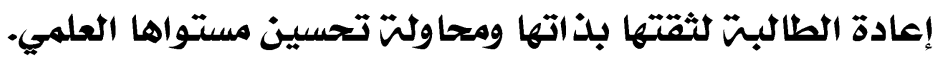

ثالثًاء نتائج اختبار صحتَ الفرض الثالث والـذي يـص على: "يختلف إدراك طالبـات ذوات صعوبات التعله بالمرحلـت

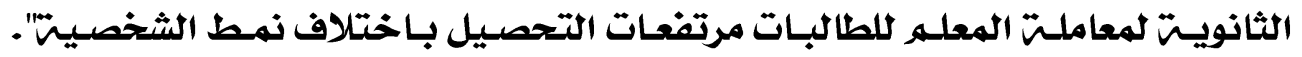

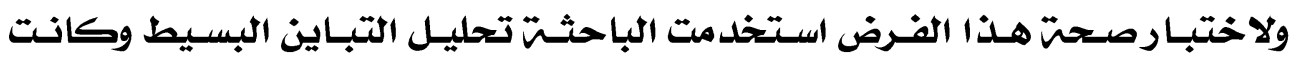
النتائج على النحو التالي: وصني: جدول (9) نتائج تحليل التباين للفروق في إدراك طالبات ذوات صعوبات التعلم

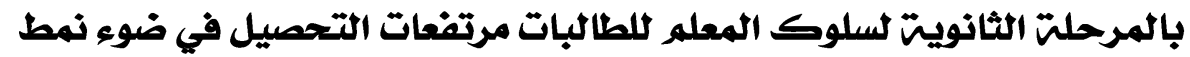
الشخصيت

\begin{tabular}{|c|c|c|c|c|c|c|}
\hline مستوي & ف & التباين & الحريت & المربموعات & التباين & المتتغيرات التابعت \\
\hline \multirow{2}{*}{ عند داله } & \multirow{2}{*}{ r. EVT } & VY..07 & $r$ & r19.179 & المججموعات & \multirow{2}{*}{ المناخ } \\
\hline & & $r 1, \cdot r q$ & 11. & FHIS. rV & المجموعات داخل & \\
\hline
\end{tabular}




\begin{tabular}{|c|c|c|c|c|c|c|}
\hline \multirow[b]{2}{*}{ غير } & \multirow[b]{2}{*}{ • ATH. } & 17.90 & $r$ & $0.61 \leqslant 9$ & المجموعات & \multirow{2}{*}{ واتجاهاته } \\
\hline & & r.:ZTr & 11. & rY $\leqslant Y, O 11$ & المجموعات & \\
\hline \multirow{2}{*}{ عاثل } & \multirow{2}{*}{$7 . \cdot 17$} & $11 \mathrm{r} .911$ & $r$ & $r \leqslant 1.970$ & المجموعات & \multirow{2}{*}{ التشجيع } \\
\hline & & MAVYA & 11. & $r+7 \cdot(1) 0$ & المجموعات داخل & \\
\hline
\end{tabular}

يتضع من الجدول السابق وجود فروق في البعد الأول والثالث من إدراك طالبات ذوات

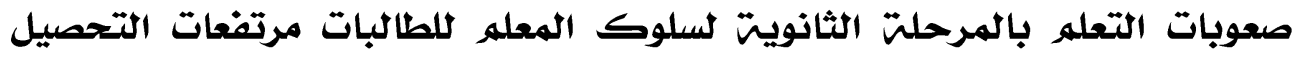

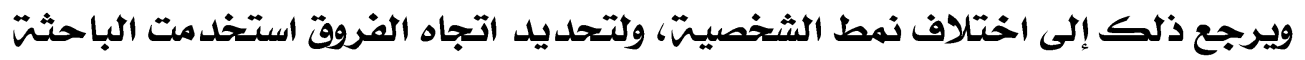

$$
\text { (LSD) طريقت }
$$

جلدول (• (1) المقا رنات المتعددة بين المتوسطات لطريقت (LSD) لتحديد اتجاه

\begin{tabular}{|c|c|c|c|c|}
\hline \multicolumn{5}{|c|}{ الفروق } \\
\hline الدلالتي & فرق & نمط الشخصيتت & نمط الشخصيت (I) & المتغيرات التعت \\
\hline غير دالت & .610 & (الاجتهاعيتر)I & \multirow{3}{*}{ D ( القياديت) } & \multirow{11}{*}{ المناخ } \\
\hline غير دالت & T.TA- & S ( المتزنتش) & & \\
\hline غير دالت & r.or- & C (التحليليت) & & \\
\hline غير دالتة & .10 & D (القياديت) D & \multirow{3}{*}{ I(الاجتماعيتش) } & \\
\hline دالتّ عند & r.IT- & S ( المتزنتش) & & \\
\hline دالت عند & r.trV- & C (التحليليت) C & & \\
\hline غير دالم & r.TA & D (القيادين) D & \multirow{3}{*}{ S ( المتزنتة) } & \\
\hline الـ دالت عند & rolt & $\begin{array}{c}\text { I } \\
\text { (الاجتماعيتش) }\end{array}$ & & \\
\hline غيرداثت &.,$- Y \xi$ & C (التحليليت) & & \\
\hline غير دالة & r.or & D (القياديت) D & \multirow{2}{*}{ C ( التحليليتش) } & \\
\hline دالت عند & r.TV & $\mathrm{I}$ & & \\
\hline
\end{tabular}




\begin{tabular}{|c|c|c|c|c|}
\hline مستوي & فرق & نمط الشخصيت & \multirow[t]{3}{*}{ نمط الشخصيت (I) } & \multirow[t]{3}{*}{ المتغيرات التابعت } \\
\hline$\cdots \cdot \cdot 0$ & & (الاجتماعيتر) & & \\
\hline غيردانت & $.6 \xi$ & S (المتزنتة) & & \\
\hline غير دالت & l.rt & $\begin{array}{c}\text { I } \\
\text { (الاجتماعيت) }\end{array}$ & \multirow{3}{*}{ D ( القياديتت) } & \multirow{12}{*}{ داخل داتجاهل ردجله } \\
\hline غير دالت & $.6 \mathrm{rV}$ & S (المتزنتة) S & & \\
\hline غيرداتم & • เ $\leqslant 0-$ & C ( التحليليت) & & \\
\hline غير دالت & 1.rY- & D D (القياديت) D & \multirow{3}{*}{ (الاجتماعيت) I } & \\
\hline غير دالت & $1.74-$ & S (المتزنت) & & \\
\hline غير دالت & $1.6 \%-$ & C (التحليليت) C & & \\
\hline غير دالتة & $.6 \mathrm{Tr}$ & D ( القياديت) & \multirow{3}{*}{ S (المتزنتة) } & \\
\hline غير دالت & 1.74 & $\begin{array}{c}\text { I } \\
\text { (الاجتماعيت) }\end{array}$ & & \\
\hline غير دالت & $\bullet \cdot \wedge-$ & C (التحليليت) C & & \\
\hline غير دالتة &. .80 & D (القياديت) D & \multirow{3}{*}{ C (التحليليتش) } & \\
\hline غير دالتة & $1.6 V$ & $\begin{array}{c}\text { I } \\
\text { (الاجتماعيت) }\end{array}$ & & \\
\hline غير دالت & $\bullet \cdot 1$ & S (المتزنتة) & & \\
\hline غير دالت & $16 \cdot 1$ & $\begin{array}{c}\text { I } \\
\text { (الاجتماعيت) }\end{array}$ & \multirow{3}{*}{ D (القياديت) } & \multirow{9}{*}{ التشجيع } \\
\hline غير دالت & r.AY- & S (المتزنتة) & & \\
\hline غير دالت & r.AI- & C (التحليليت) & & \\
\hline غير داثة & $1 \cdot \cdot 1-$ & D (القياديت) D & \multirow{3}{*}{ (الاجتماعيت) I } & \\
\hline الـ دالت عند & r.9r- & S ( المتزنت) & & \\
\hline الـ دالتّ عند & $\varepsilon, A \Lambda-$ & C (التحليليتش) & & \\
\hline غير دالن & r.14 & D (القياديت) D & \multirow{3}{*}{ S ( المتزنتة) } & \\
\hline الـ دالت عند & r.9r & $\begin{array}{c}\text { I } \\
\text { (الاجتماعيت) }\end{array}$ & & \\
\hline غير دالت & $.90-$ & C (التحليليت) C & & \\
\hline
\end{tabular}




\begin{tabular}{|c|c|c|c|c|}
\hline مستوي & فرق & نمط الشخصيتة & نمط الشخصيت (I) & المتغيرات التابعت \\
\hline غير دالت & r(A) & D ( القياديتش) & \multirow{3}{*}{ C ( التحليليتت) } & \\
\hline دالتّ عند & $\varepsilon, 1 \mathrm{~A}$ & $\begin{array}{c}\text { I } \\
(\text { الاجتماعيتش) }\end{array}$ & & \\
\hline غير دالت & .990 & S ( المتزنتة) & & \\
\hline
\end{tabular}

يتضح من الجدول السابق أن اتجاه الفروق كانت:

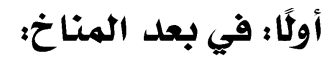

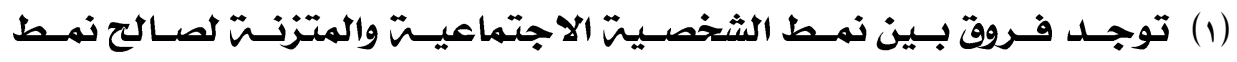

الشخصيت المتزنته.

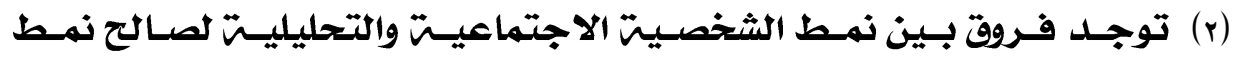

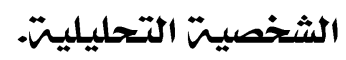

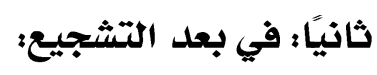

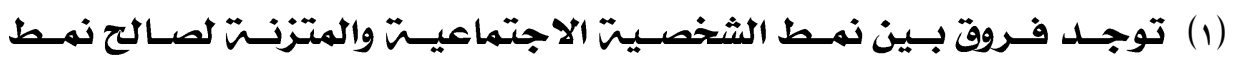

الشخصيت المتزنته.

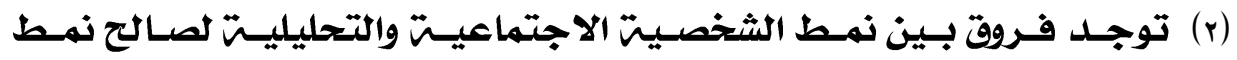

الشخصيت التحليليت.

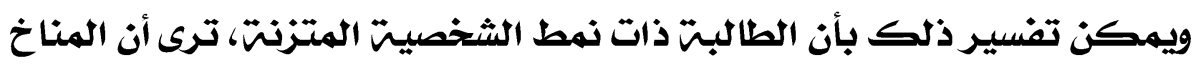

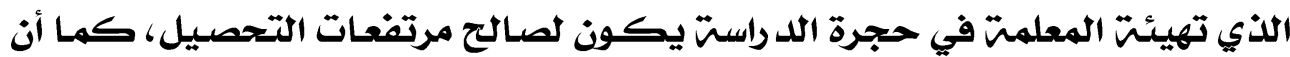

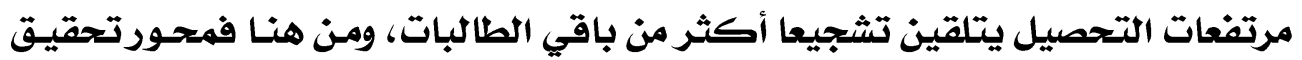

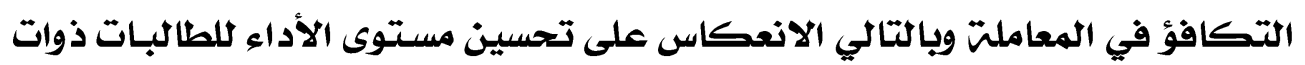

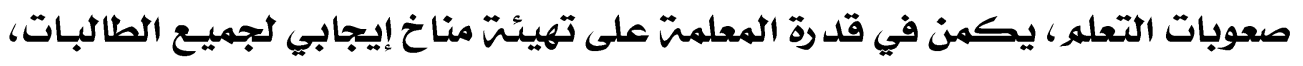

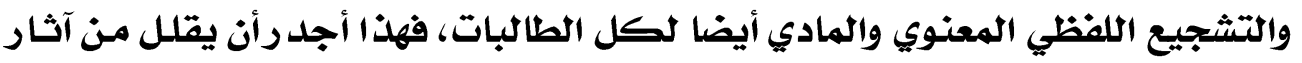
صعوبت التعله للدي بعض الطالبات.

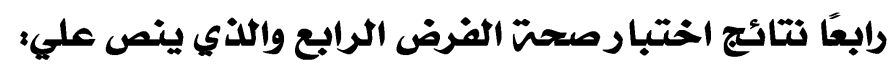

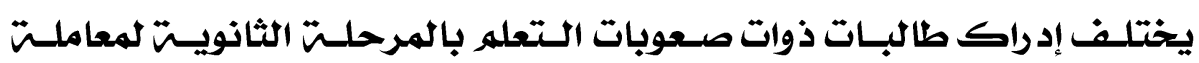

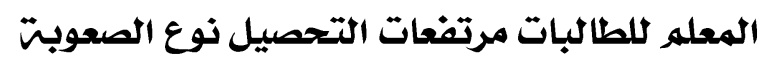

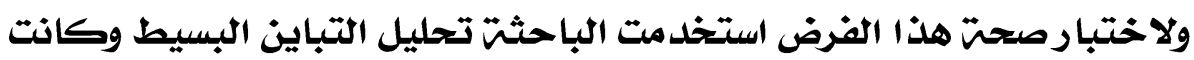
النتائج على النحو التالي: 
جلدول (11) نتائج تحليل التباين للفروق في إدراك طالبات ذوات صعوبات التعله

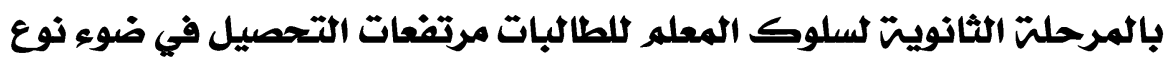

الصعوبت الصنات

\begin{tabular}{|c|c|c|c|c|c|c|}
\hline مستوي & ف & التباين & الحريت & المربعوع & التباين & المتتغيرات التعت \\
\hline \multirow{2}{*}{ غير } & \multirow{2}{*}{. . Or } & $\cdot 6 \cdot+7$ & $r$ & $\cdot 6 \cdot 1 r$ & الهجموعات & \multirow{2}{*}{ المناخ } \\
\hline & & .6118 & 1.9 & $1 T .87$ & الهجموعات & \\
\hline \multirow[b]{2}{*}{ غير } & \multirow[b]{2}{*}{$.0 \mathrm{OV}$} & $\cdot 6 \cdot \Delta r$ & $r$ & .6170 & بين المجموعات & \multirow{2}{*}{ واتجاهل } \\
\hline & & $01 \leqslant 8$ & 1.9 & $10 . V \leqslant 9$ & الهجموعات & \\
\hline \multirow{2}{*}{ غير } & \multirow{2}{*}{.6179} & $\cdot 6 \cdot r V$ & $r$ & $\bullet \cdot v \varepsilon$ & المجموعات & \multirow{2}{*}{ التشجيع } \\
\hline & & $\begin{array}{ll}\cdot 6 \\
\end{array}$ & 1. & $\begin{array}{ll}\text { rr. } & \\
& \text { 9ro }\end{array}$ & المجموعات داخـل & \\
\hline
\end{tabular}

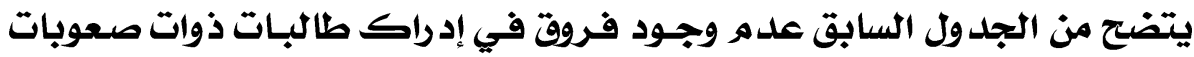

التعله بالمرحلت الثانويت لسلوك المعله للطالبات مرتفعات التحصيل يرجع إلى نوع

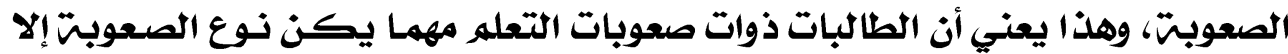

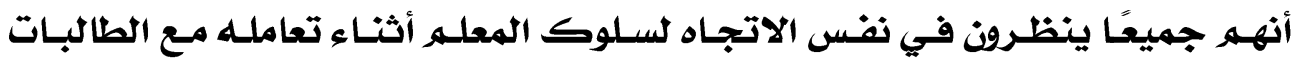

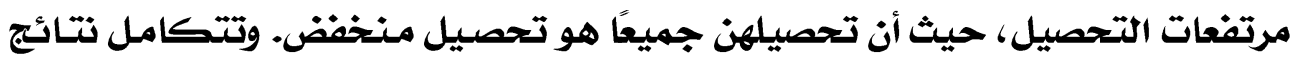

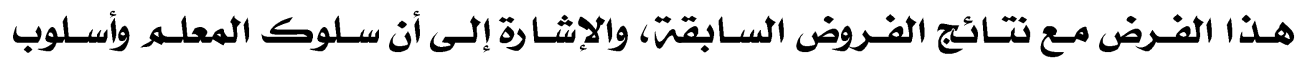
المعاملت داخل حجرة الد راست كفيليتت بالقضاء على الفوارق في أداء طالبـات الدمئج مع أداء زميلاتهن. 


\section{المراجع}

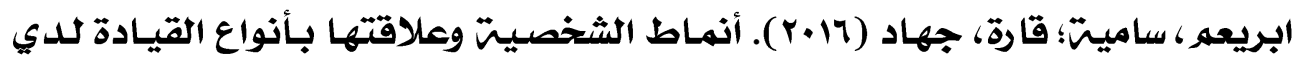

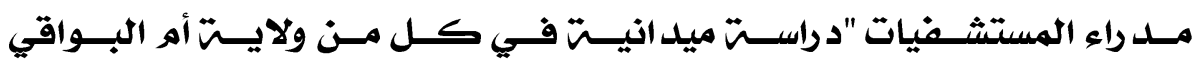

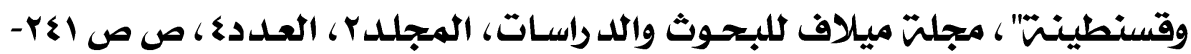

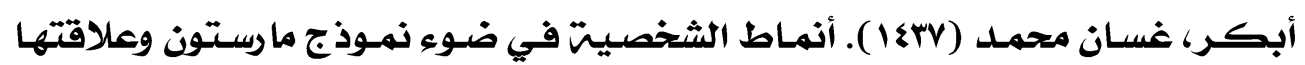

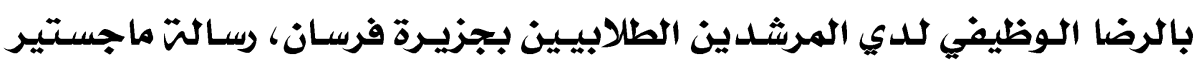

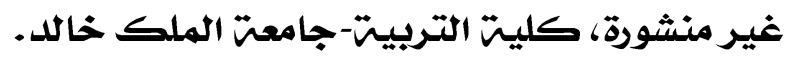

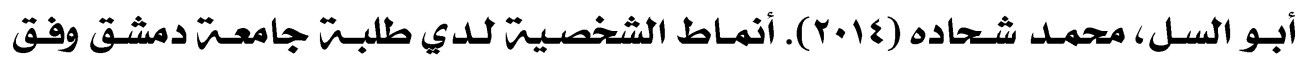

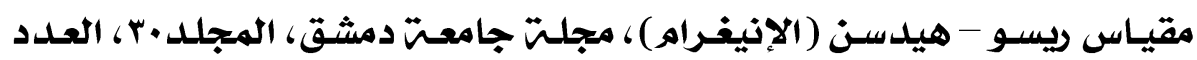

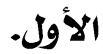

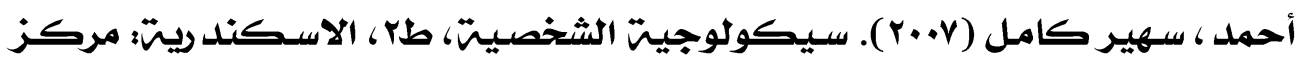

$$
\text { الإسكند ريت اللكتاب. }
$$

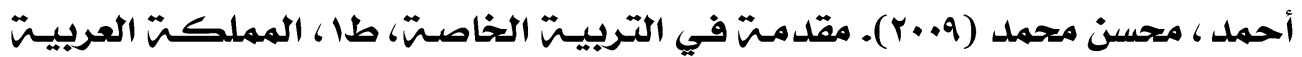

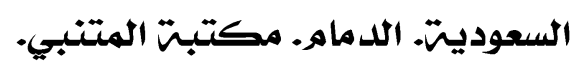

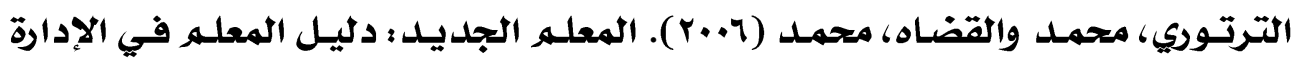

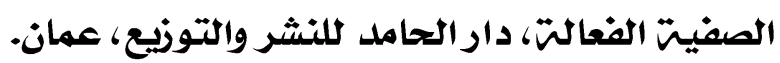

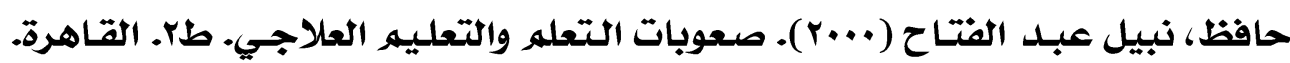

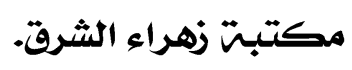

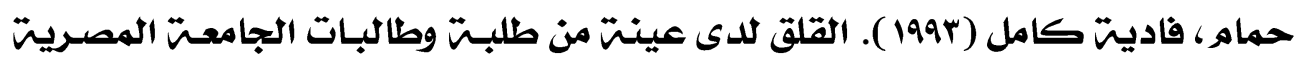

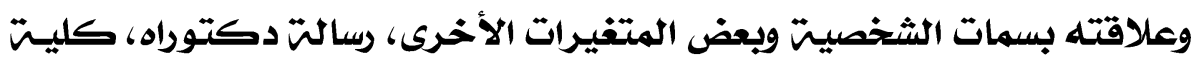

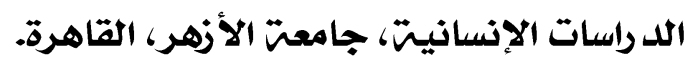

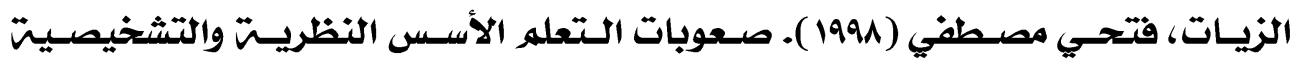

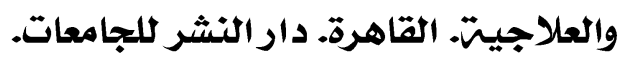

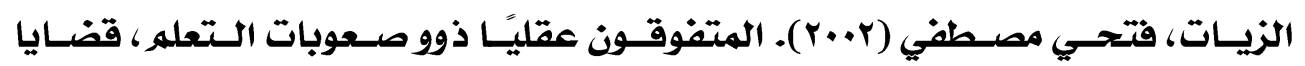

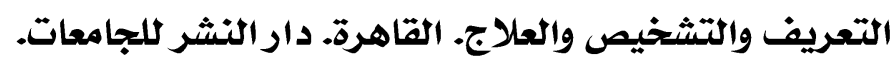

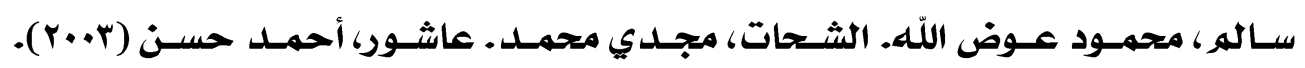

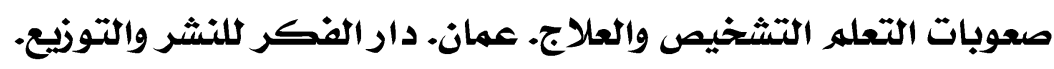

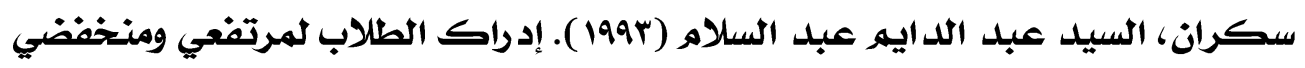

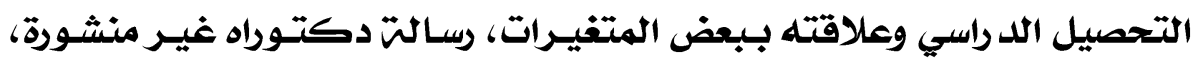

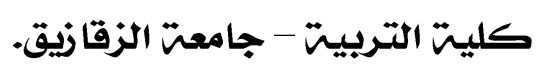

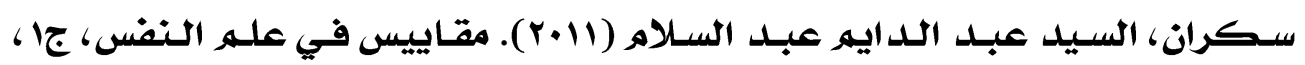
خميس مشيط: مكتبتر كوشان. 


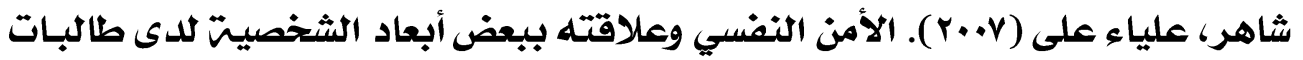

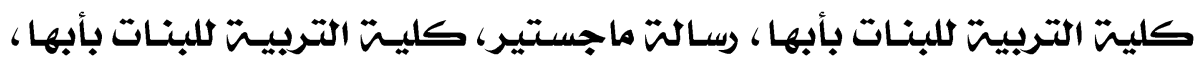

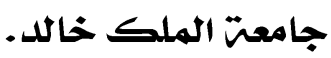

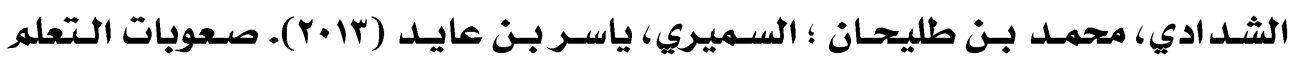

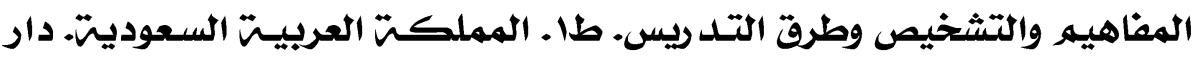

$$
\text { الناشر الدولي للنشر والتوزيع. }
$$

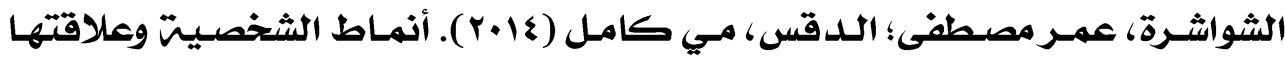

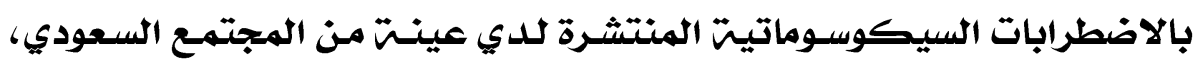

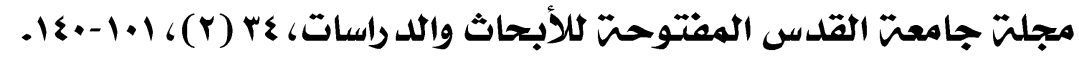

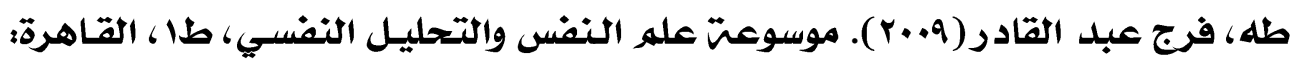
مكتبت الأنجلو المصريتّ.

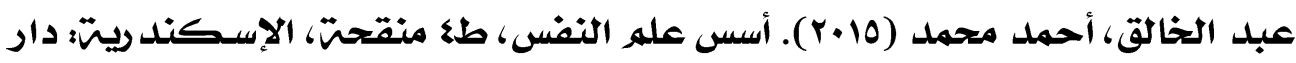

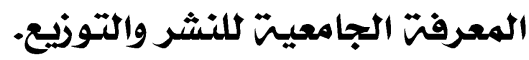

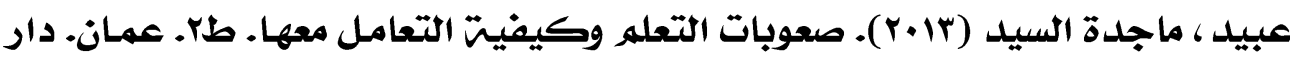
صفاء للنشر والتوزيع. علي، محمد محمود محمد (1997) ). عله النفس المعاصر في ضوء الإسلاهر، طب، جـدة: دار الشرقة.

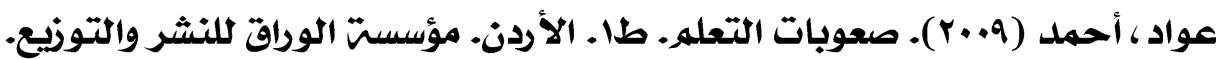
غنيه، ، سيد (19V1) ). سيكولوجيت الشخصيتت، القاهرة: دار النهضت العربيت.

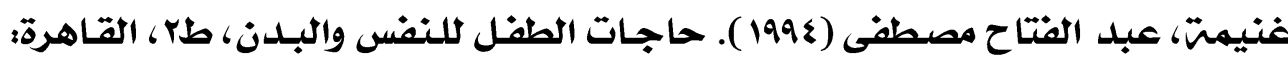
دار الكتب. كامل، محمد علي (1997) ـ سيكولوجيت الفئات الخاصتة. القاهرة. مكتبتت النهضت المصريت.

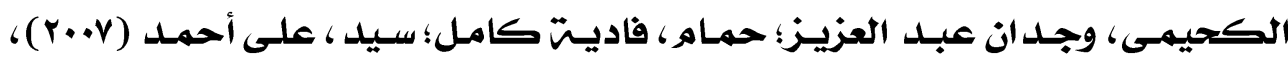

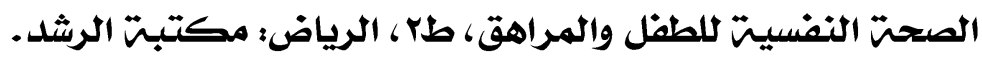

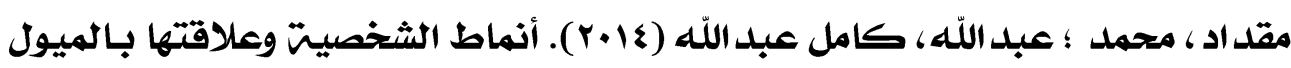

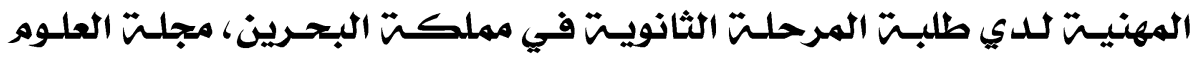

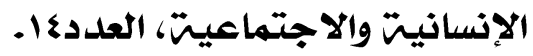

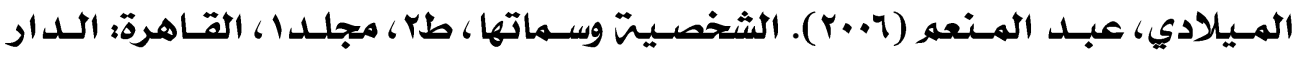
العربيتت للنشر والتوزيع.

Assor, A., \& Connell, J. P. (1992). The validity of students' selfreports as measures of performance affecting self-appraisals. In D. H. Schunk \& J. L. Meece (Eds.), Student perceptions 
in the classroom (pp. 25 - 47). Hillsdale, N. J.: Lawrence Erlbaum Associates.

Babad, E. (1990). Measuring and changing teachers' differential behavior as perceived by students and teachers. Journal of Educational Psychology, 82, 683-690.

Babad, E. (1993). Teachers' differential behavior. Educational Psychology Review, 5, 347-376.

Babad, E. (1995). The "teacher's pet" phenomenon, teachers' differential behavior, and students' morale. Journal of Educational Psychology, 87, 361-374.

Babad, E. (1998). Preferential affect: The crux of the teacher expectancy issue. In J. Brophy (Ed.), Advances in research on teaching: Expectations in the Classroom (Vol. 7, pp. 183214). Greenwich, CT: JAI Press.

Babad, E. Y., Inbar, J., \& Rosenthal, R. (1982). Pygmalion, Galatea and the Golem: Investigations of biased and unbiased teachers. Journal of Educational Psychology, 74, 459-474.

Babad, E., \& Taylor, P. B. (1992). Transparency of teacher expectancies across language, cultural boundaries. Journal of Educational Research, 86, 120-125.

Babad, E., Bernieri, F., \& Rosenthal, R. (1987). Nonverbal and verbal behavior of preschool, remedial, and elementary school teachers. American Educational Research Journal, 24, 405-415.

Babad, E., Bernieri, F., \& Rosenthal, R. (1989). Nonverbal communication and leakage in the behavior of biased and unbiased teachers. Journal of Personality and Social Psychology, 56, 89-94.

Babad, E., Bernieri, F., \& Rosenthal, R. (1991). Students as judges of teachers' verbal and nonverbal behavior. American Educational Research Journal, 28, 211-234.

Brattesani, K. A., Weinstein, R. S., \& Marshall, H. H. (1984). Student perceptions of differential teacher treatment as moderators of teacher expectation effects. Journal of Educational Psychology, 76, 236-247. 
Brophy, J. (1983). Research on the self-fulfilling prophecy and teacher expectations. Journal of educational psychology, 75, 631-661.

Brophy, J. E. (1985). Teacher-student interaction. In J. B. Dusek (Ed.), Teacher expectancies (pp. 303 - 328). Hillsdale, N. J.: Lawrence Erlbaum Associates.

Brophy, J., \& Good, T.(1974).Teacher-student relationships: Causes and consequences. New York: Holt, Rinehart and Winston.

Cooper, H., \& Good, T. (1983). Pygmalion grows up: Studies in the expectation communication process. New York: Longman.

Dolando, G.R. \& Heleen, J. (2002). Is there a Retire early Personality type www.in - themood.com examination In undergraduate medical educaton. P.12-14.

Dusek, J., \& Joseph, G. (1985). The bases of teacher expectancies. In. J. Dusek (Ed.), Teacher expectancies. Hillsdale, NJ: Erlbaum.

Eccles, J., \& Wigfield, A. (1985). Teacher expectations and student motivation. In J. B. Dusek (Ed.), Teacher expectancies (pp. 185-226). Hillsdale, N. J.: Lawrence Erlbaum Associates.

Egan, O., \& Archer, P. (1985). The accuracy of teachers' ratings of ability: A regression model. American Educational Research Journal, 22, 25-34.

Gill, S., \& Reynolds, A. J. (1999). Educational expectations and school achievement of urban African American children. Journal of School Psychology, 37, 403-424.

Good, T., \& Brophy, J. (1987). Looking in classrooms (4 ${ }^{\text {th }}$ ed.). New York: Harper \& Row.

Good, T. \& Brophy, J. (2003). Looking in classrooms ( $9^{\text {th }}$ ed.). Boston, MA: Allyn \& Bacon.

Hay, I., Ashman, A. F., \& Van Kraayenoord, C. E. (1998). Educational characteristics of students with high or low selfconcept. Psychology in the Schools, 35, 391-400.

Hoge, R., \& Butcher, R. (1984). Analysis of teacher judgments of pupil achievement level. Journal of Educational Psychology, 76, 777-781. 
http://expertisegrp.blogspot.com/p/blog-page_16.html. http://www.mcrel.org/products/noteworthy/noteworthy/loycec.as $\mathrm{p}$.

Jussim, L., Smith, A., Madon, S., \& Palumbo, P. (1998). Teacher expectations. In J. E. Brophy (Ed.), Advances in research on teaching: Expectations in the classroom (Vol. 7, pp. 1-48). Greenwich, Connecticut: JAI Press.

Kovacs, J. (2012). Teacher Treatment of Student Varies Across High Schools, Students. https:// www.blog.ctnews.com

Kuklinski, M. R., \& Weinstein, R. S. (2000) Classroom and grade level differences in the stability of teacher expectations and perceived differential treatment. Learning Environments Research, 3, 1-34.

Kuklinski, M. R., \& Weinstein, R. S. (2001). Classroom and developmental differences in a path model of teacher expectancy effects. Child Development, 72, 1554-1578.

Kuklinski, M. R.; \& Weinstein, R. S. (2000). Classroom and Grade Level differences in the Stability of Teacher Expectations and Perceived differential Teacher Treatment. Learning Environments Research 3, 1-34.

Lynch, J. (2002). Parents' self-efficacy beliefs, parents' gender, children's reader self-perceptions, reading achievement and gender. Journal of Research in Reading, 25, 54-67.

Marshall, H., \& Weinstein, R. (1984, April). Classrooms where students perceive high and low amounts of differential teacher treatment. Paper presented at the annual meeting of the American Educational Research Association, New Orleans.

Mitman, A. (1985). Teachers' differential behavior toward higher and lower achieving students and its relation to selected teacher characteristics. Journal of Educational Psychology, 77, 149-161.

Monk, M. (1983). Teacher expectations? Pupil responses to teacher mediated classroom climate. British Educational Research Journal, 9, 153-166.

Monteiro, S.; Almeida, L. S. \& Vasconcelos, R. M (2012). The role of teachers at university: what do high achiever 
Students look for?. Journal of the Scholarship of Teaching and Learning, 12(2), pp. 65-77.

Pedulla, J., Airasian, P., \& Madaus, G. (1980). Do teacher ratings and standardized test results of students yield the same information? American Educational Research Journal, 17, 303-307.

Pellegrini, A. D., \& Blatchford, P. (2000). The child at school: Interactions with peers and teachers. London: Arnold.

Rubie-Davies, C. M. (2014). Teacher expectations and student self-perceptions: Exploring relationships, doctoral dissertation by the author completed at the University of Auckland, New Zealand.

Weinstein, R. S. (1986). The teaching of reading and children's awareness of teacher expectations. In T. Raphael (Ed.), The contexts of school-based literacy. NY: Random House.

Weinstein, R. S. (1989). Perceptions of classroom processes and student motivation: Children's views of self-fulfilling prophecies. In A. R. \& A. C. (Eds.), Research on motivation in education (Vol. 3, pp. 187-221). NY: Academic Press.

Weinstein, R. S. (2002). Reaching higher: The power of expectations in schooling Cambridge, Massachusetts: Harvard University Press.

Weinstein, R. S. 1993. Children's knowledge of differential treatment in school: Implications for motivation. In T. M. Tomlinson (Ed.), Motivating students to learn: Overcoming barriers to high achievement. Berkeley, CA: McCutchan.

Weinstein, R. S., \& Middlestadt, S. E. (1979). Student perceptions of teacher interactions with male high and low achievers. Journal of Educational Psychology, 71, 421-431.

Weinstein, R. S., Marshall, H. H., Brattesani, K. A., \& Middlestadt, S. E. (1982). Student perceptions of differential teacher treatment in open and traditional classrooms. Journal of Educational Psychology, 74, 678692.

Weinstein, R., Marshall, H., Sharp, L., \& Botkin, M. (1987). Pygmalion and the student: Age and classroom differences in children's awareness of teacher expectations. Child Development, 58, 1079-1093. 